\title{
WestVirginiaUniversity
}

THE RESEARCH REPOSITORY @ WVU

Graduate Theses, Dissertations, and Problem Reports

1999

\section{Geophysical investigations of near-surface mine sites in northern West Virginia}

Peter E. Fahringer

West Virginia University

Follow this and additional works at: https://researchrepository.wvu.edu/etd

\section{Recommended Citation}

Fahringer, Peter E., "Geophysical investigations of near-surface mine sites in northern West Virginia" (1999). Graduate Theses, Dissertations, and Problem Reports. 1007.

https://researchrepository.wvu.edu/etd/1007

This Thesis is protected by copyright and/or related rights. It has been brought to you by the The Research Repository @ WVU with permission from the rights-holder(s). You are free to use this Thesis in any way that is permitted by the copyright and related rights legislation that applies to your use. For other uses you must obtain permission from the rights-holder(s) directly, unless additional rights are indicated by a Creative Commons license in the record and/ or on the work itself. This Thesis has been accepted for inclusion in WVU Graduate Theses, Dissertations, and Problem Reports collection by an authorized administrator of The Research Repository @ WVU. For more information, please contact researchrepository@mail.wvu.edu. 


\title{
Geophysical Investigations of Near-Surface Mine Sites in Northern West Virginia
}

\author{
Peter E. Fahringer \\ Thesis submitted to the College of Arts and \\ Sciences at West Virginia University \\ in partial fulfillment of the \\ requirements for the degree of \\ Master of Science \\ in \\ Geology
}

Committee Members:

Dr. Thomas H. Wilson, chair

Dr. Lawrence M. Gochioco, CONSOL Inc.

Dr. Paul F. Ziemkiewicz

Dr. Henry W. Rauch

Department of Geology and Geography

Morgantown, WV

1999

Keywords: Geophysics, Terrain Conductivity, Acid Mine Drainage, Preston County, Monongalia County 


\begin{abstract}
Geophysical Investigations of Near-Surface Mine Sites in Northern West Virginia
\end{abstract}

Peter Fahringer

The production of acid mine drainage (AMD) from surface and underground coal mine sites in northern West Virginia is a major environmental problem and continues to receive much attention in affected communities. Reclamation efforts at these sites often require extensive and costly treatments and are based on limited subsurface information. Use of geophysical techniques to characterize these sites, monitor remedial efforts, and provide additional subsurface information is evaluated in this study. Terrain conductivity (EM31 and EM34) grids as well as resistivity and magnetic profiles were collected at a mine spoil and two abandoned underground mine sites in northern West Virginia. Data were contoured and modeled using computer software to evaluate various subsurface conditions. Geophysical data were used in conjunction with hydrologic, geochemical, and borehole data previously collected to develop a better understanding of subsurface conditions at each site. At both underground sites, near-surface features (a gas transmission line and a fly-ash pile) partially concealed deeper $(\sim 15 \mathrm{~m}$ and $\sim 25 \mathrm{~m})$ targets and limited the effectiveness of geophysical techniques used. Results from the surface mine site demonstrate the ability of the terrain conductivity technique to locate posttreatment sludge and lime slurry plumes in a mine-spoil at various depths, from 4.5 to 25.5 meters. The metal-rich sludge and alkaline slurry appears as an anomalously high conductivity region. High conductivity zones extending downgradient from sludge-filled and slurry-filled pits at the surface suggest the terrain conductivity method can be used to identify preferred flow paths in a mine-spoil as well. Because terrain conductivity data can be collected rapidly and interpreted easily, it is the most promising of the techniques used in this study. Results of this study illustrate the potential benefits of geophysical surveys to mine site evaluation as well as some limitations. Work is continuing to better define the role of geophysics in mine site characterization in the region. Results of this study may help improve the effectiveness of future remedial efforts. 
Acknowledgements

The author would like to take this opportunity to thank some of the individuals and organizations that have made this work possible. I would like to thank Lawrence Gochioco of CONSOL Inc. Research and Development for providing the magnetometer and EM-31 terrain conductivity meter used at the Greer Site as well as for interest in this work. I would also like to thank Terry Ackman of the USDOE Federal Energy Technology Center in Pittsburgh for the use of the EM-34 terrain conductivity meter and the Geonics 856 magnetometer/gradiometer used at the Irish ridge and Greer sites. I would like to thank Joe Dean and Greer Industries for providing access to the Greer Mansion site and for paying equipment rental fees. I'd like to thank Dr. Paul Ziemkiewicz of the National Research Center for Coal and Energy for his interest in this work, providing research sites, and for providing funding to make it possible. Thank you to Dr. Robert Shumaker and the Shumaker fund for funding field work activities. Field work would not have been tolerable without the help of Jon Remo and D. Rob Gill who sweated and shivered in the field with me. I'd like to give special thanks to my advisor, Dr. Thomas Wilson, for his continuous support and input in this work. Finally, I'd like to thank all the family and friends who have helped me through my studies over the years. 


\section{TABLE OF CONTENTS}

ABSTRACT .................................................................. ii

ACKNOWLEDGEMENTS................................................... iii

TABLE OF CONTENTS .................................................... iv-v

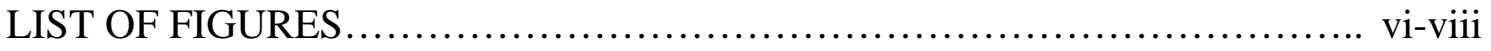

LIST OF TABLES........................................................... ix

CHAPTER 1 - Introduction............................................. 1

1.1. Statement of Problem............................................... 1

1.2. Previous Research................................................ 2

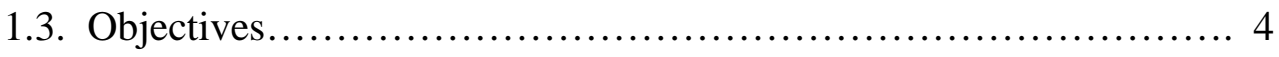

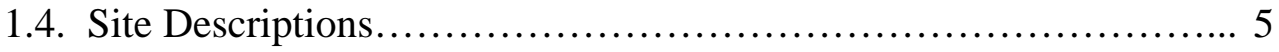

1.4.1. Irish Ridge......................................... 5

1.4.2. Greer Mansion......................................... 9

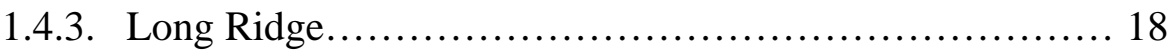

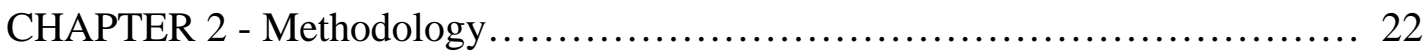

2.1. Discussion of Field Techniques.................................... 22

2.1.1. Magnetics.......................................... 22

2.1.2. Terrain Conductivity................................. 25

2.1.3. Resistivity ............................................ 33

2.2. Geophysical Approach........................................ 35

CHAPTER 3 - Results................................................. 38

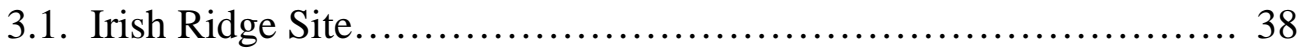

3.1.1. Magnetics......................................... 38

3.1.2. Terrain Conductivity ................................ 42

3.1.3. Resistivity........................................... 46

3.2. Greer Mansion Site.......................................... 49

3.2.1 Line Data............................................ 49

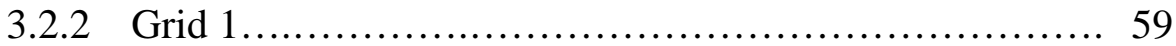

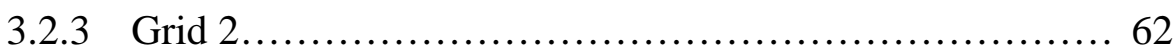

3.2.4 Grid 3................................................. 66

3.2.5 Resistivity Data...................................... 85

3.3. Long Ridge Site .............................................. 86

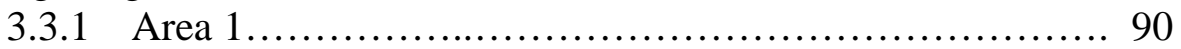




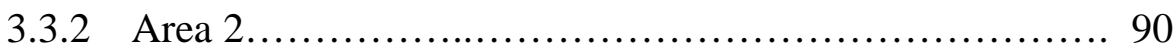

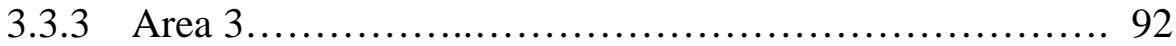

CHAPTER 4 - Modeling Results and Discussion............................. 97

4.1. Irish Ridge Site ........................................... 97

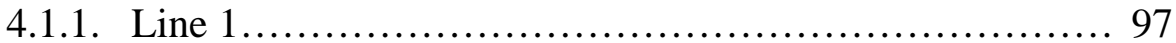

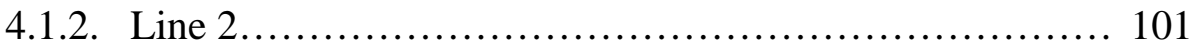

4.2. Greer Mansion Site........................................ 103

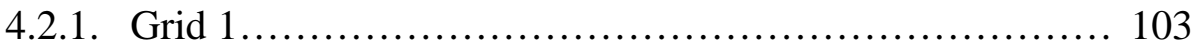

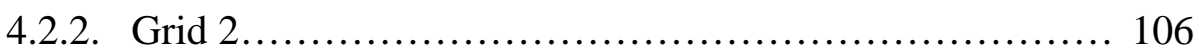

4.2.3. Grid 3................................................ 109

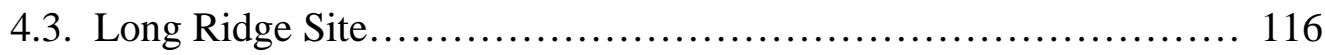

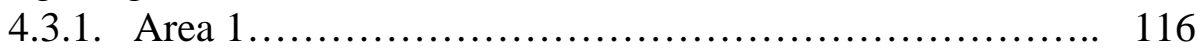

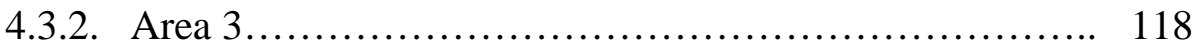

CHAPTER 5 - Conclusions and Significance ............................... 123

5.1. Key Findings.............................................. 123

5.1.1. Irish Ridge ....................................... 123

5.1.2. Greer Mansion........................................... 123

5.1.3. Long Ridge........................................ 124

5.2. Significance of findings........................................ 125

5.3. Suggestions for future work................................ 126

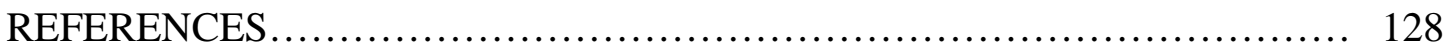




\section{LIST OF FIGURES}

Figure 1. West Virginia map showing Irish Ridge study area................ 6

Figure 2. $\quad$ Irish Ridge site map.................................... 7

Figure 3. Irish Ridge stratigraphic column........................... 8

Figure 4. West Virginia map showing Greer Mansion site location.............. 10

Figure 5a. Greer Mansion site map showing surface topography and well locations 11

Figure 5b. Greer Mansion site map showing well to spring tracer results......... 14

Figure 5c. Conceptual model of flow at the Greer site....................... 15

Figure 5d. Greer Mansion site map showing EM profiles and grids............. 17

Figure 6. $\quad$ Long Ridge location map.................................. 20

Figure $7 . \quad$ Long Ridge stratigraphic column............................... 20

Figure $8 . \quad$ Long Ridge site map...................................... 21

Figure 9. Apparent conductivity verses true conductivity for the EM 34....... 27

Figure 10. Geometry for EM response modeling........................... 29

Figure 11a. EM 31 response model..................................... 30

Figure 11b. EM 3410 meter response model............................. 30

Figure 11c. EM 3420 meter response model............................. 31

Figure 12. Relationship between earth resistivity and total dissolved solids....... 34

Figure 13. Irish Ridge magnetics, upper sensor.......................... 39

Figure 14. Irish Ridge magnetics, lower sensor.......................... 40

Figure 15. Irish Ridge magnetics, gradient.............................. 41

Figure 16. Irish Ridge 10 meter vertical data........................... 43

Figure 17. Irish Ridge 20 meter horizontal data........................... 44

Figure 18. $\quad$ Irish Ridge resistivity soundings.............................. 47 


\section{LIST OF FIGURES}

Figure 19. Greer site map showing survey lines............................... 50

Figure 20. Greer EM Line A................................................. 51

Figure 21. Greer EM Line B.............................................. 53

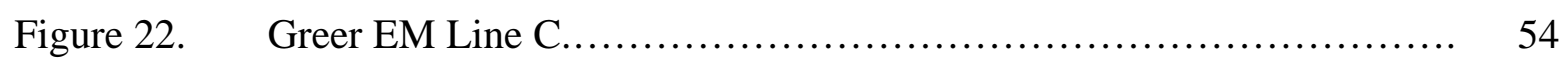

Figure 23. Greer EM Line D............................................ 56

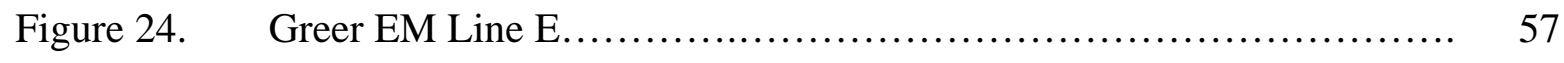

Figure 25. Greer EM Line F............................................. 58

Figure 26. Greer EM Line G........................................... 60

Figure 27. Greer Grid 1, EM 31 data, fall 1998................................ 61

Figure $28 \quad$ Greer Grid 1, EM 31 data, spring 1999............................ 63

Figure 29. Greer Grid 2, EM 3410 meter data over GR20 injection well .......... 64

Figure 30. Greer Grid 2, EM 3420 meter data over GR20 injection well .......... 65

Figure 31. Greer Grid 3, 10 meter readings before the new trench ............... 68

Figure 32. Greer Grid 3, 20 meter readings before the new trench................. 69

Figure 33. Greer Grid 3, 10 meter readings after one lime application.............. 71

Figure 34. Greer Grid 3, 20 meter readings after one lime application............. 72

Figure 35. Greer Grid 3, 10 meter difference one lime application - before digging 73

Figure 36. Greer Grid 3, 20 meter difference one lime application - before digging 74

Figure 37. Greer Grid 3, 10 meter readings after three lime applications............ 76

Figure 38. Greer Grid 3, 20 meter readings after three lime applications............ 77

Figure 39. Greer Grid 3, 10 meter difference of three - one lime applications....... 78

Figure 40. Greer Grid 3, 20 meter difference of three - one lime applications...... 79

Figure 41. Greer site map showing modeled line locations....................... 82

Figure 42. Greer Grid 3, Line 3A over the new trench......................... 83 


\section{LIST OF FIGURES}

Figure 43. Greer Grid 3, Line 3B over the new trench..................... 84

Figure 44. Greer resistivity soundings................................ 86

Figure 45. Long Ridge EM, 20 meter horizontal data....................... 87

Figure 46. Long Ridge EM, 10 meter vertical data.......................... 88

Figure 47. Long Ridge EM, 20 meter vertical data........................ 89

Figure 48. $\quad$ Long Ridge Area 2, cross section over area 2.................... 91

Figure 49. Long Ridge Area 3 enlargement 20 meter horizontal data.............. 93

Figure 50. Long Ridge Area 3 enlargement 10 meter vertical data............... 94

Figure 51. Long Ridge Area 3 enlargement 20 meter vertical data............... 95

Figure 52. Irish Ridge site and conductivity maps........................ 98

Figure 53. Irish Ridge modeled Line 1 results........................... 100

Figure 54. $\quad$ Irish Ridge modeled Line 2 results.............................. 102

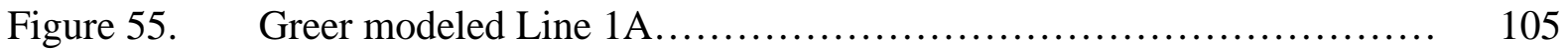

Figure 56. Greer modeled Line 1B................................... 107

Figure 57. Greer Grid 2, modeled line 2 with fixed geometry $\quad$.................. 108

Figure 58. Greer Line 3A, fixed conductivity modeled responses............... 110

Figure 59. Greer Line 3B, fixed conductivity modeled responses................ 111

Figure 60. Greer Line 3A, fixed geometry modeled responses.................. 112

Figure 61. Greer Line 3B, fixed geometry modeled responses................. 113

Figure 62. $\quad$ Long Ridge Line 1, structural effects model, (Area 1)............... 117

Figure 63. Long Ridge Line 3, forward model results...................... 120

Figure 64. Long Ridge Line 3, inverse model results....................... 122 


\section{LIST OF TABLES}

Table 1. Average magnetic susceptibilities for rocks.................. 23

Table 2. $\quad$ EM 31 and EM 34 exploration depths...................... 28 


\section{CHAPTER 1 - Introduction}

\subsection{Statement of Problem}

The production of acid mine drainage (AMD) from surface and underground coal mines in the Appalachian region has been a major environmental problem since mining began in the region and continues to receive much attention in affected communities. Untreated AMD entering surface and ground water degrades the water quality and reduces the value of affected lands. The Surface Mining Control and Reclamation Act (SMCRA) requires that if mining activity contaminates or interrupts the ground water or surface water supply of adjacent users, the mine operator must remediate or replace the water supply. Remedial procedures are often set up in response to the need to be in compliance of SMRCA water quality standards and are frequently extensive and costly. Lack of site-specific subsurface information often limits the effectiveness and increases the cost of these techniques.

Organizations such as the National Mine Land Reclamation Center (NMLRC), US Department of Energy, and West Virginia University have been focusing on the development of more effective and less costly remediation techniques. Three such techniques are: injection of alkaline fly ash grout into underground mines, injection of sodium hydroxide into the mine spoil of a recontoured surface mine, and surface applications of alkaline sludge. In order to test the effectiveness of these remedial efforts, site characterization and evaluation should be conducted before and during remediation efforts. Traditional methods of site characterization and evaluation include water quantitative and qualitative testing of seeps, flooded rooms, and monitoring wells. Data 
collected using these methods is useful but provides limited information about the subsurface at a given study area. Additional information and understanding of the subsurface conditions at a site can be obtained through the use of near-surface geophysics.

\subsection{Previous Research}

Previous geophysical studies have demonstrated their effectiveness in delineating zones of AMD (Ladwig, 1983; Ladwig, 1983; Ackman et al, 1998; Stoller and Roux, 1975; Merkel, 1972; Ebraheem et al, 1990; Benson and Addams, 1998; King and Hynes, 1994). More than 25 years ago Merkel (1972) used the electrical resistivity technique to effectively delineate zones of AMD in groundwater near an underground mine in central Pennsylvania. Merkel used a buried current source and measured the resistivity at the surface to map AMD plumes downstream of a mine and trace them back to their source within the mine. Benson and Addams (1998) used 49 Wenner array soundings at a mine site in Central Pennsylvania to delineate areas of AMD from AMD-free areas. Their measurements were correlated with drillers logs and water samples and found to effectively show where AMD exists in the subsurface of a shallow AMD-producing mineral mine. These examples, as well as others, show that resistivity surveys continue to be used and perfected today.

Terrain conductivity, also known as electromagnetic (EM) induction, has been used successfully in the last 15 years to delineate zones of AMD and detect pillar locations (Ladwig, 1983; Ladwig, 1982; King and Hynes, 1994; Ackman et al, 1998). Ladwig (1982) conducted terrain conductivity surveys over three separate surface coal 
mines in Pennsylvania to evaluate the use of the technique to AMD remediation programs. He found that the high conductivity associated with AMD and AMD sources (primarily pyrite) is a good target for electromagnetic detection. Citing ease of field operation and good resolution of AMD associated anomalies he demonstrated that the terrain conductivity technique is a valuable method for characterizing surface mine sites before implementation of remediation programs.

Ackman et al (1998) studied a small, unmapped underground coal mine site in Western Maryland where ash grouts were injected into the mine voids. They collected terrain conductivity and magnetic data at the site to locate wet areas. Results suggest the terrain conductivity technique can be used to delineate flooded mine voids and pillars; however, a thorough interpretation was not presented in their report. Because terrain conductivity data can be collected rapidly and interpreted easily, it is the most promising of the techniques in this study and has been used at all field sites.

While not used extensively in the past to delineate AMD or locate pillars, the magnetic method has proven useful in detecting metallic features in the subsurface related to mining activity and other human activities. Buried metallic objects can produce anomalous conductivity readings at the surface which may be mistaken for zones of AMD production or areas of sludge using terrain conductivity. Magnetic data collected in this study were used to locate sources of interference in other geophysical techniques such as terrain conductivity. 


\subsection{Objectives of this Study}

The primary aim of this study is to evaluate various non-invasive geophysical approaches to characterization of shallow underground mines and mine-spoils and to monitoring of remediation efforts in these settings. By utilizing two or three separate geophysical techniques at three different sites, this study seeks to:

1) determine if room and pillar locations and flooded areas in an underground mine can be identified

2) locate and evaluate effectiveness of in-situ barriers including grouting

3) identify and locate sodium hydroxide plumes in a mine-spoil

4) identify and locate post-treatment sludge and lime slurry plumes in a minespoil

5) identify preferred flow paths within a mine-spoil

6) identify any mined areas in an area of unknown mining history

7) determine if the techniques used here can be used to monitor remediation efforts at these and other sites

8) establish optimal conditions for successful use of this techniques

9) define procedures to be followed in the future application of these techniques

The three sites include the Irish Ridge mine, Greer mine spoil, and Long Ridge mine. At the Irish Ridge site, attempts were made to correlate the pattern of ground conductivity anomalies to pillar locations, AMD pools, and fly-ash grout barriers in an underground mine. At the Greer site, ground conductivity anomalies were correlated with monitoring well and hydrologic data in an attempt to identify and map sodium hydroxide plumes and zones of sludge migration from the surface to the pitfloor of a 
surface mine. At the Long Ridge site, attempts were made to associate terrain conductivity highs with pooled AMD at depth within an underground mine.

\subsection{Site Descriptions}

\subsubsection{Irish Ridge}

The Irish Ridge mine site is located in western Preston County, West Virginia, at approximately $39^{\circ} 26.3^{\prime} \mathrm{N}, 79^{\circ} 47.5^{\prime} \mathrm{W}$ (see Figure 1). The site was mined in the 1950's and abandoned in the mid 1960's. The total area of the site is approximately 12 acres and is owned by Anker Energy Properties. Field work was completed in a nine acre open field area over the mine. Layout of the mine is irregular, but consists of two entrances on the western end of the site which lead to several areas that were mined using the room and pillar technique. A map of the mine, surveyed by Courtney Black and Paul Ziemkiewicz of NMLRC, was later correlated to the geophysical station grid used in this study (Figure 2). The headings are typically $4 \mathrm{ft}$ high and approximately $12-16 \mathrm{ft}$ wide. A set of metal rail tracks, once used to remove coal from the site, enter the mine at the northern water-filled entrance (Figure 2) and extend an unknown distance into the mine. These rails are a potential source of interference in the terrain conductivity survey but were not detected in the magnetic or terrain conductivity surveys. In addition, a 6 inch natural gas pipeline buried approximately 3 feet beneath the surface runs east-west across the northern portion of the property. This pipeline produces large amplitude, long wavelength anomalies in the terrain conductivity data. The pronounced effect of this pipeline on the terrain conductivity data eliminates the possibility of observing conductivity variations within the mine near the pipeline. All mine workings follow the 
Upper Freeport coal seam which is about 4 feet thick in this area and lies about 1810 feet above sea level. A generalized stratigraphic column of the Irish Ridge site is shown in Figure 3.

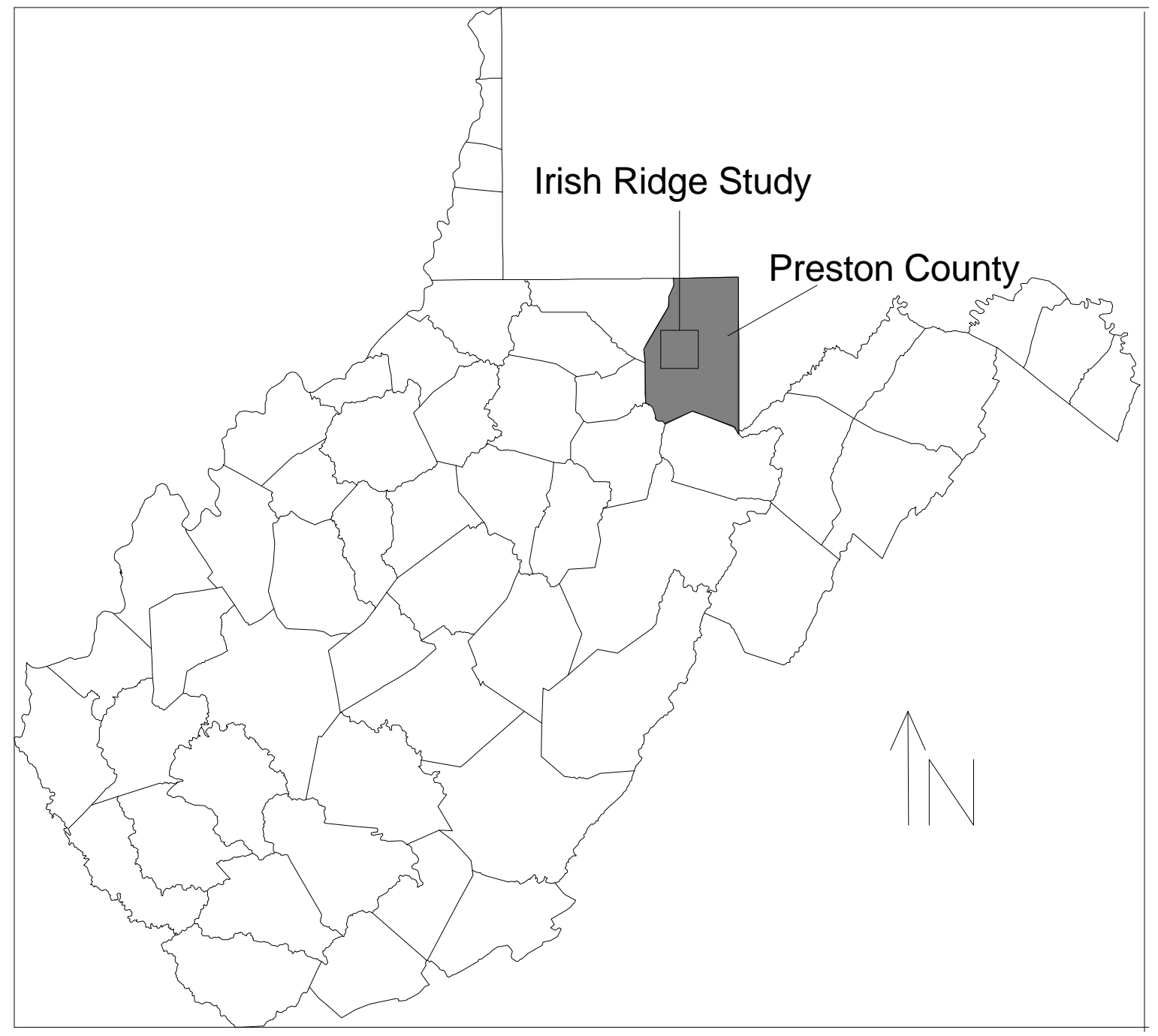

Figure 1 West Virginia state map showing Irish Ridge study area 


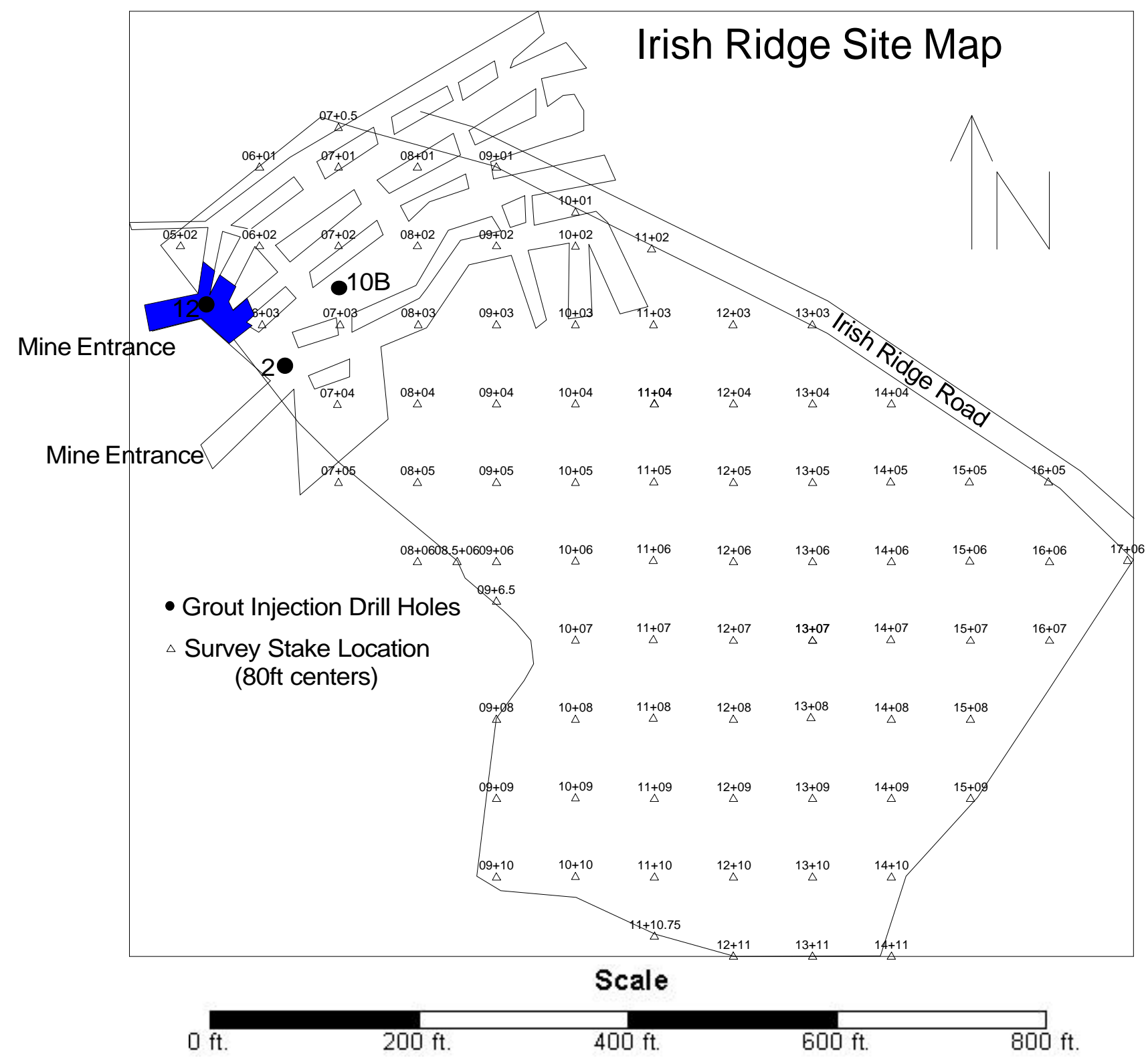

Figure 2. Irish Ridge site map. 


\section{Stratigraphic Unit}

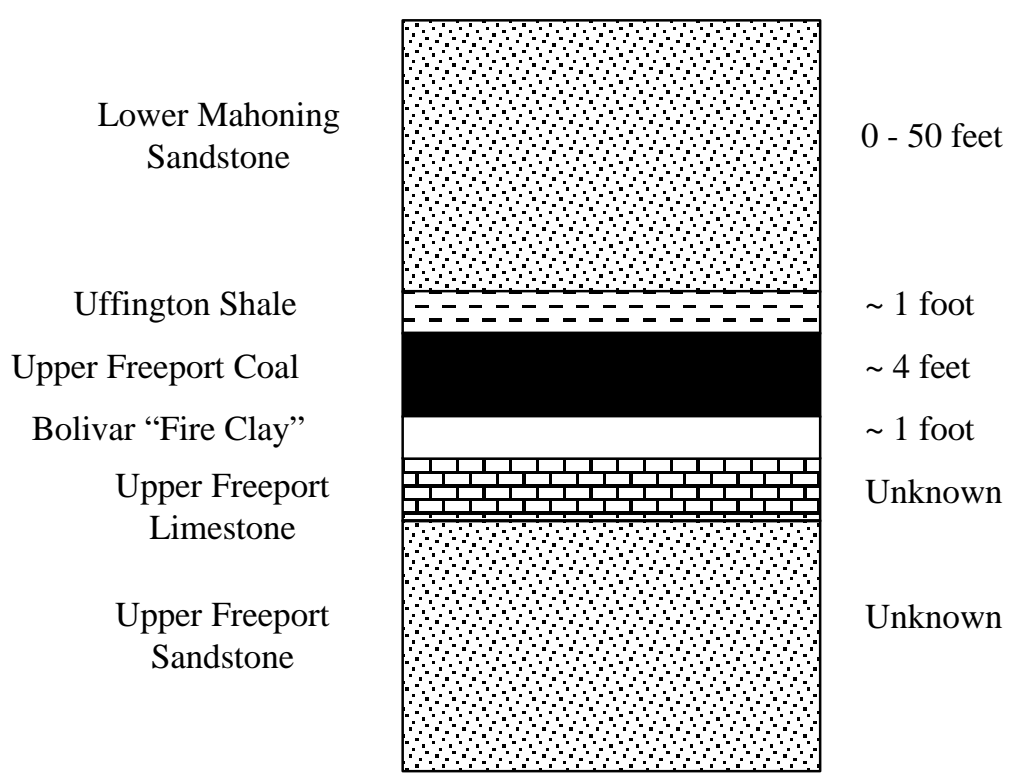

Figure 3. Irish Ridge stratigraphic column.

The majority of the overburden consists of the Upper Mahoning sandstone. A thin layer of Uffington shale, approximately 1 foot thick, lies directly above the Upper Freeport coal. Overburden thickness at the northern end of the site is more than 50 feet and thins abruptly at the southern end where the land surface slopes toward a small intermittent stream and intersects the Upper Freeport coal. Despite its age, the mine has subsided little due to the thick sandstone layer above it, however, the western entrance has collapsed and is partially water-filled. The mine map made by the NMLRC (seen in Figure 2) was used to determine where to inject the fly ash grouts used at the site.

The northwestern portion of the mine has been flooded creating a metal-rich pool of acid mine drainage (AMD) estimated by NMLRC to be 30,000 gallons. Flows measured at the northern mine entry were typically 1 gallon per minute, with a peak of 16 
gallons per minute occurring in August 1994 (NMLRC, 1996). The AMD migrates through the mine and flows through the northern mine entrance on the western edge of the site as well as into the floor of the mine. Efforts by NMLRC to seal off parts of the mine and limit the flow of AMD from the site took place during 1994 and 1995. These efforts included pumping bottom ash and fluidized bed combustion (FBC) ash grout into two boreholes in separate parts of the mine. Initially, 9 uncased drillholes were drilled at the surface. Borehole 2 (Figure 2) was used to inject a total of 144 tons of flyash grout into the mine before rejecting further additions. Camera observations showed that the ash traveled approximately 100 feet from the point of injection and approached the roof of

the mine shaft. A second injection of ash was done at borehole 10b (Figure 2). This hole accepted 100 tons of ash before refusing further additions. Neither of these injections were in contact with the mine pool in the northwestern portion of the mine. Injection of the FBC grout was done at the surface through several uncased 8 3/4 inch boreholes extending down to the mine from the surface.

\subsubsection{Greer}

The Greer Mansion Mine site is located about 4 miles northeast of Morgantown and West Virginia University at approximately $39^{\circ} 40.4^{\prime} \mathrm{N}, 7^{\circ} 52.7^{\prime} \mathrm{W}$ (Figure 4). From 1981 to 1987, the Pittsburgh and Sewickley coal beds were mined using surface-mining techniques and the site was later backfilled and recontoured to the original topography (Sincock, 1998). The 80 acre site has produced some of the worst AMD in West Virginia surface mines due to low $\mathrm{pH}$, high acidity, high metal concentration, and high sulfate content (Barker, 1998). Efforts to characterize the mine- 


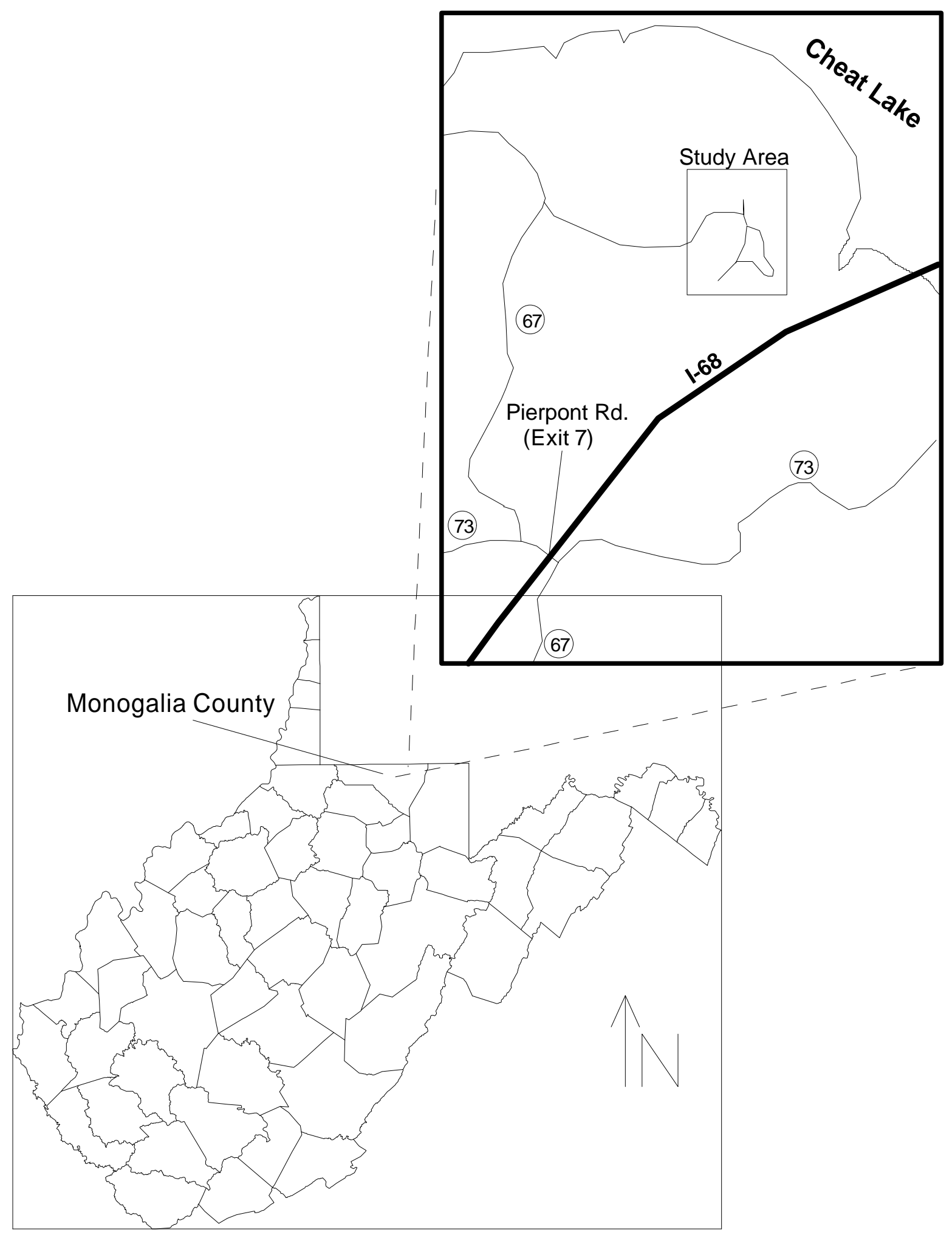

Figure 4. West Virginia state map showing Greer Mansion site location. 


\section{Greer Site Map}

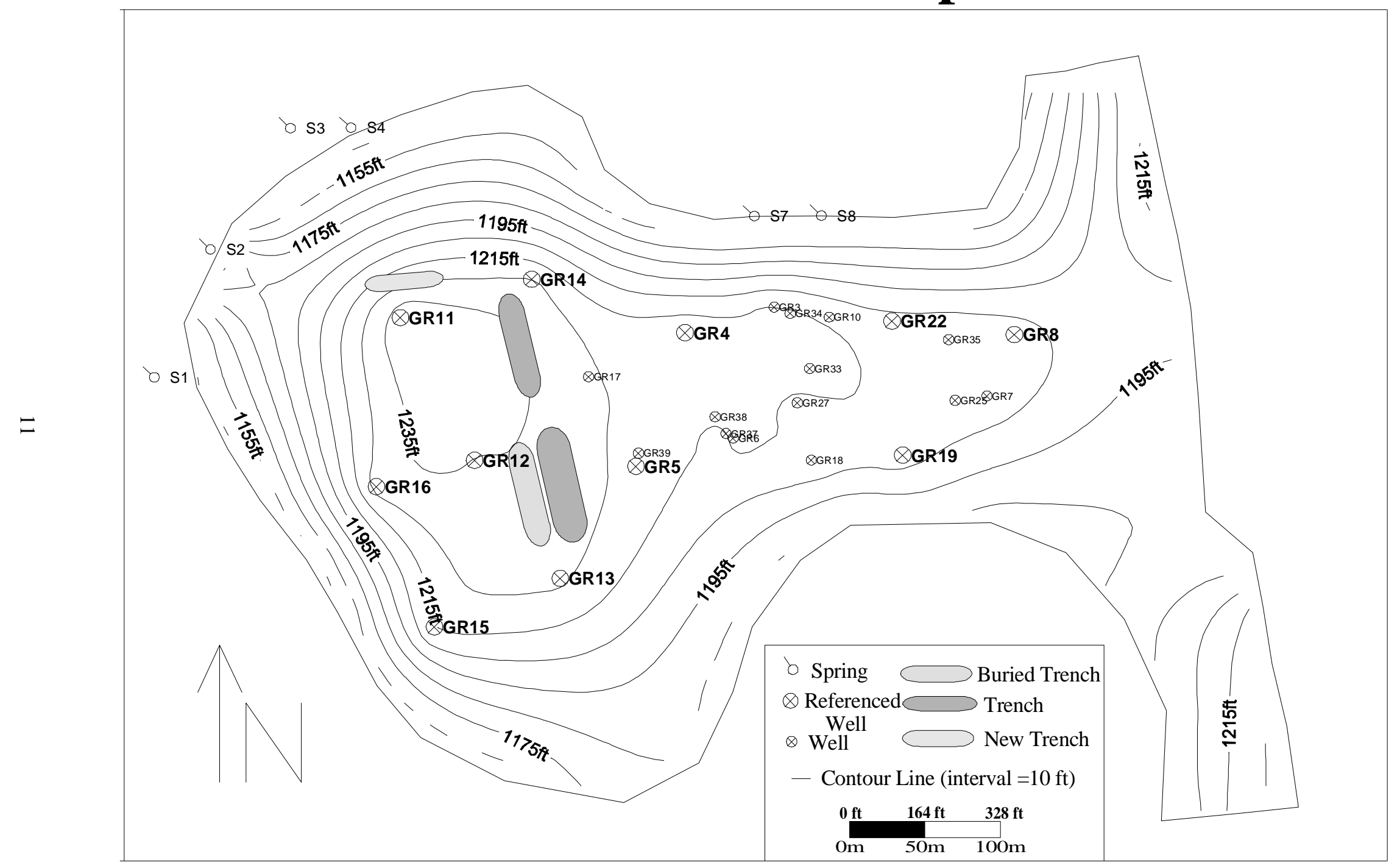

Figure 5a. Greer site map showing well locations and surface topography. 
spoil aquifer have included the installation of 38 wells between November 1994 and June 1996. Five of these wells are 4-inch injection wells for alkaline fluids (GR 20, 25, 27, and 37 in Figure 5a).

Extensive study of this site by Sincock (1998), Barker (1998), Ritter (1997) and others at West Virginia University has provided knowledge of the hydrogeology and geochemistry of the site. The discharge from the spoil drains through six springs on the northern and northwestern sides of the site (S1-S8 in Figure 5a). This discharge enters a shallow ditch where the water is treated with anhydrous ammonia and calcium hydroxide (lime) in the southwest corner of the site (Sincock, 1998). Treated water collects in settling ponds before being discharged into a tributary of the Cheat River.

Sincock (1998) used natural well-to-spring tracer tests as well as one and twodimensional transport models to determine average groundwater velocities in the minespoil aquifer. She found one-dimensional models yield relatively rapid average groundwater velocities of approximately 1 to $32 \mathrm{~m} /$ day (mean $6 \mathrm{~m} /$ day; median 2.5 $\mathrm{m} /$ day) while the two-dimensional transport models yield average velocities approximately $25 \%$ less than the one-dimensional models. The variations in average groundwater velocities are related to heterogeneities within the spoil with the higher values more representative of conditions along preferred flow paths. In addition, Sincock found that 10 of her 36 tracer tests resulted in ambiguous results or non-arrival at any of the springs (1998). These ambiguous results are explained by the presence of preferred flow paths (PFP's) and the extremely heterogeneous nature of the spoil aquifer. 
To summarize the findings of Sincock and others at Greer, a map of well-to-well and well-to-spring observations was generated and is shown in Figure 5b. This map shows the general flowpaths inferred from Sincock's single-salt tracer test, as straight line vectors of flow from 10 wells to 5 springs. It is important to note that multiple flowpaths from a single well exist due to advection and dispersion of the salts and that flowpaths are not straight as depicted in Figure 5b. A conceptual model of flow over the site is shown in Figure 5c based on observed potentiometric surfaces and the potentiometric map presented in Sincock's thesis (1998). In this model, both multiple flowpaths and extreme heterogeneity in the spoil are ignored mainly because they are poorly known. The flowpaths in Figure 5c should be thought of as ideal paths rather than actual paths which are controlled by heterogeneities in the spoil such as: pitfloor irregularities, variations in sediment size and compaction, variations in porosity, and changes in saturated thickness. Actual flowpaths may vary over time with hydrologic changes in the spoil.

Efforts to treat the AMD in-situ have taken place in the last three years and have included injection of sodium hydroxide $(\mathrm{NaOH})$ into the spoil as well as surface applications of post-treatment alkaline sludge and lime slurry into ditches. Barker (1998) studied the effects produced by injection of 2000 gallons (7550 liters) of $20 \% \mathrm{NaOH}$ into well GR-20 (see Fig. 5a). Barker found that the injected sodium hydroxide had little, if any, impact on the $\mathrm{pH}$ of springs that discharge from the aquifer. She found that a serial buffer system from $\mathrm{pH} 8$ to 3.5 formed in the aquifer buffering the effects of the $\mathrm{NaOH}$ at the springs. Elevated sodium concentrations (40-95 meq/L) above pre-injection baseline concentrations of $0.6 \mathrm{meq} / \mathrm{L}$ in the injection well (GR-20) for at least 219 days after injection suggest that a phase of $\mathrm{NaOH}$ or a related reaction product may have become 


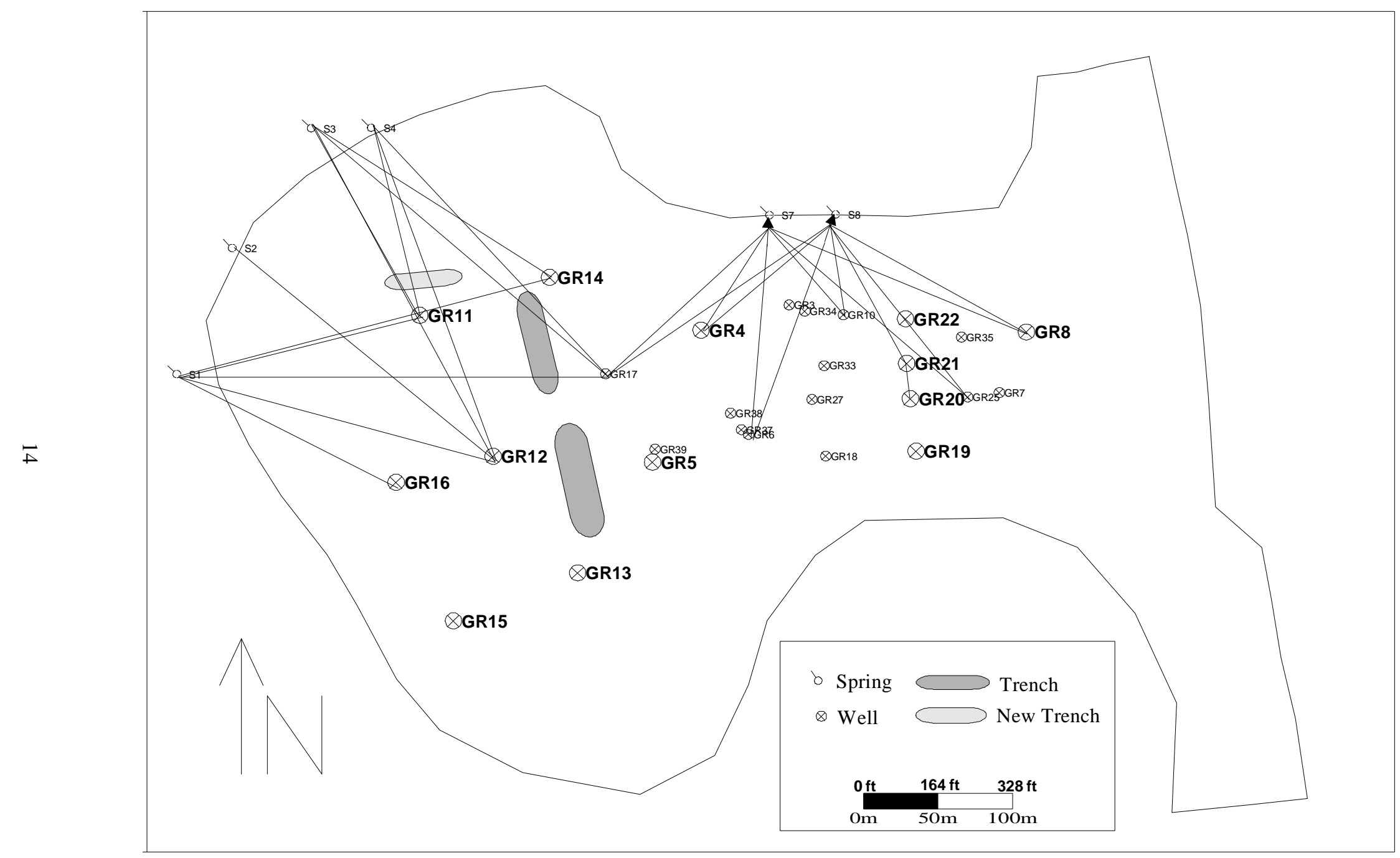

Figure 5b. Greer site map showing well to spring tracer results (after Sincock, 1998). 


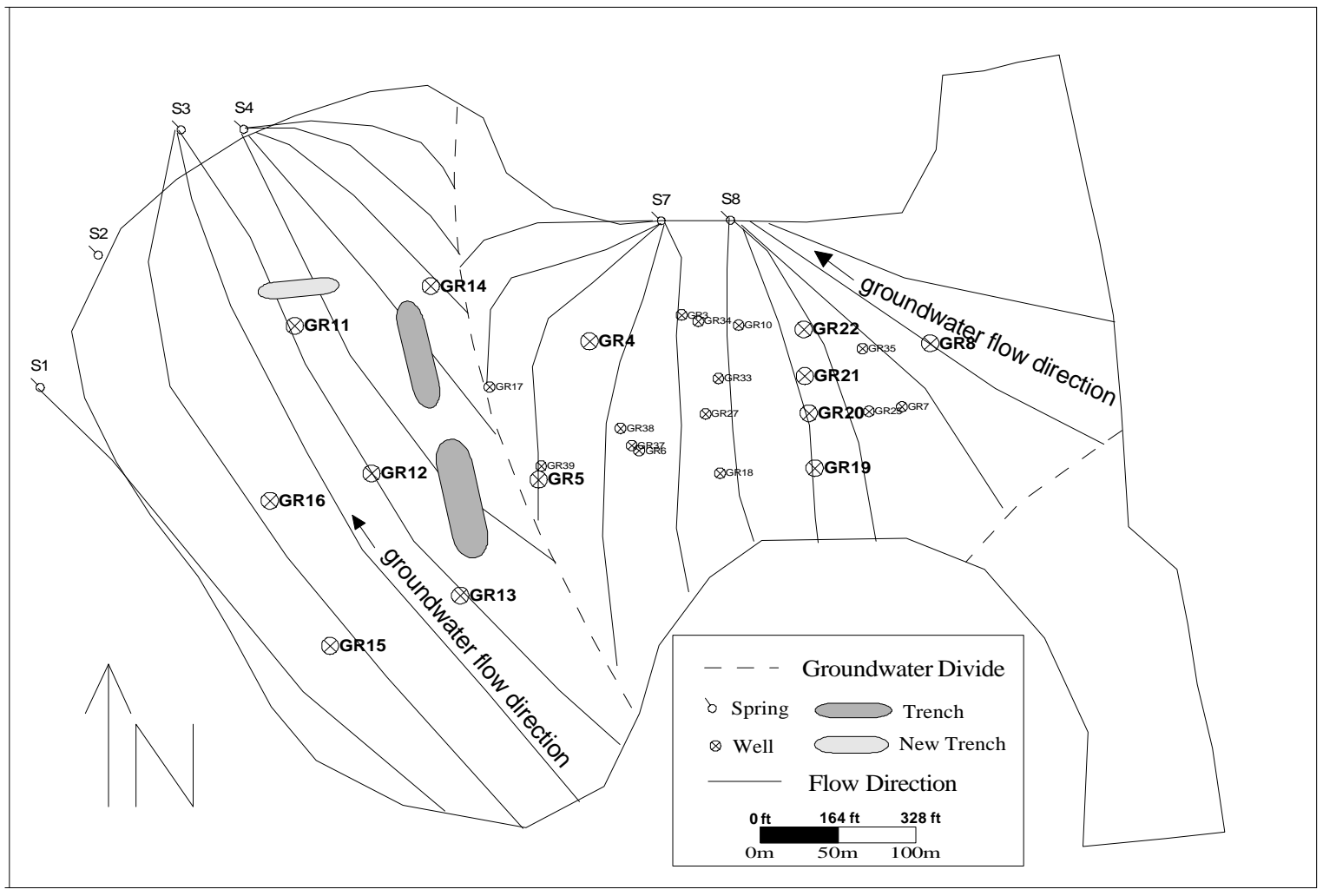

Figure 5c. Conceptual model of flow 
immobilized. Data from Donovan and Werner (1998) show the minimum travel time from well GR-20 to well GR-21, a distance of 18 meters, was 212 days. This yields a maximum average groundwater velocity of $0.085 \mathrm{~m} /$ day. They suggest that the injected $\mathrm{NaOH}$ flows by a dual phase transport mechanism, suggesting that Sincock's (1998) calculated groundwater velocity of $1-32 \mathrm{~m} /$ day may not be representative of all flow conditions in all parts of the spoil.

This injection and ten later injections of 400-600 gallons of $20 \%$ and $50 \% \mathrm{NaOH}$ solutions have likely produced sludge of reaction products on the pitfloor surrounding the well. Concentrated sodium hydroxide and metal-rich sludge have higher conductivity than native groundwater therefore plumes and/or sludge bodies, if they remain, should be detectable as regions of anomalously high conductivity. Measurements taken over this area of the spoil in spring 1999 indicate the presence of anomalously high conductivity which could be related to sludge or reaction products at the pitfloor formed from the earlier $\mathrm{NaOH}$ injections.

On the surface of the mine three of trenches were dug to dispose of treated sludge and AMD. These trenches are located near a groundwater divide (Sincock, 1998) and trend northwest-southeast in the western portion of the site (see Figures 5a and 5d). These trenches were dug before this study began. The northern trench was completely filled with sludge from June 1997 to in early 1998 and then abandoned. The southern trench, dug in May 1998, is still in use as of December 1999 and has accepted at least $5 \times 10^{6}$ gallons of treated sludge. This sludge is a slurry of alkaline metal-rich hydroxide solids formed by lime treatment of AMD seeping from the spoil. Application of activated lime and ammonia to AMD at the site results in an increased $\mathrm{pH}$ and the 


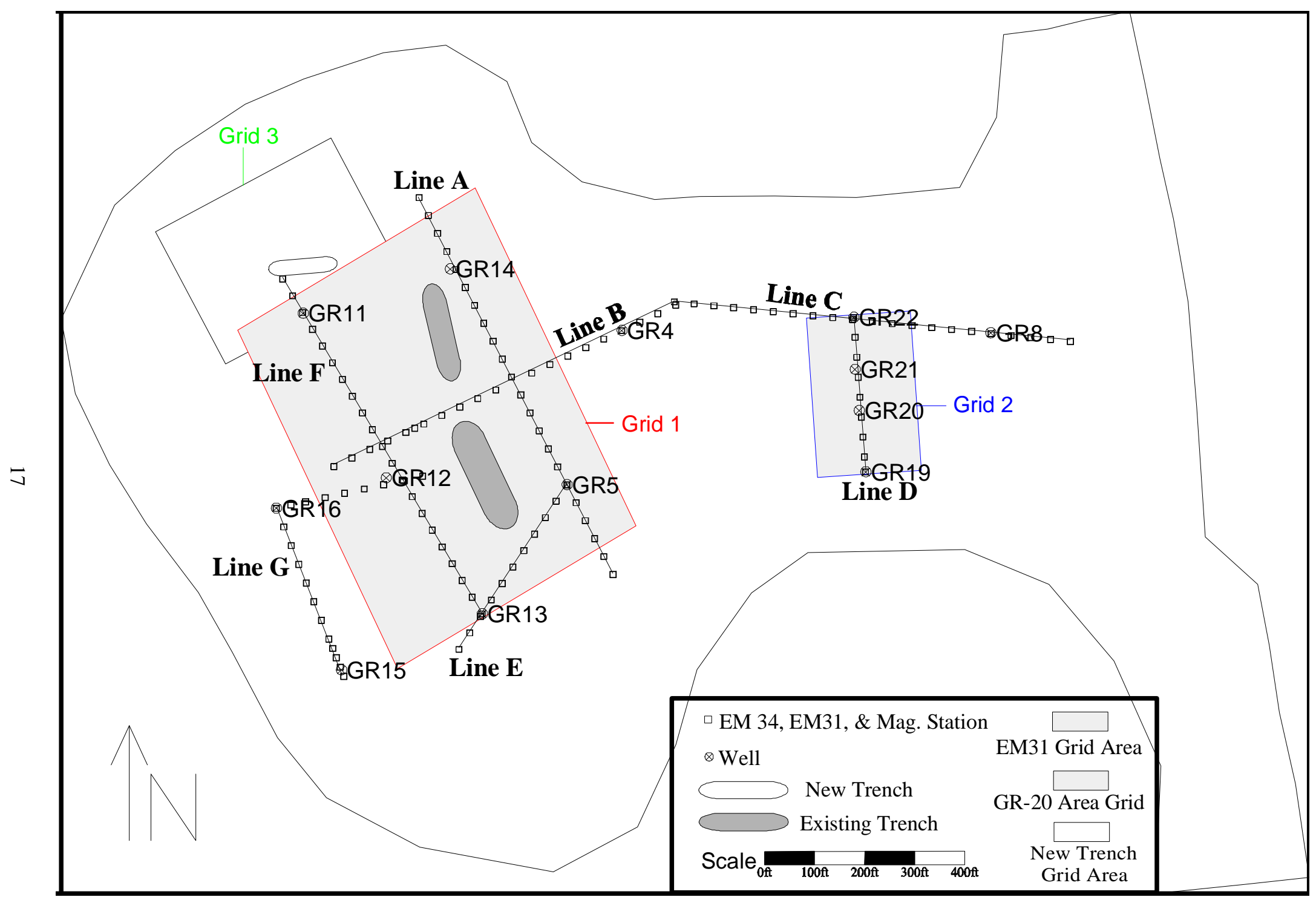

Figure 5d. Greer site map showing EM profiles. 
associated geochemical reactions cause the metals in solution to precipitate in ponds downstream of the treatment area. Because the sludge is moderately alkaline and because its disposal is expensive, it is transported to the top of the mine spoil by vacuum truck as needed and emptied into the southern surface trench. The alkalinity left in the sludge is believed to help neutralize AMD in the spoil, increasing its $\mathrm{pH}$. The metal-rich sludge appears more conductive than the surrounding spoil and creates a detectable terrain conductivity anomaly at the surface. EM 31 field measurements taken around sludgefilled trenches at the Greer site in the fall of 1998 and EM 34 measurements taken in the spring of 1999 show conductivity highs extending from the trenches. These conductivity highs originate at the trench and extend along pathways through the surrounding spoil. The magnetic technique was also used at the Greer site to check for metallic objects in the spoil and prevent erroneous interpretation of these features in the conductivity data.

In the spring of 1999, during this study, another trench was dug into the northwestern portion of the spoil. This trench runs nearly east-west and is approximately $35 \mathrm{ft}$ wide, 125 feet long, and was nearly 20 feet deep when filling began. After the trench was dug it was filled with a high $\mathrm{pH}$ lime slurry and flushed with water and ammonia in an effort to raise the $\mathrm{pH}$ of the springs downgradient of it.

\subsubsection{Long Ridge}

The Long Ridge site is owned by Anker Energy and is located in Preston County, West Virginia about 26 miles southeast of Morgantown (Figure 6). The property includes both surface and underground mines. This study focuses on a portion of the property where an underground mine exists. The study area is partially wooded and is accessed by a gravel road following the crest of Long ridge. The Upper Freeport coal 
seam was mined at the site and is overlain by a thick sandstone unit known as Lower Mahoning Sandstone with some thin beds of shale including the Uffington Shale (Figure 7). A generalized stratigraphic column is shown in Figure 7 and represents the typical layering over the site.

The site lies on the northwestern limb of the Preston anticline which is one in a series of anticlines in the western Appalachians. Preston anticline generally trends about $\mathrm{N} 20^{\circ} \mathrm{E}$ with Long Ridge trending closer to $\mathrm{N} 45^{\circ} \mathrm{E}$. Dip over the mined area is to the northwest at about $2^{0}$. The mine follows Long Ridge and is $\sim 2700$ feet long, 125 to 1000 feet wide, and 75 to 85 feet below the ground surface. Exposure to oxygen and water has oxidized the pyrite within the mine producing iron and sulfate-rich acid mine drainage (AMD) that drains to an augerhole near the lowest point in the mine, at the northwestern tip of the mine (Figure 8). Downdip of the augerhole, the mine is thought to be flooded Ziemkiewicz (1999).

During the spring of 1999, a fluidized-bed combustion (FBC) ash grout mixture was injected into 4 boreholes at the site in an effort to reduce the flow and improve the quality of the water discharging from the augerhole. Grouting at boreholes 9, 9a, 9b, and 10 (Figure 8) has produced a barrier to flow in the mine. It is thought that upgradient of this barrier the mine is flooded. At the time of this study grouting efforts led by the National Mine Land Reclamation Center (NMLRC) were continuing near hole 10 and a pile of fly ash at the surface was present over a small portion of the study area. In addition, large metal equipment used to mix the fly ash grout was also present in these same areas at the time of the survey. Both the fly ash and metal machinery are sources of electromagnetic interference in this study. 


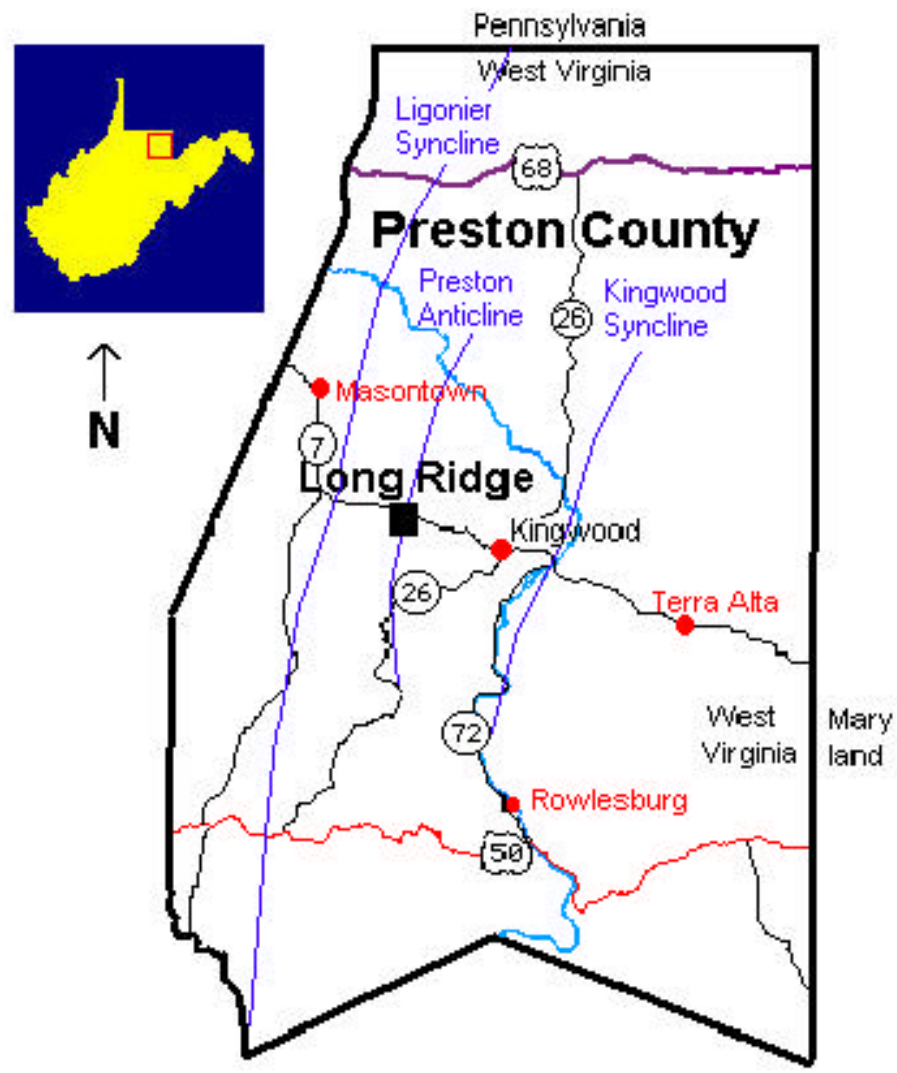

Figure 6. Long Ridge location map.

\section{Stratigraphic Unit}

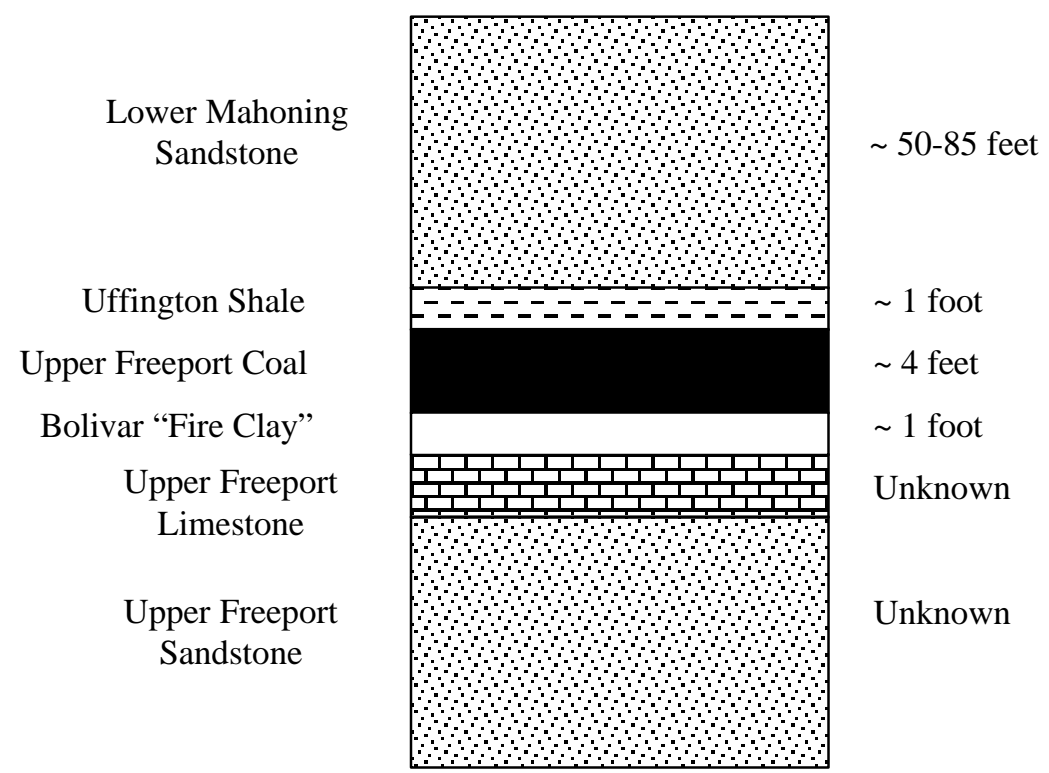

Figure 7. Long Ridge stratigraphic column. 


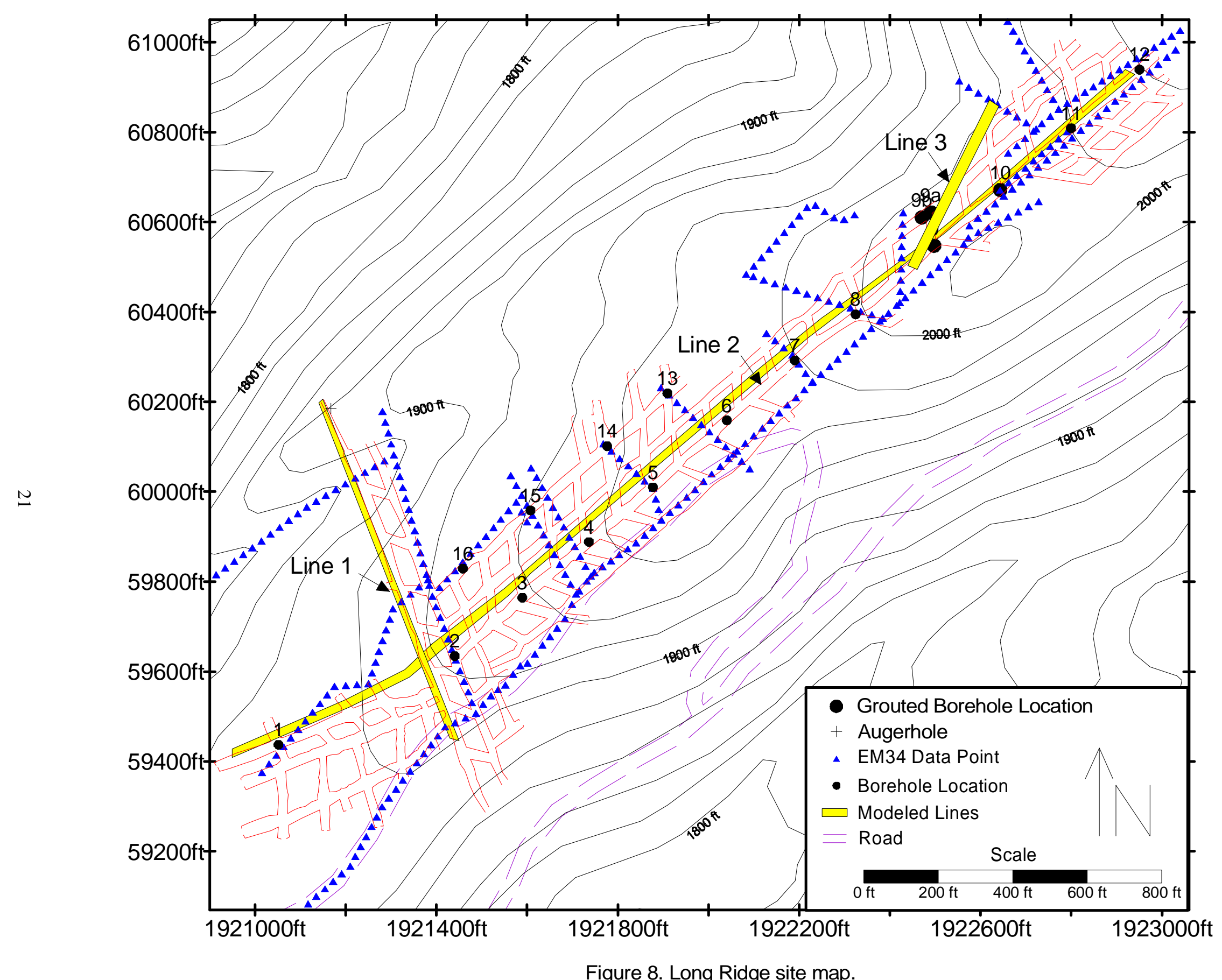

Figure 8. Long Ridge site map. 


\section{CHAPTER 2 - Methodology}

\subsection{Discussion of Field Techniques}

\subsubsection{Magnetics}

Magnetic surveys have proven useful in a variety of environmental applications where there is local variation in the quantity of ferrous or ferromagnetic material in the shallow subsurface (Sweatmen and Bergstrom, 1993, Ackman et al., 1998, Schlinger, 1990). By measuring variations in the earth's total magnetic field or its vertical gradient at the surface we can interpret subsurface conditions. These variations in field intensity are caused by three main factors: spatial variations in the earth's main magnetic field, temporal magnetic field variations produced by interactions of solar winds with the earth's magnetosphere, and local magnetic anomalies related to the geological conditions of the site (Telford et al., 1990). The first two variations may be considered as background noise in a local magnetic survey. In cases of intense magnetic storms they could significantly affect survey measurements but such conditions were not encountered during data collection as reoccupation of a base station did not show significant variations in the magnetic field with time. Local perturbations of the earth's magnetic field are related to local geologic conditions such as basaltic dikes, zones of hydrothermal alteration, depositional changes in sediments, or other structural features affecting the distribution of magnetic minerals. Magnetic anomalies may also arise from cultural and industrial features such as fence posts, pipelines, cars, machinery and other ferromagnetic man-made material. These anomalies are produced by differences in magnetic susceptibility. All earth materials have some value of magnetic susceptibility ranging 
from near 0 for quartz, halite, and calcite to $19.2 \times 10^{3}$ SI units for magnetite. In the study area average rock susceptibilities are relatively low as shown in table 1. Because of this, the expected natural magnetic anomalies in all field areas should be low.

\begin{tabular}{lcl} 
Rock Type & Average Susceptibility (X 10 $10^{3}$ SI units) \\
\hline Limestone & 0.3 & $(0-3)$ \\
Sandstone & 0.4 & $(0-20)$ \\
Shale & 0.6 & $(0.01-15)$ \\
Coal & 0.02 & \\
Clays & 0.2 &
\end{tabular}

(Data from Telford et al., 1990)

Table 1. Average magnetic susceptibilities for rocks.

In this study, field measurements were made using a proton precession magnetometer at the Irish Ridge and Greer sites. The instrument used at the Greer site is a one-man unit consisting of a portable controller, a two-meter aluminum pole, and a cylindrical sensor at the top of the pole. The sensor is a coil of wire with hydrogen ionrich liquid in its core. A DC current is applied through the coil creating an internal magnetic field oriented along the axis of the sensor. This oriented field forces the spin axis of each proton in the liquid into alignment with the induced field of the coil. After power is turned off the protons begin to wobble or precess about the earth's magnetic field. This precession induces a small alternating current in the coil (Burger, 1992). The frequency of the current alternations is measured by the controller, converted to a total magnetic field intensity $\left(\mathrm{F}_{\mathrm{E}}\right)$, and displayed on a digital display. The resulting measurement is generally independent of sensor orientation and need only be approximately vertical. 
At the Irish Ridge site, a gradiometer was also used. The gradiometer incorporates observations from a second magetometer located on the same staff but $1 / 2$ meter above the first (one at 1.75 meters and another at 2.25 meters). Using rapid successive readings of the two sensors, the difference in the two readings defines the vertical gradient in the total magnetic field. The gradient is generally unaffected by diurnal magnetic variations and is often more effective at sensing or isolating local magnetic anomalies of shallow origin (Sweatmen and Bergstrom, 1993).

Total field intensity measurements taken in the field are typically expressed in nanoTeslas (nT) and vertical gradient field measurements usually have units of nanoTeslas per meter (nT/m). The nanoTesla (nT) is $10^{-9}$ Tesla (T) and is the SI unit equivalent to 1 gamma $(1 \gamma)$ or $10^{-5}$ gauss $(\mathrm{G})$ in cgs units. The sensitivity of most magnetometers is in the range of 0.1 to $1 \mathrm{nT}$, by comparison the earth's total magnetic field intensity is 54,000 to 55,000 nT in the northern West Virginia field areas. It should also be noted that the magnetic response due to an anomalous isolated dipole in the field drops off proportional to $1 / \mathrm{r}^{3}$ where $\mathrm{r}$ is the distance from the dipole center to the instrument. In contrast, the magnetic gradient associated with a dipole drops off proportional to $1 / \mathrm{r}^{4}$. From this, it can be shown that gradiometer readings generally respond best to shallow bodies and help to separate or enhance anomalies associated with shallow objects from those having deeper origins.

Magnetic field measurements proved to be of limited use to this study because they are most affected by cultural noise and because the variation in magnetic material at depth on these sites is small. Both large and small electrical power lines can also be a source of interference. A small rural electrical power line runs along the northern 
boundary of the Irish Ridge site. In addition there are buried rail tracks in at least part of the western portion of the mine and there is a buried gas transmission line in the northern section of the Irish Ridge site. The rails had no obvious effect on data collected in the magnetic or terrain conductivity surveys. However, the gas line produced a significant linear anomaly in both the total magnetic field (Figures 8 and 10) and gradient (Figure 11). The boreholes drilled at the surface for the injection of the fly ash grout remained uncased and are not a source of interference as they were in the study done by Ackman and others (Ackman et al., 1998). The utility of the magnetic method in these surveys is to separate cultural noise from signal due to AMD or sludge.

\subsubsection{Terrain Conductivity (EM)}

Terrain conductivity, also known as time-domain electromagnetic (EM) induction, is a useful subsurface geophysical method for the mapping of groundwater contamination, detection of subsurface cavities, mapping of bedrock topography, general geologic mapping, archaeological exploration, and other applications (McNeill, 1980). The technique has also been utilized to delineate AMD and saturated areas within minespoils (Ladwig, 1982; Ladwig, 1983; King and Hynes, 1994) and to distinguish rooms from pillars in a room and pillar mine (Ackman, 1998).

In the electromagnetic (EM) induction method an alternating electrical current is sent through a transmitter coil, creating an alternating electromagnetic field (with primary magnetic field intensity, $\left.\mathrm{H}_{\mathrm{P}}\right)$. This electromagnetic field penetrates the shallow subsurface and induces a secondary electromagnetic field intensity $\left(\mathrm{H}_{\mathrm{S}}\right)$ in earth materials. A receiver coil, spaced a set distance away $(\mathrm{S})$, receives both the primary and 
secondary electromagnetic fields. If the frequency and amplitude of the alternating field are known as well as the coil spacing, then $\mathrm{H}_{\mathrm{S}}$ can be computed directly from the response in the receiver. The apparent conductivity $\left(\sigma_{\mathrm{a}}\right)$ can then be computed directly from the ratio of the secondary to primary field (equation 1)(McNeill, 1980).

$$
\sigma_{\mathrm{a}}=\left(4 / \omega \mu_{0} \mathrm{~S}^{2}\right)\left(\mathrm{H}_{\mathrm{S}} / \mathrm{H}_{\mathrm{P}}\right)
$$

where $\sigma_{\mathrm{a}}$ is apparent conductivity in $\mathrm{mho} / \mathrm{m}, \omega$ is equal to $2 \pi \mathrm{f}$ where $\mathrm{f}$ is the current frequency in $\mathrm{Hz}, \mu_{0}$ is the permeability of free space, $\mathrm{S}$ is the coil spacing in meters, $\mathrm{H}_{\mathrm{S}}$ is the secondary magnetic field at the receiver coil, and $\mathrm{H}_{\mathrm{P}}$ is the primary magnetic field at the receiver coil.

A simplifying assumption of the above equation is that the induction number (B) is low (i.e. $\mathrm{B}<<1$ ). The induction number $\mathrm{B}$ is defined as the ratio of intercoil spacing (s) to skin depth $(\delta)$ (i.e. $\mathrm{B}=\mathrm{s} / \delta$ ). Assuming the earth to be a homogeneous half space, the skin depth is the distance within the earth at which a propagating wave's amplitude is attenuated to 1/e ( 0.368) of its amplitude at the surface and can be calculated as:

$$
\delta=.\left(2 / \omega \mu_{0} \sigma\right)
$$

where $\omega$ is equal to $2 \pi f$ and $f$ is the current frequency in $\mathrm{Hz}, \mu_{0}$ is the permeability of free space, and $\sigma$ is actual conductivity in $\mathrm{mho} / \mathrm{m}$.

A plot of apparent conductivity derived from the low induction relationship (equation 1) versus true conductivity for the EM 34 is shown in Figure 9. The upper "true conductivity" line is what we hope to measure with the EM 34 and the two lines just below this line are what the EM 34 indicates in the horizontal and vertical dipole orientations. The two lowest lines are the fractional error between the indicated and true conductivities for the horizontal and vertical orientations. The plot indicates that 


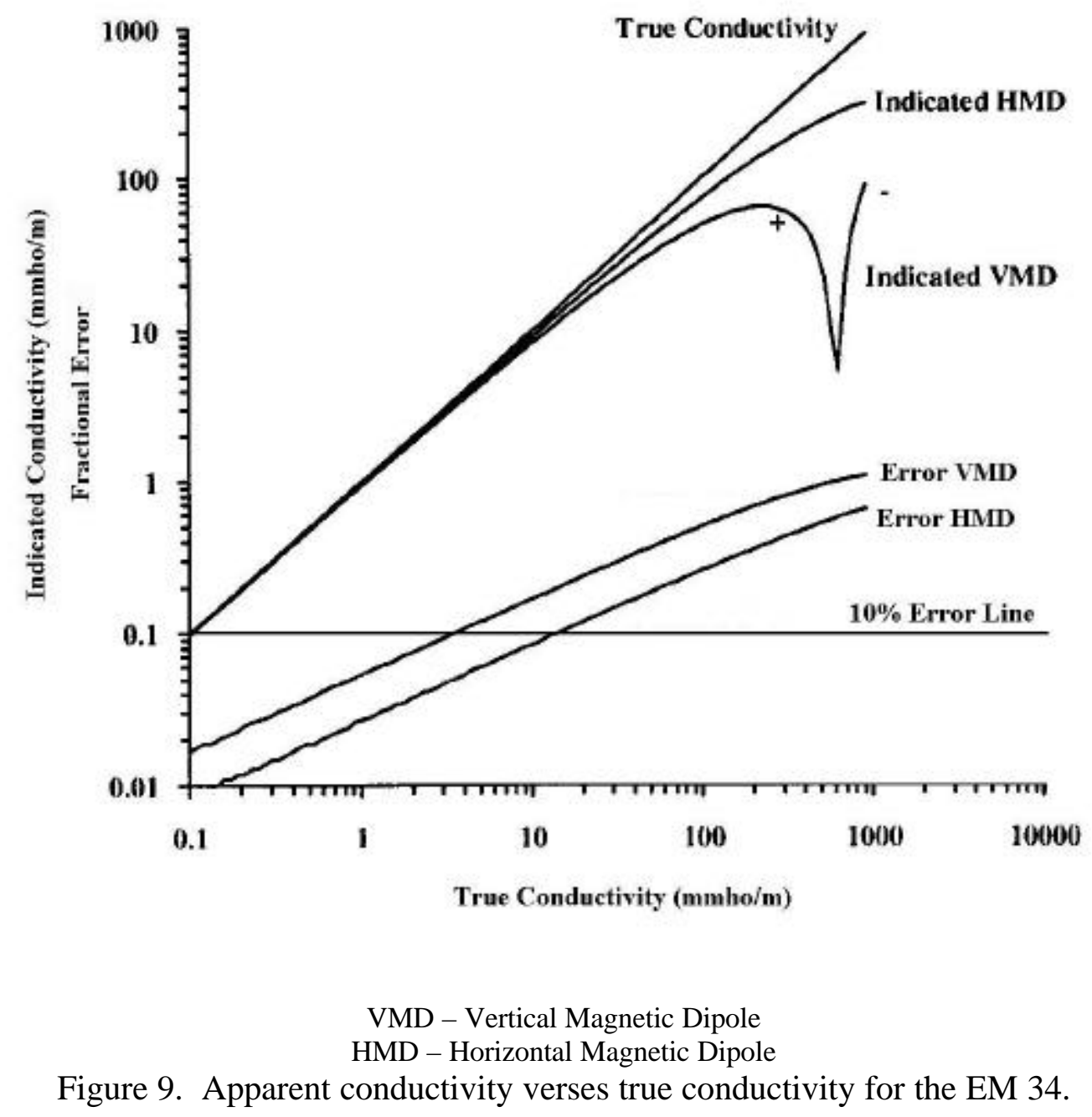

operation at low induction number is an accurate assumption (within 10\% error) when measurements are made of materials having conductivities of less than $3 \mathrm{mmho} / \mathrm{m}$ in the vertical dipole orientation and less than $15 \mathrm{mmho} / \mathrm{m}$ in the horizontal dipole orientation. Indicated conductivity values remain usably close to actual values up to about 40 $\mathrm{mmho} / \mathrm{m}$ where indicated values vary substantially from true conductivity values.

The apparent conductivity reading $\left(\sigma_{\mathrm{a}}\right)$ obtained by the terrain conductivity meter represents a net response derived from the conductivities of all detectable layers in the 
subsurface. This value is the true conductivity only in cases where the earth is isotropic below the instrument. In most cases, heterogeneities exist in the subsurface, thus the observed apparent conductivity is actually a weighted average of the conductivities associated with subsurface layering or other structures. In this study, the apparent conductivity differences at the surface are significantly affected by the lateral changes in subsurface conductivity at each of the sites.

Coil spacings using available equipment are 3.7 (EM 31), 10, 20, and 40 meters (EM 34-3). These spacings result in exploration depths from 2.2 to 50 meters depending on coil orientation. The term "exploration depth" is commonly used to describe the depth at which the response of material from below that depth contributes 1/e (36.78\%) of the total apparent conductivity reading. The response of material from above the exploration depth contributes 1 - (1/e) or $(63.22 \%)$ of the total response. The depth 1/e is also referred to as the skin depth. It is important to recognize that intervals with depths substantially shallower and deeper than this tabulated "exploration depth" still contribute significantly to the measured apparent conductivity. Table 2 shows approximate relationships between exploration depth and coil spacing.

\begin{tabular}{cccc} 
& \multicolumn{3}{c}{ Exploration Depth } \\
Coil Spacing $(\mathrm{m})$ & Horizontal Dipole & Vertical Dipole & Current Frequency $(\mathrm{Hz})$ \\
\hline 3.7 & $2.2 \mathrm{~m}(7.2 \mathrm{ft})$ & $4.7 \mathrm{~m}(15.3 \mathrm{ft})$ & 9800 \\
10 & $5.88 \mathrm{~m}(19.3 \mathrm{ft})$ & $12.6 \mathrm{~m}(41.5 \mathrm{ft})$ & 6400 \\
20 & $11.8 \mathrm{~m}(38.6 \mathrm{ft})$ & $25.2 \mathrm{~m}(82.9 \mathrm{ft})$ & 1600 \\
40 & $23.6 \mathrm{~m}(77.2 \mathrm{ft})$ & $50.4 \mathrm{~m}(165.8 \mathrm{ft})$ & 400
\end{tabular}

Table 2. EM 31 and EM 34 exploration depths. 
As can be seen from Table 2, the vertical dipole mode has an exploration depth approximately double that of the horizontal dipole mode, given the same coil separation, hence the response of the two modes of operation (vertical and horizontal dipole) is not the same.

Using equations from McNeill (1980), response curves for a diffuse 3 meter thick contaminate plume within the mine spoil were modeled to show the expected response of the EM 31 and EM 34 conductivity meters. Models were generated for the EM 31 vertical and horizontal dipoles as well as for the EM 34 at 10 and 20 meter coil spacings. The geometry of the model is shown in Figure 10. The apparent conductivity variations observed along the length of the dipping contaminate plume (Figure 10) are shown for the horizontal and vertical dipole orientation for each intercoil spacing in Figures 11a, 11b, 11c. From these plots we see that the horizontal dipole mode generally responds best to near-surface features. Additionally, we see that the instruments are sensitive to changes above and below the "exploration depth".

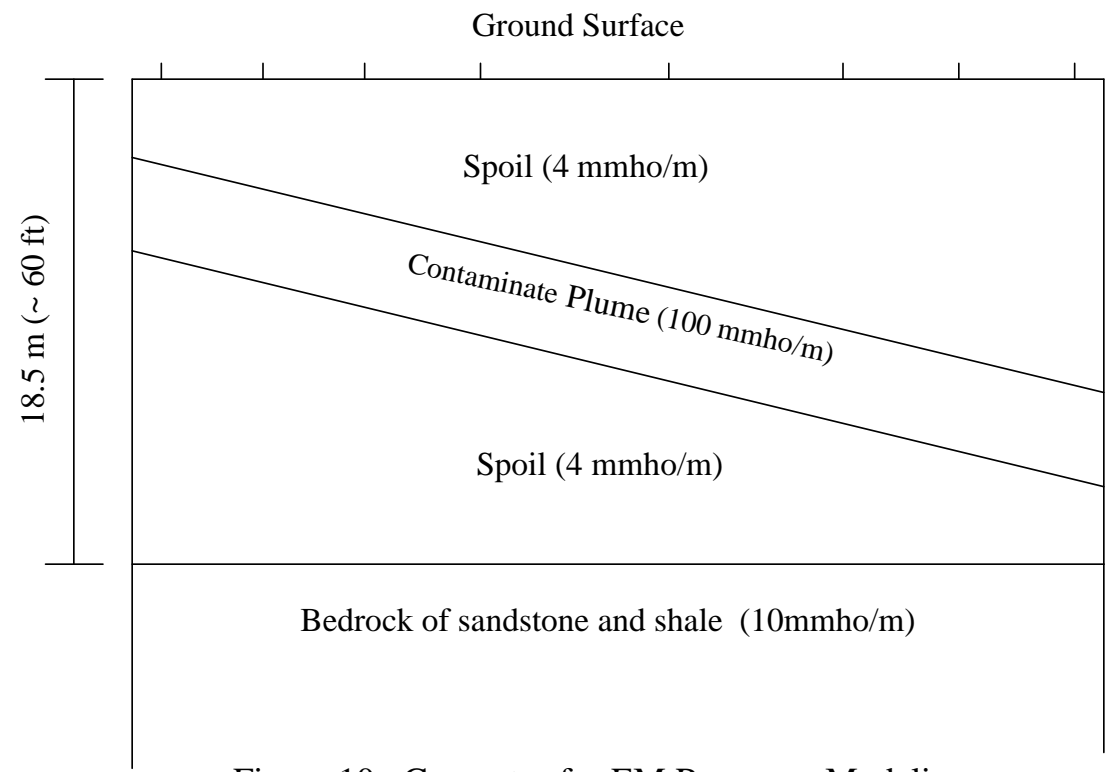

Figure 10. Geometry for EM Response Modeling 
EM 31 Response to a $3 \mathrm{~m}$ thick $(100 \mathrm{mmho} / \mathrm{m})$ plume in an $18.5 \mathrm{~m}$ thick $(4 \mathrm{mmho} / \mathrm{m})$ mine spoil with $10 \mathrm{mmho} / \mathrm{m}$ bedrock

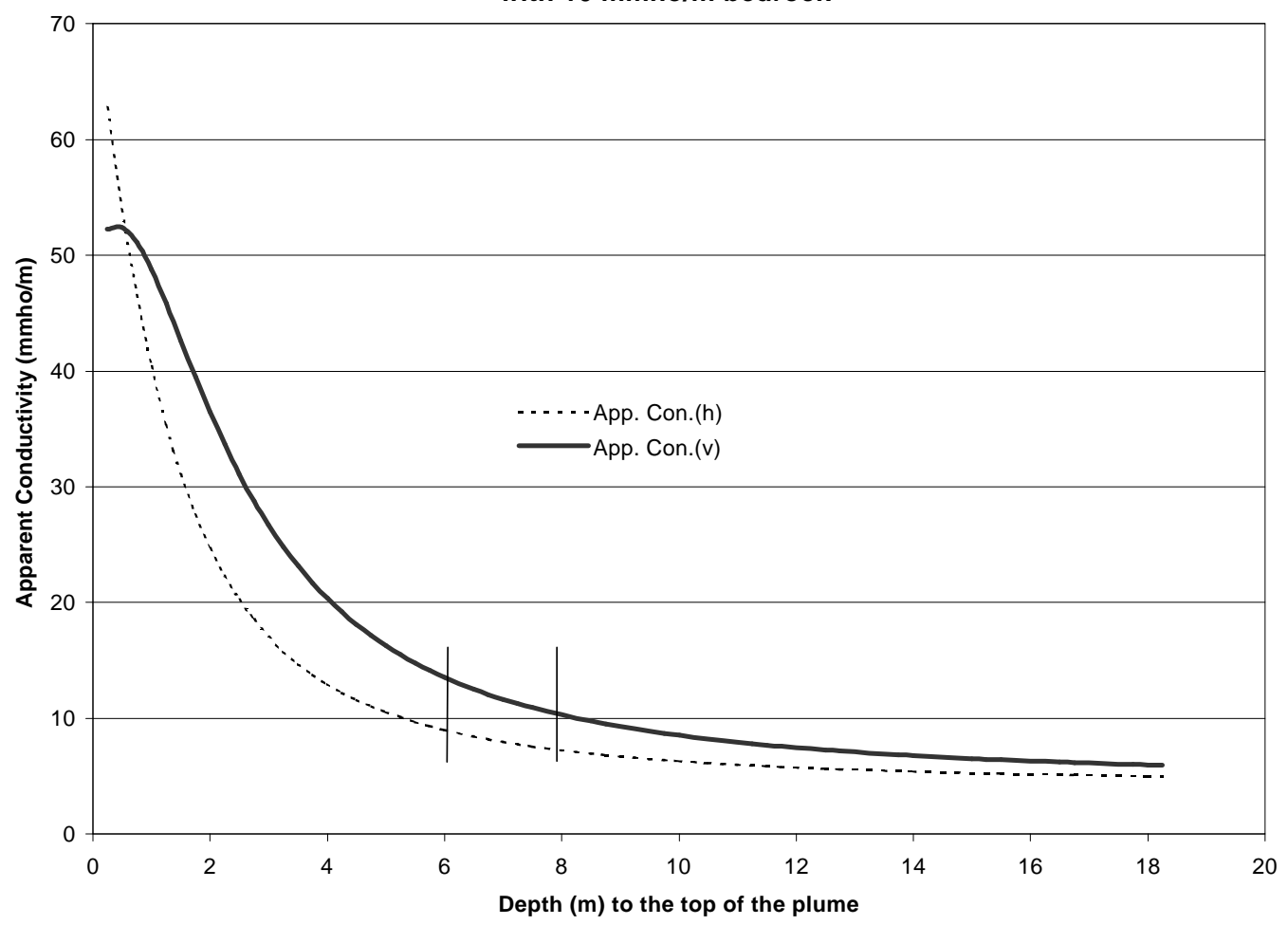

Figure 11a. EM 31 response model.

EM34-10m Response to a $3 \mathrm{~m}$ thick (100mmho) plume in an $18.5 \mathrm{~m}$ thick $(4 \mathrm{mmho} / \mathrm{m}) \mathrm{mine}$ spoil with $10 \mathrm{mmmho} / \mathrm{m}$ bedrock

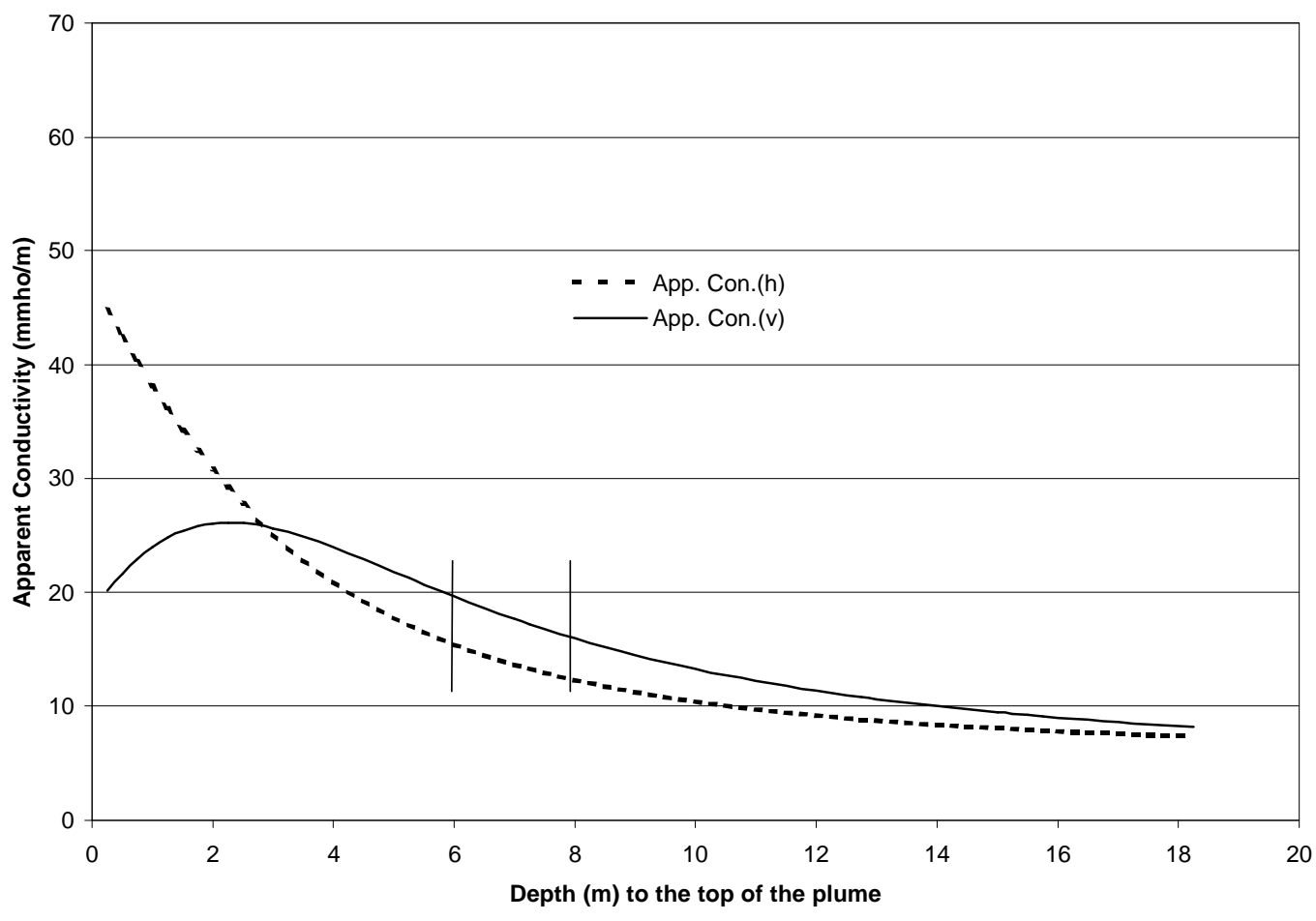

Figure 11b. EM 3410 meter response model. 
EM34-20m Response to a $3 \mathrm{~m}$ thick $(100 \mathrm{mmho} / \mathrm{s})$ plume in an $18.5 \mathrm{~m}$ thick $(4 \mathrm{mmho} / \mathrm{m}) \mathrm{mine}$ spoil with $10 \mathrm{mmho} / \mathrm{m}$ bedrock

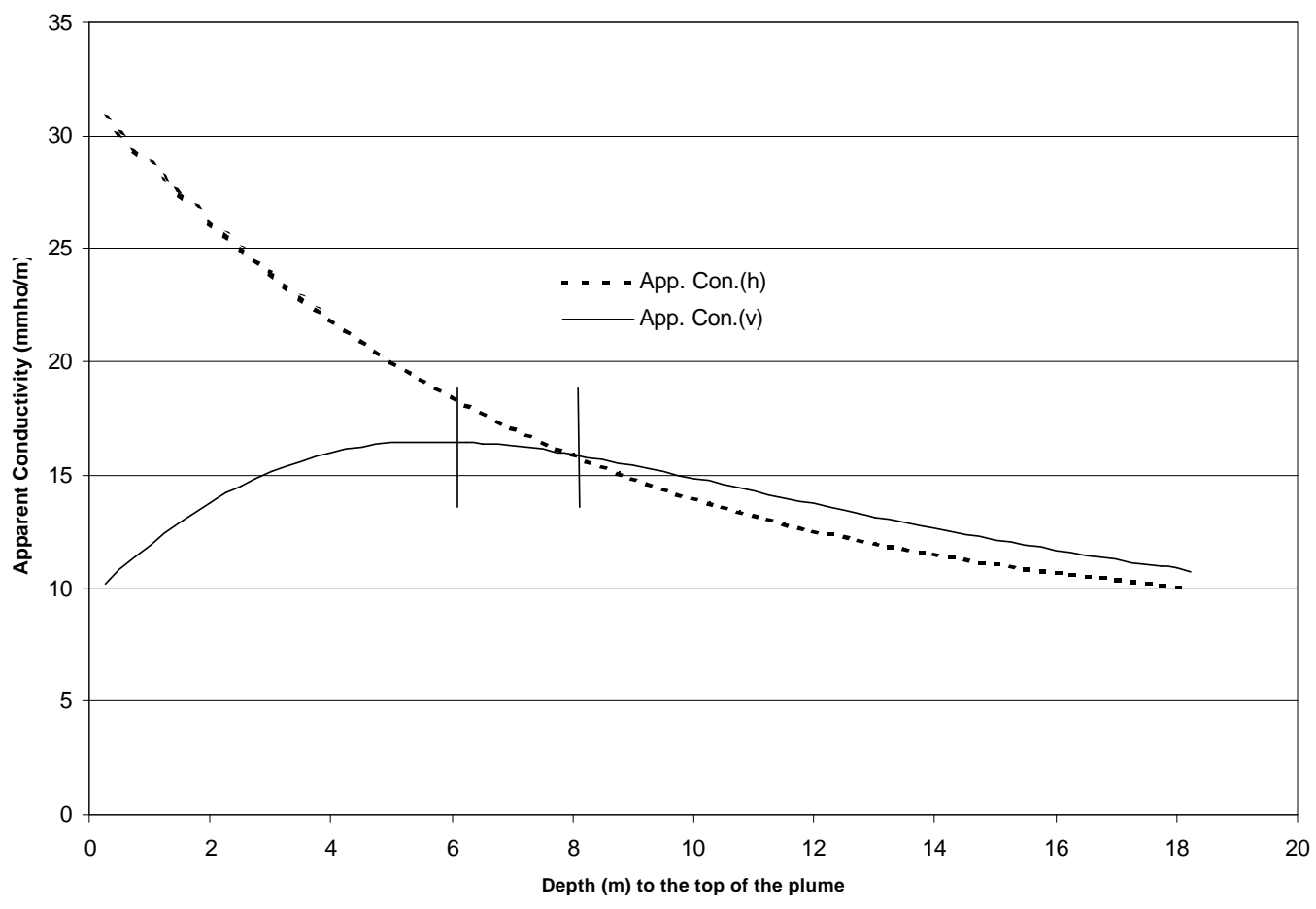

Figure 11c. EM 3420 meter response model.

For example, the EM 31 response in Figure 11a shows the difference in apparent conductivity between depths to plume-top of 6 to 8 meters is $4 \mathrm{mmhos} / \mathrm{m}$ for the vertical dipole measurement and $2 \mathrm{mmho} / \mathrm{m}$ for the horizontal dipole measurement. Differences for the EM 34 with 10 meter coil separation are 4 and $3 \mathrm{mmhos} / \mathrm{m}$ for the vertical and horizontal, respectively, while for the EM 3420 meter coil separation the differences are 3 and $0.5 \mathrm{mmhos} / \mathrm{m}$ for the vertical and horizontal coil orientations, respectively. Although depth to plume-top is well outside the presumed "exploration depth" of the EM 31, the differences in apparent conductivity measured by the EM 31 are of comparable 
magnitude. Also, as the plume descends to 18 meters the differences in apparent conductivity measured by the EM31, while slightly less than those for the EM 3410 and 20 meter spacing are nonetheless detectable.

Current frequencies for the EM 31 and EM 34 are in the audio (100's to 1000's of $\mathrm{Hz}$ ) range and decrease with increased coil spacing so as to keep induction numbers low. Field equipment used in this study includes both the Geonics Limited EM 31 and EM 343. The EM 31 is a one-man portable unit with transmitter and receiver coils fixed to a control unit in the center. The unit is carried using a shoulder or neck strap and does not normally come in contact with the ground. The instrument is most sensitive at a depth of approximately 5.6 meters when operated in the vertical dipole mode. Apparent conductivity is displayed as millisiemens per meter $(\mathrm{mS} / \mathrm{m})$ which also equal millimhos per meter (mmho/m). The EM 31 was used only at the Greer site due to time constraints. The EM 34-3 provides three coil spacings for variable sensing depths, depending on user needs. In this study only the 10 and 20 meter spacings were used since the depths to be sensed are only 20 to 85 feet (6-25 meters). The EM 34-3 is a two person instrument with the two coils connected with wires to the control unit. One person carries the transmitter and the transmitter coil while the other carries the receiver and the receiver coil. The coil spacing is determined electronically and the controller automatically processes the data to provide an apparent conductivity reading on a meter. Like the EM 31 , the unit never directly touches the ground and provides apparent conductivity values in milliSiemens per meter $(\mathrm{mS} / \mathrm{m})$ or millimhos per meter $(\mathrm{mmho} / \mathrm{m})$.

Data collection and interpretation are relativity simple for either instrument. For the EM 31, readings can be taken as fast as the operator can record the data and walk to 
the next station. For the EM 34-3, an apparent conductivity reading can be obtained directly from the meter once the coils are correctly spaced. In cases of low apparent conductivity, this procedure can take a minute or more. Additionally, it was found that the EM 34-3 produces erratic results if the ground surface is wet, for example, after a precipitation event or in the morning after a dew. At the Irish Ridge site, where the apparent conductivity is low, the data collection took 6 field days to complete. Raw terrain conductivity data at all sites has been grided in Surfer and presented as contour plots of apparent conductivity.

\subsubsection{Resistivity}

Previous studies have shown that AMD is highly conductive, and that nearsurface accumulations of significant thickness, provide an excellent target for resistivity studies (Merkel 1972, Ebraheem et. al. 1990, Stollar and Roux, 1975, Benson and Addams, 1998). In addition dry rooms within a shallow mine act as infinitely resistive voids in the subsurface and may provide a significant resistivity contrast at the surface. Over 30 years ago Caruccio (1967) studied acid mine waters in Western Pennsylvania and was able to correlate the ion concentration and specific conductance of various waters. Caruccio found linear log-log relationships between resistivity and ion concentration for various ions in solution. The log-log relationship between total dissolved ion concentration and earth resistivity (reciprocal conductivity) can be seen in Figure 12. 


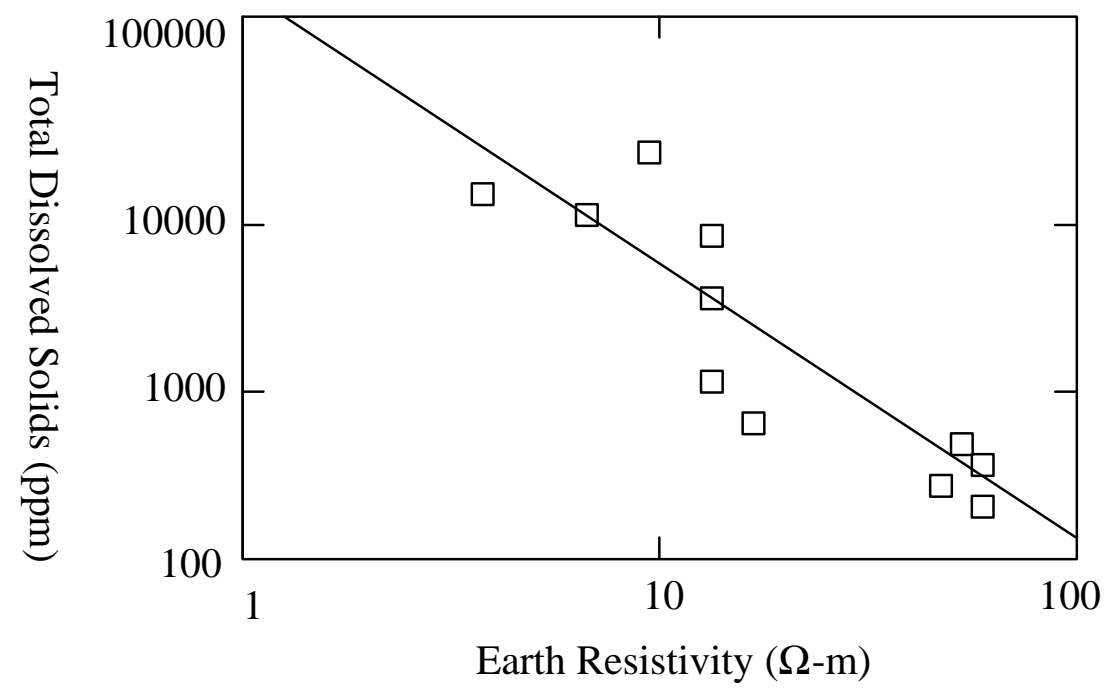

Figure 12. Relationship between earth resistivity and total dissolved solids.

This study employed the resistivity profiling technique at the Irish Ridge and Greer Mansion sites. In both cases, very limited profiling was done using a standard Wenner array. The a-spacing (electrode spacing) is, as a rule of thumb, approximately equal to the sounding depth in this electrode configuration. At both the Irish Ridge and Greer sites five resistivity profiles were collected to assist in later computer modeling of terrain conductivity data. Earth resistivity was measured in ohm-feet in this study. Resistivity values are related to apparent conductivity readings in the following way: 1/ resistivity equals conductivity, so $1000 \Omega$-m equals $1 \mathrm{mmho} / \mathrm{m}$ and $1 \Omega$-ft equals 1 mho/ft. 


\subsection{Geophysical Approach}

This study utilized three geophysical techniques: terrain conductivity, magnetics, and resistivity. Each technique is non-invasive and measurements are made at the surface. Fieldwork began in mid-September 1998 at the Irish Ridge site, in early November 1998 at the Greer site, and in May 1999 at the Long Ridge Site. Data acquisition was completed at all sites by mid-July of 1999 .

At the Irish Ridge site, elevation and station location control were established using an electronic distance meter (EDM). Stations were marked with non-conductive wooden survey stakes in a grid with 80 foot centers (Figure 2). Readings were taken at $1 / 3$ of this spacing, resulting in a station spacing of $262 / 3 \mathrm{ft}(6.1 \mathrm{~m})$ over the entire nine acre, open field area of the Irish Ridge site. The same station locations were used for both the terrain conductivity and magnetics surveys. This spacing produced a grid of approximately 675 stations for the terrain conductivity and magnetics surveys. Magnetic data were collected over two field days and corrected for drift by re-occupying a control point periodically. Terrain conductivity data were then collected over the same area in a

6 day period. In the spring of 1999 , additional terrain conductivity data were collected to determine if significant changes in conductivity occurred with time and to confirm findings from the previous fall. One resistivity profile and four resistivity soundings were also collected.

At the Greer site well locations provided reference points for geophysical station locations and grids. Data collection efforts in fall 1998 included acquisition of 8 terrain conductivity and magnetic profiles across the site as well as developing a grid of EM31 
data over the two older trenches. Magnetic and terrain conductivity profile data were collected using 20 and 40 foot spacings and by traversing the top of the spoil from one well towards another. Data points are shown in Figures (5a and 5d). To collect the EM31 grid data wooden stakes were placed 100 feet apart and stations were paced out at 25 foot centers. The EM31 grid is shown by the red box (Grid 1) in Figure 5d. In the spring of 1999, EM31 data were again collected over this grid and compared to the fall 1998 data. EM34 grid data were also collected in the spring of 1999 in two new grids, one between GR19 and GR22 (Grid 2, the blue area in Figure 5d) and one over the new trench area (Grid 3, the green area in Figure 5d). Grid 2 has a station spacing of 20 feet with 40 feet between lines. Grid 3 has a station spacing of 25 feet with 50 feet between lines. Over the new trench, data were collected three times, once before excavation, once as the trench was first being filled, and once after two lime slurry applications. These data sets were compared to one another to provide a "time-lapse" picture of changes in the subsurface. One resistivity profile and four resistivity soundings were also collected. Selected terrain conductivity profiles were modeled using Interplex's EMIX34P modeling software to aid interpretation of the data.

At the Long Ridge site, well locations were already known and were used to establish geophysical station locations and grids. Terrain conductivity surveys were conducted in May 1999 over the mined area of the site, approximately 15 acres. All data were collected using a Geonics EM34 conductivity meter. At each station a 10 meter vertical, 20 meter horizontal, and 20 meter vertical reading was taken. Because of thick underbrush and wooded conditions, data were collected in lines along roads and trails over the mined area. A total of approximately 340 data points spaced 25 feet apart were 
collected. Data point locations were surveyed by tape and compass using borehole locations as known survey points. Figure 8 shows the individual data point locations and their relationship to the mine, boreholes, and West Virginia state grid coordinates. Once field data was collected, it was entered into a database, grided, and contoured using Golden Software's Surfer program. Contour plots of the apparent ground conductivity over the mined area for each of the three readings were generated in Surfer. Selected terrain conductivity profiles were modeled using Interplex's EMIX34P modeling software to aid interpretation of the data. 


\section{CHAPTER 3 - Results}

\subsection{Irish Ridge}

\subsubsection{Magnetics}

Initial efforts at the Irish Ridge site consisted of setting up the survey grid described earlier. Magnetic field intensity measurements were made using a Geometrics 856 magnetometer with a gradiometer attachment with two readings between survey stakes. This results in $262 / 3$ foot $(8.13 \mathrm{~m})$ station intervals. The lower sensor was mounted on a staff 1.75 meters from the ground, while the upper sensor was mounted at 2.25 meters from the ground. The gradient in the magnetic field intensity is obtained by subtracting the upper sensor reading from the lower sensor reading at each station. Readings were manually recorded in the field and entered into an Excel spreadsheet. The resulting data set includes 678 stations of data each with a lower and upper sensor reading and a gradient calculation. Diurnal (daily) variations in the magnetic field are to be expected during a survey of this type and as a result, several reoccupations of a base station were made. Reoccupations were made at least once an hour. A linear drift correction was made to the raw field data. Corrected data were then gridded in Surfer. Once the data were gridded, surface contour maps were constructed using Surfer (Figures 13, 14 and 15). One obvious feature that shows up on all plots is a series of highs and lows that trend NW-SE. These anomalies are due to the steel gas transmission line mentioned earlier and are a source of interference. Two north-south trending anomalies appear in the upper and lower total intensity data (Figures 13 and 14). North-south trends are also suggested in the magnetic gradient map (Figure 15) The magnetic data were collected to identify metallic objects that would show anomalies in the terrain 


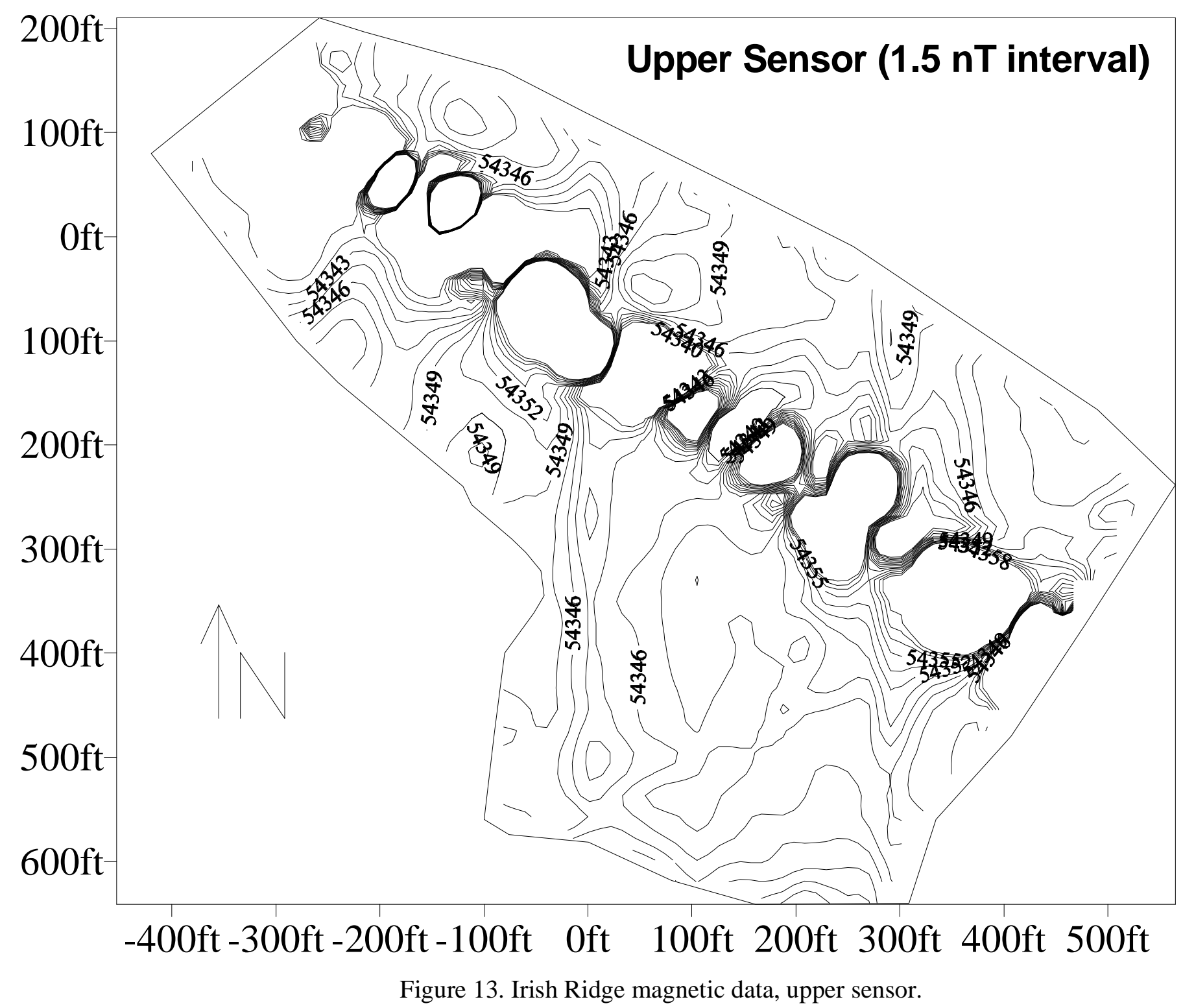




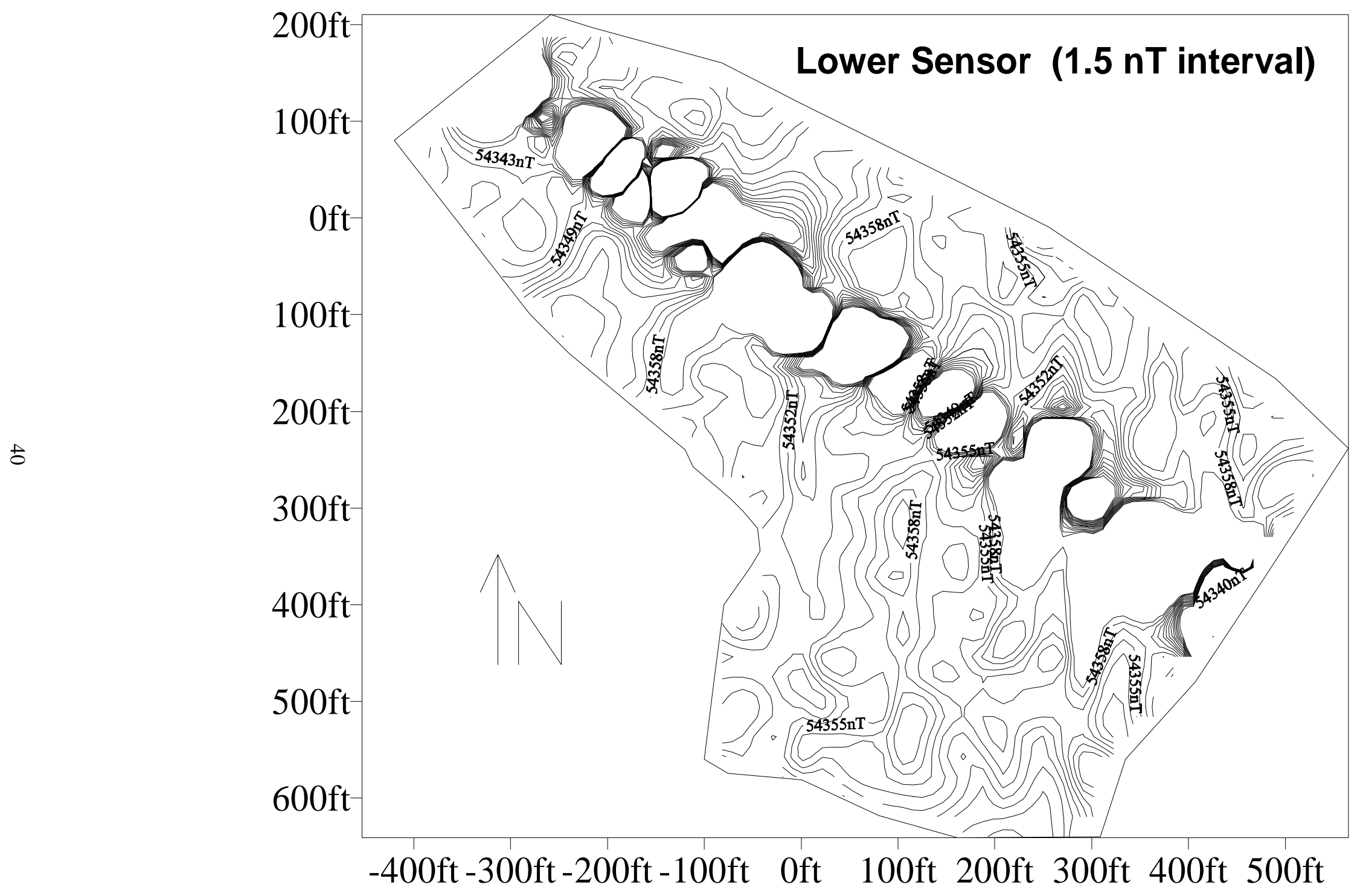

Figure 14. Irish Ridge magnetic data, lower sensor. 


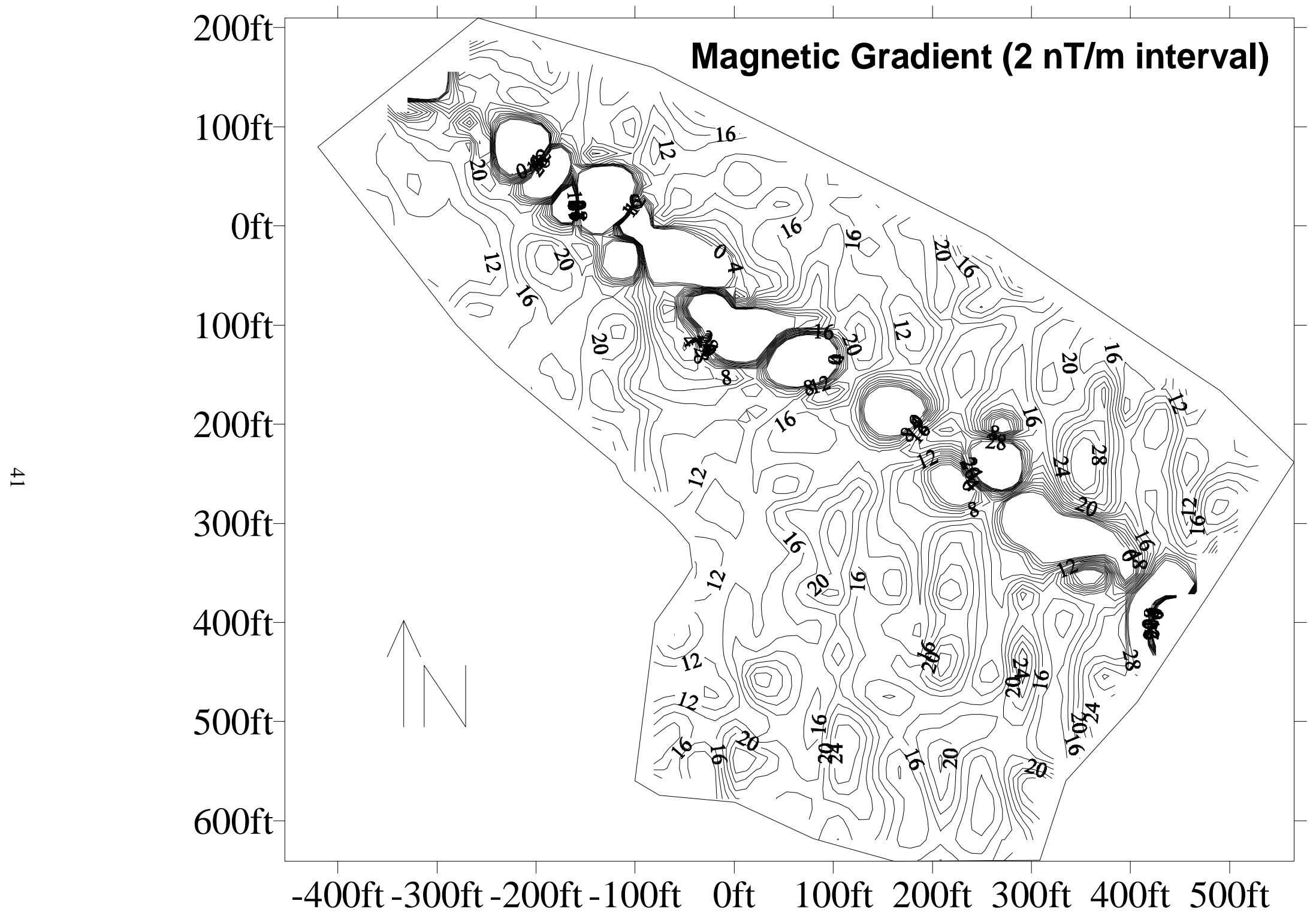

Figure 15. Irish Ridge magnetic data, gradient. 
conductivity data. The gas transmission line was the only source of metallic contamination identified at the site.

\subsubsection{Terrain Conductivity}

Terrain conductivity field data were collected using a Geonics EM 34-3 terrain conductivity meter. Terrain conductivity measurements were made at the same stations occupied in the magnetic survey. At each station, two measurements were made; a vertical dipole reading with a 10 meter coil spacing $(10 \mathrm{~m} \mathrm{~V})$, and a horizontal dipole reading with a 20 meter coil spacing $(20 \mathrm{~m} \mathrm{H})$. Exploration depths for both of these spacings are about 12 meters (40 feet) (see table 2) although the 20 meter horizontal reading tends to respond more strongly to near-surface features than the 10 meter vertical reading due to a different relative response function. Readings were collected by hand in the field and transferred to spreadsheet. A base station was reoccupied several times during each field session to check for instrument drift. Corrections were made in several cases where a significant discrepancy was encountered. Corrected data were grided and plotted in Surfer. Resulting plots can be seen in Figures 16 and 17. Again, the gas transmission line is a distinct feature particularly in the 10 meter vertical plot. Since this anomaly is related to a highly conductive body (a steel pipeline) the assumption that the EM-34 instrument is operating at low induction number is not valid. The gas line response obscures true ground conductivity anomalies. 


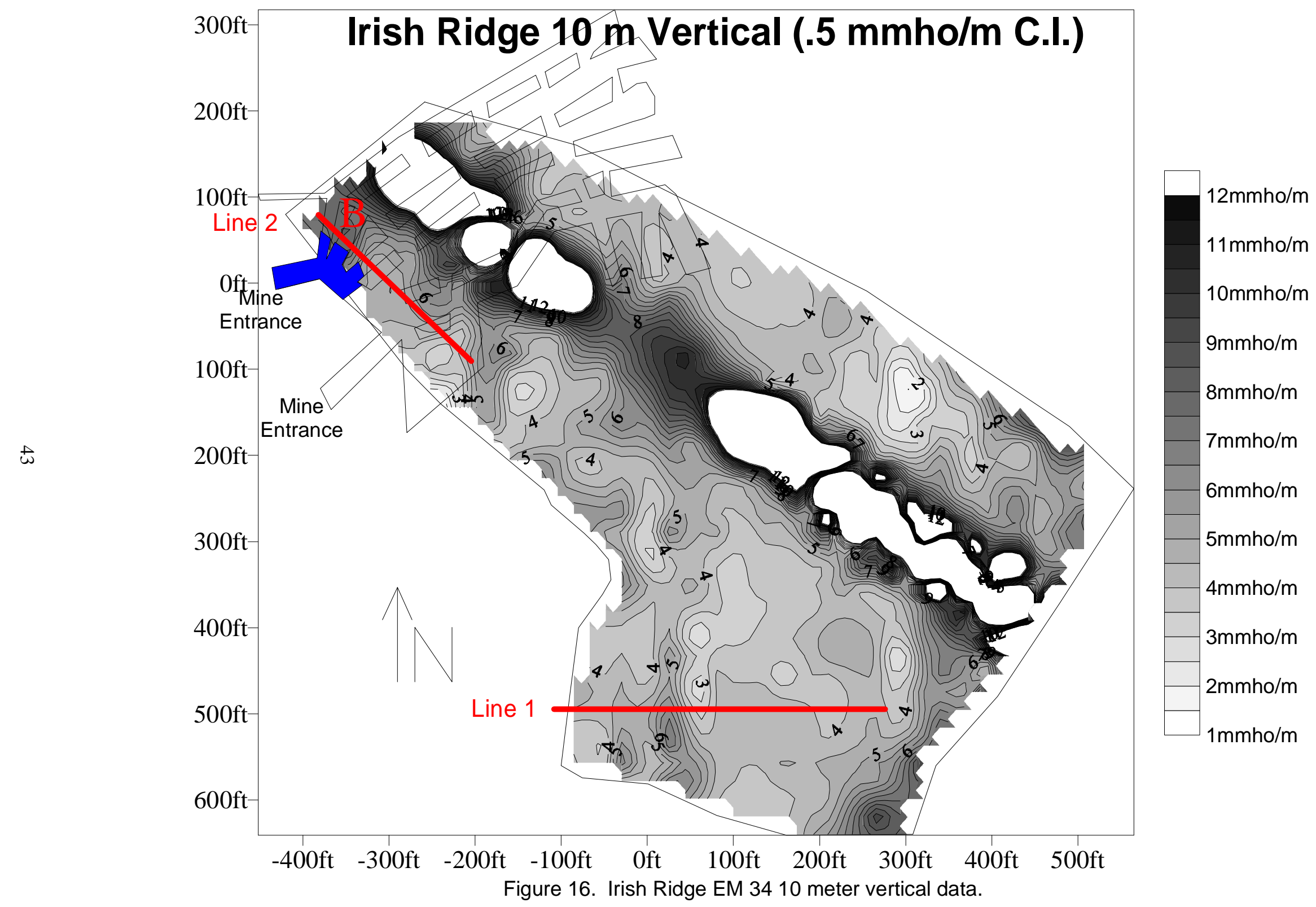




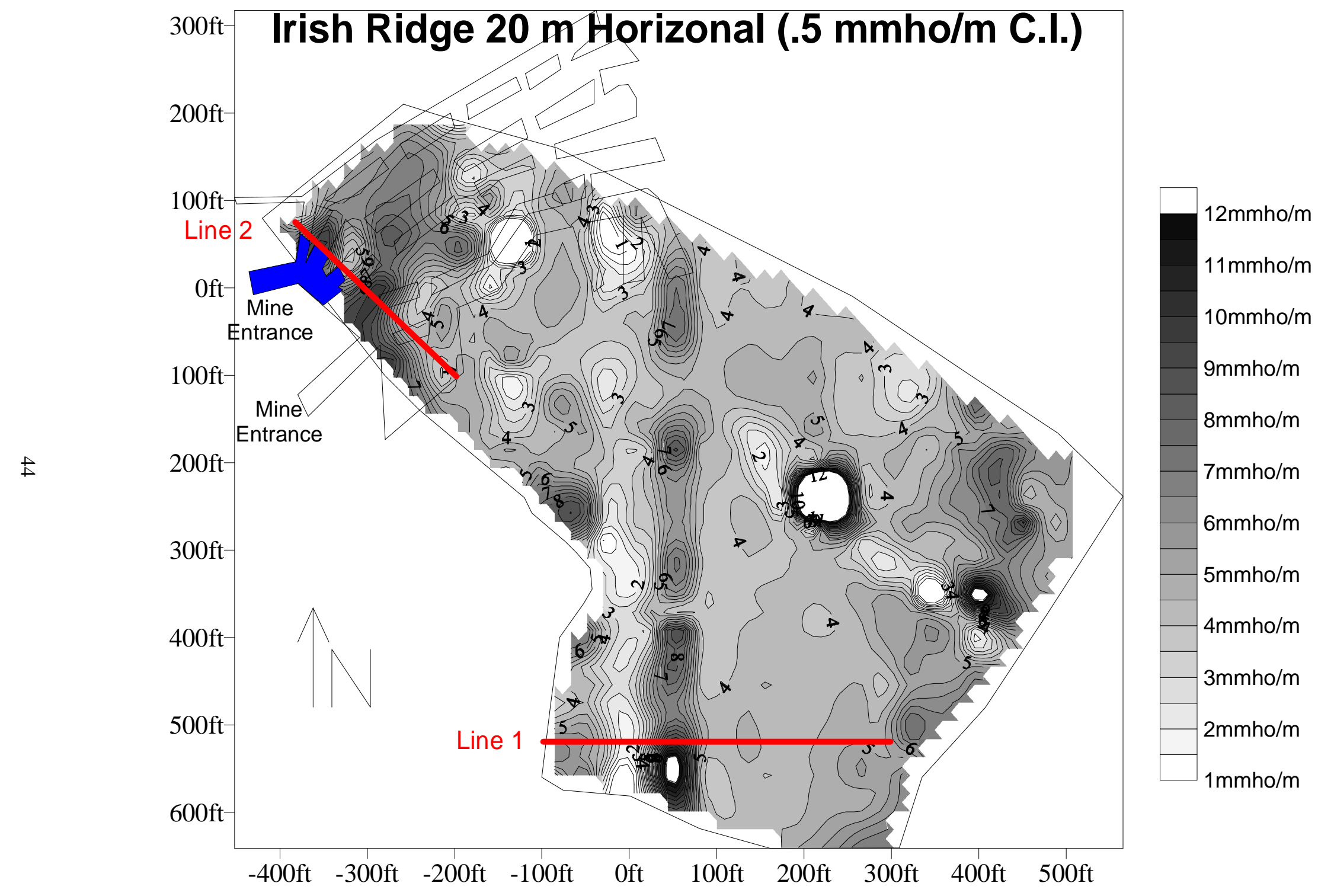

Figure 17. Irish Ridge EM 3420 meter horizontal data. 
A distinct and linear conductivity high, trending approximately north-south, appears in the EM 20m horizontal data (Figure 17) and, to a lesser extent, in the $10 \mathrm{~m}$ vertical data (Figure 16). This feature can be seen east of the mapped mine area, at approximately 50ft west on the surveyed grid. Is was proposed that this anomaly correlates with a vertical fracture zone over a portion of the mine (Rauch, personal comm., 1999). In addition, fractures in the hanging wall of the mine were observed in the east area of the mine where this anomaly runs near the edge of the mined area. While map data suggest that this feature is not over a mined interval, it still appears plausible that the conductivity high observed correlates with a vertical fracture zone that may have prevented further mining to the east. With this in mind three lines of data over this feature were re-collected in the spring of 1999. Resulting measurements closely follow those of the previous fall, confirming the feature as reproducible and non-transient. The data along one of the lines was modeled using EMIX34P software to evaluate the possible subsurface conditions responsible for its existence. A discussion of modeling results appears in Chapter 4 of this document.

An increase in apparent conductivity in the northwest portion of the survey area can be seen in the 10 meter vertical map (Figure 17) and, more distinctly, in the 20 meter horizontal map (Figure 16). The increase is approximately $3 \mathrm{mmho} / \mathrm{m}$ in the 10 meter vertical data and approximately $4 \mathrm{mmho} / \mathrm{m}$ in the 20 meter horizontal data. This terrain conductivity increase may be attributed to the mine pool at depth located over approximately the same area. With an estimated 30,000 gallons of pooled AMD in this 
section of the study area, this is the most plausible explanation for the increase in terrain conductivity over this area. The effects on terrain conductivity of injections of 100 tons of grout in hole $10 \mathrm{~b}$ and 140 tons of grout in hole 2 are at least partially masked by the pipeline and are difficult to determine since a "baseline" geophysical survey was not planned as part of the AMD abatement efforts. It should be noted that limited EM 31 terrain conductivity surveys were also conducted at the site. The EM 31 unit was carried over several stations on the eastern side of the site. All readings collected were at or near $0 \mathrm{mmho} / \mathrm{m}$. The unit was then carried over portions of the remainder of the site with the same result. The only area where EM 31 measurements were not near $0 \mathrm{mmho} / \mathrm{m}$ is over the gas transmission line. The areas near the north-south trending EM 34 anomaly and in the northwest portion of the mine were not targeted during the EM 31 survey since the EM 31 survey took place before the EM 34 data were plotted. AMD and grout are distributed at depths of 50 feet (15 meters) or more with thicknesses less than 2 meters. As noted the penetration depth of the EM 31 is shallower than that of the EM 34 (Table 2). In the relative response function generated for the EM 31 (Figure 11a) the anticipated differences in conductivity associated with a 3 meter thick $100 \mathrm{mmho} / \mathrm{m}$ zone at a depth of 15 meters is expected to be quite small or undetectable.

\subsubsection{Resistivity}

Five electrical resistivity soundings were made at the Irish Ridge site using a standard Wenner array. The location of each sounding is shown by a black $\mathrm{X}$ in Figure 18a. Results are shown in Figure 18B. Resistivities range from less than 20,000 $\Omega$-ft 

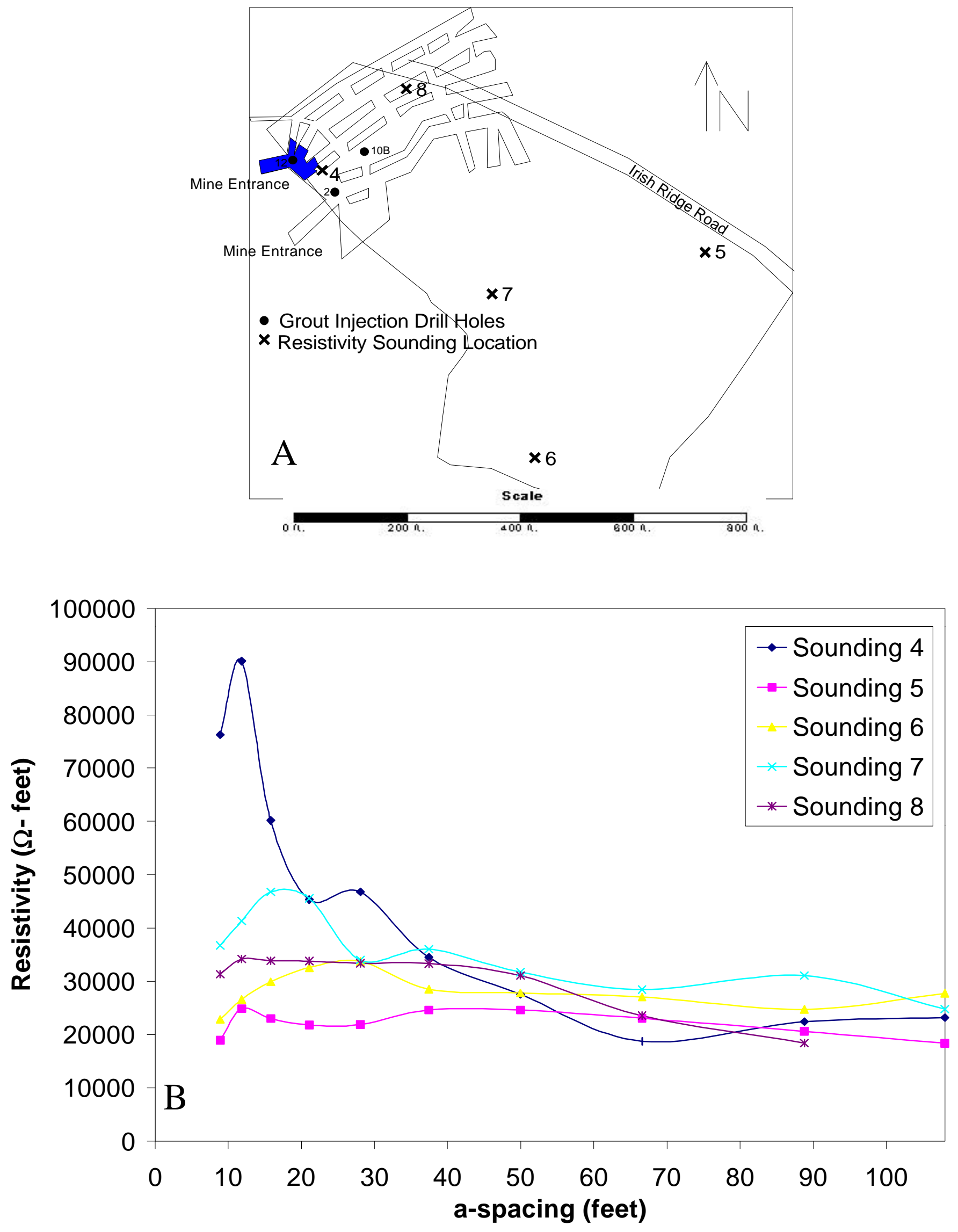

Figure 18. Irish Ridge resistivity soundings. 
to over $90,000 \Omega$-ft which is very resistive for any rock type. The high apparent resistivities may be the result of poor electrical connection with the ground and the electrodes. Water was not applied to the area around the electrodes to improve electrical connection during the survey due to lack of readily available water and inexperience in collecting resistivity data. If the results are accurate, they show near-surface resistivities significantly lower than the 10-30 foot a-spacing interval. The near-surface low resistivity readings are interpreted to be the effect of increased soil and pore moisture from a brief shower a day before measurements were taken. The high resistivity zone from 10 to 30 feet a-spacing is thought to be a massive sandstone layer (the Lower Mahoning Sandstone). The drop in resistivity at a-spacings greater than 30 feet is interpreted to be the result of increased moisture content. Soundings 4 and 7 show a drop in resistivity at the 66.6 foot a-spacing which may be the result of pooled AMD within the mine since conductive fluids such as AMD would lower the bulk resistivity (and increase the conductivity) of a layer. It is thought that the regional water table lies below the sensing depth of the deepest soundings collected. The exceptionally high resistivity values observed do not agree with terrain conductivity data collected at the site and are somewhat suspect. The usefulness of these measurements to aid in modeling is limited by this lack of agreement. The drought-like conditions present at the time of the resistivity survey are most likely responsible for the exceptionally high resistivity values observed. Improved ground coupling by wetting the ground at electrode sites was not persuded and may not have improved the response to the desired accuracy. 


\subsection{Greer}

\subsubsection{Line Data}

Approximately 27 wells extend from the surface to the pitfloor at the Greer mine spoil. Selected wells were used to reference survey station locations used in the EM 31 and EM 34-3 terrain conductivity line surveys. Figure 19 shows the line (or profile) locations. A $20 \mathrm{ft}$ station grid was used for the magnetic and EM 313.7 meter vertical surveys, while a 40 foot spacing was used for the 10 and 20 meter horizontal and vertical (EM 34-3) surveys. This data is presented as lines A through G in profile form (Figure A) and as cross-sectional plots of conductivity (Figure B) in Figures 20-26. The crosssectional plots were generated by using the exploration depth of each reading as the $\mathrm{Y}$ axis and plotting the actual measurement in the $\mathrm{Z}$ axis. In this section, numerous interpretations are made. Several of these interpretations will be explained further by modeling in Chapter 4.

Several anomalous features appear in the profiles. Line A (Figure 20) runs northnorthwest to the southeast on the east side of the trenches in the center of the spoil (Figure 19). Changes in apparent conductivity along the line indicate a change in subsurface conditions from the central and northern end of the line to the southern end. The high conductivity region between GR-17 and GR-14 may be the result of sludge plumes migrating downward and outward from the sludge trenches to the west of the line. 


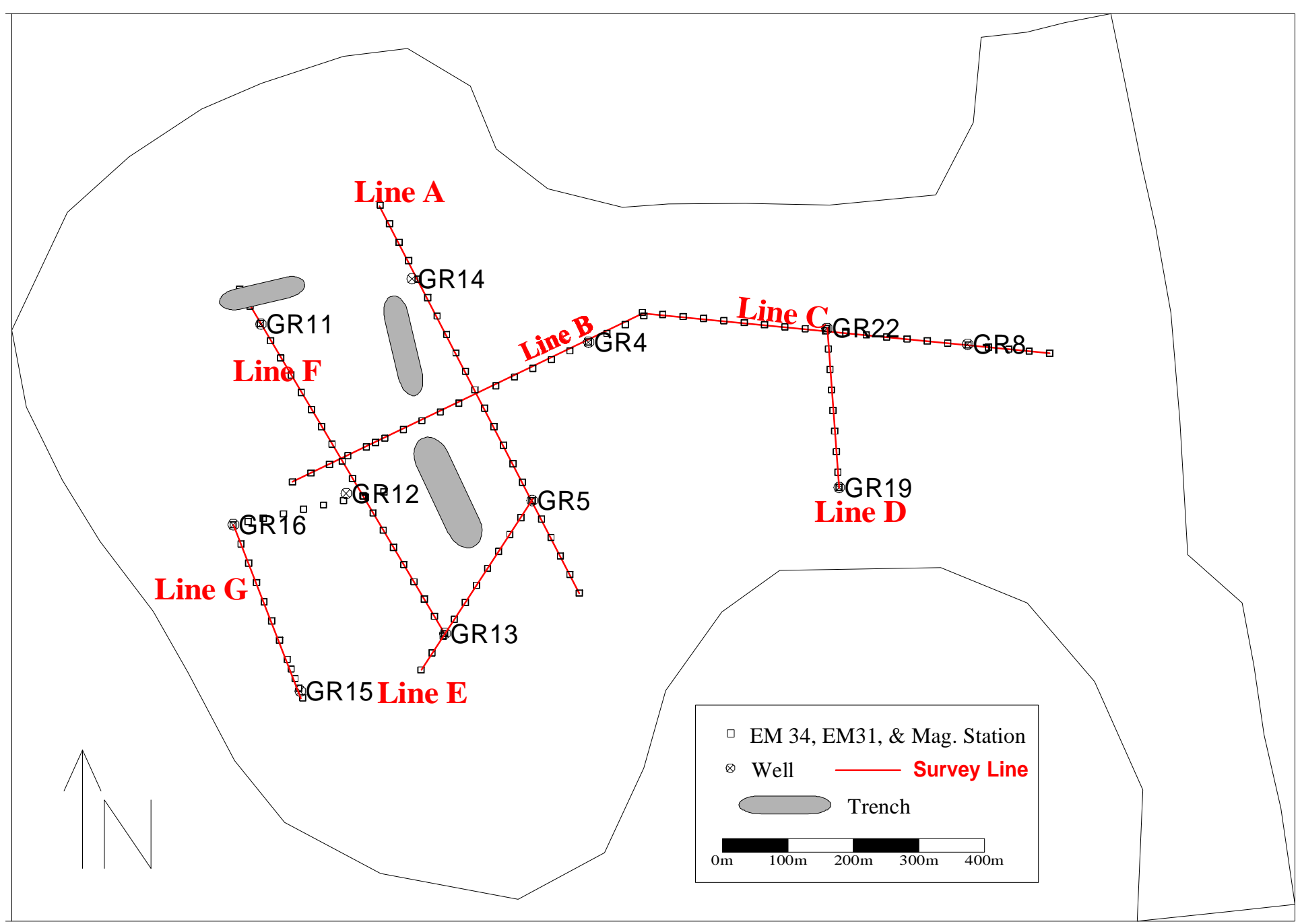

Figure19. Greer site map showing EM profiles. 

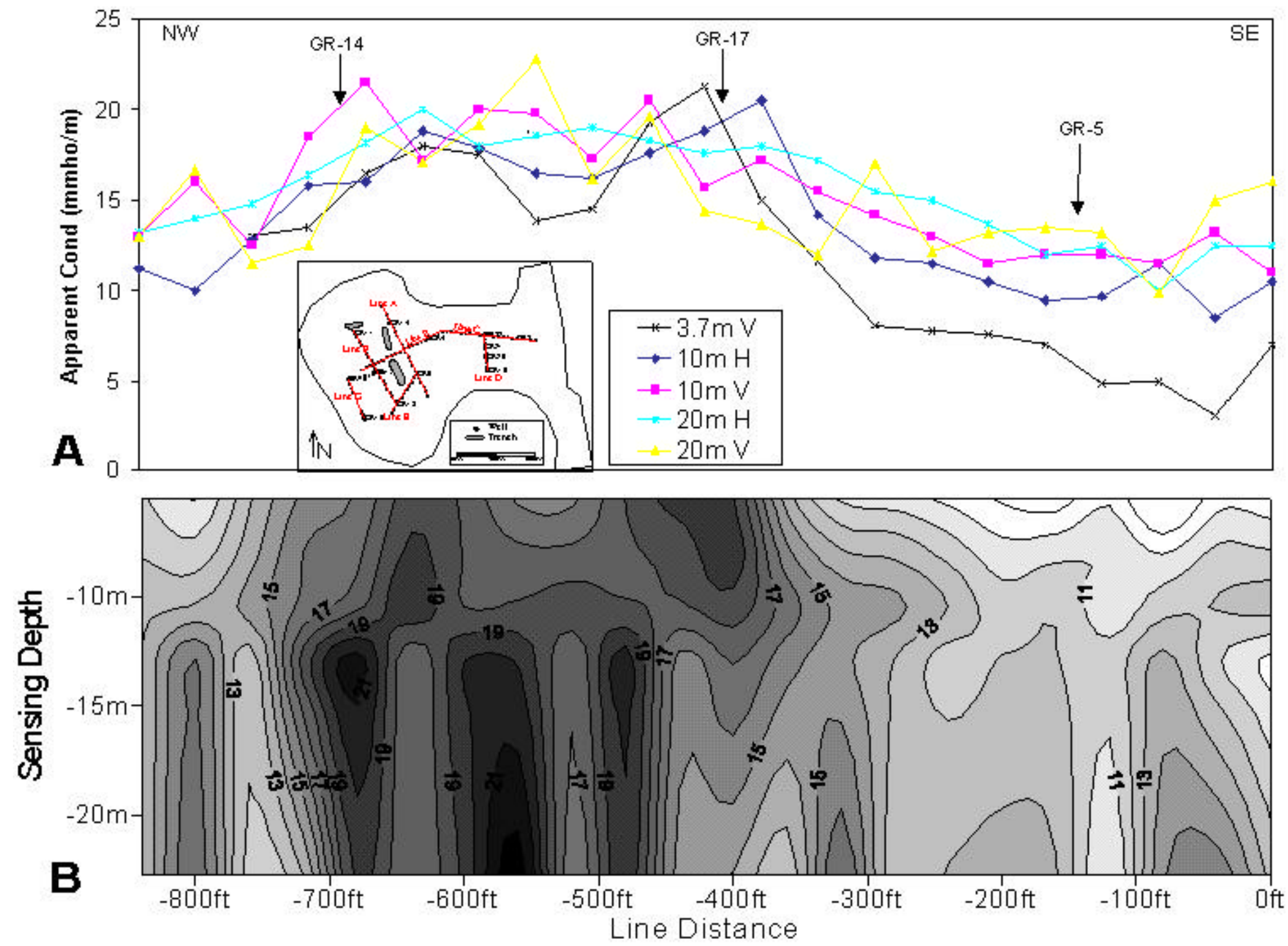

Figure 20. Greer EM Line A, conductivity profile (A) and cross-section (B). 
Line B (Figure 21) runs perpendicular to line A and crosses it at GR-17 (Figure 19). This line passes between the surface trenches. Along this line, two distinct conductivity highs appear on either side of the trenches, each with a different character. The locations of these peaks adjacent to the trench suggest they are the result of sludge plumes migrating down into the spoil from the surface trench. However, this interpretation is complicated by the fact that a buried sludge-filled trench is present west of the existing trench and would be expected to create a conductivity high. While the western peak may be a static high related to a buried trench, the eastern peak may represent a currently active sludge migration pathway. The region west of GR-17 remains high in conductivity, with the highest readings coming from the deepest sounding (20 meter vertical). This suggests that the conductivity high is from a deeper source on the pitfloor or in the bedrock.

Line C (Figure 22) runs east-west along the break in slope in the northern section of the spoil. The western third of the line shows relatively low conductivity at the surface with moderate conductivity readings at depth. A spike in conductivity at $\sim 280$ feet along the line may be associated with residual high conductivity material related to injections of Sodium hydroxide $(\mathrm{NaOH})$ in Fall 1996. The western two-thirds of line $\mathrm{C}$ reveals the presence of increased shallow and deep conductivities. This implies that that the subsurface in this region contains either greater quantities of conductive fluids or fluids of higher conductivity. 

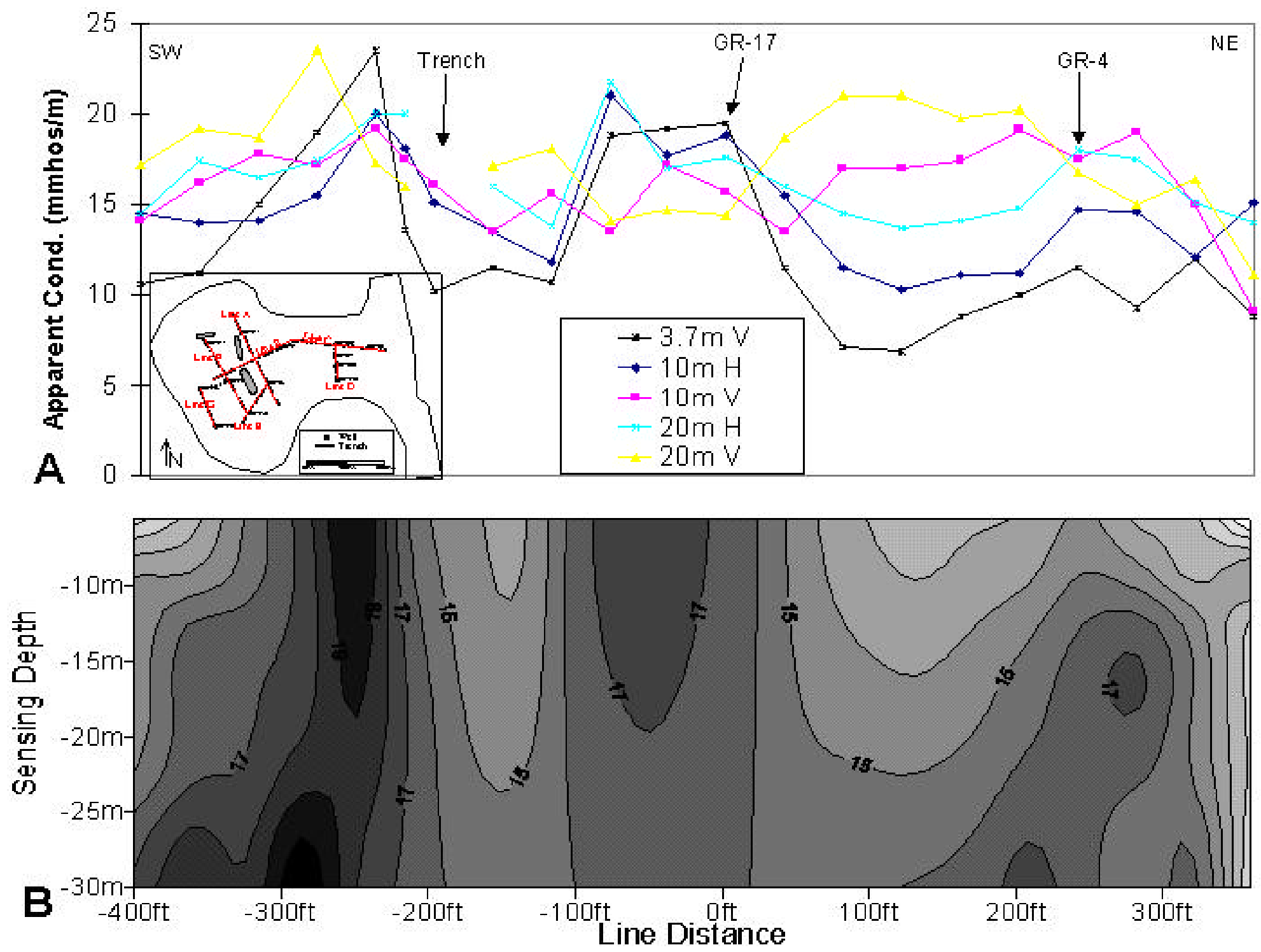

Figure 21. Greer EM Line $B$, conductivity profile (A) and cross-section (B). 

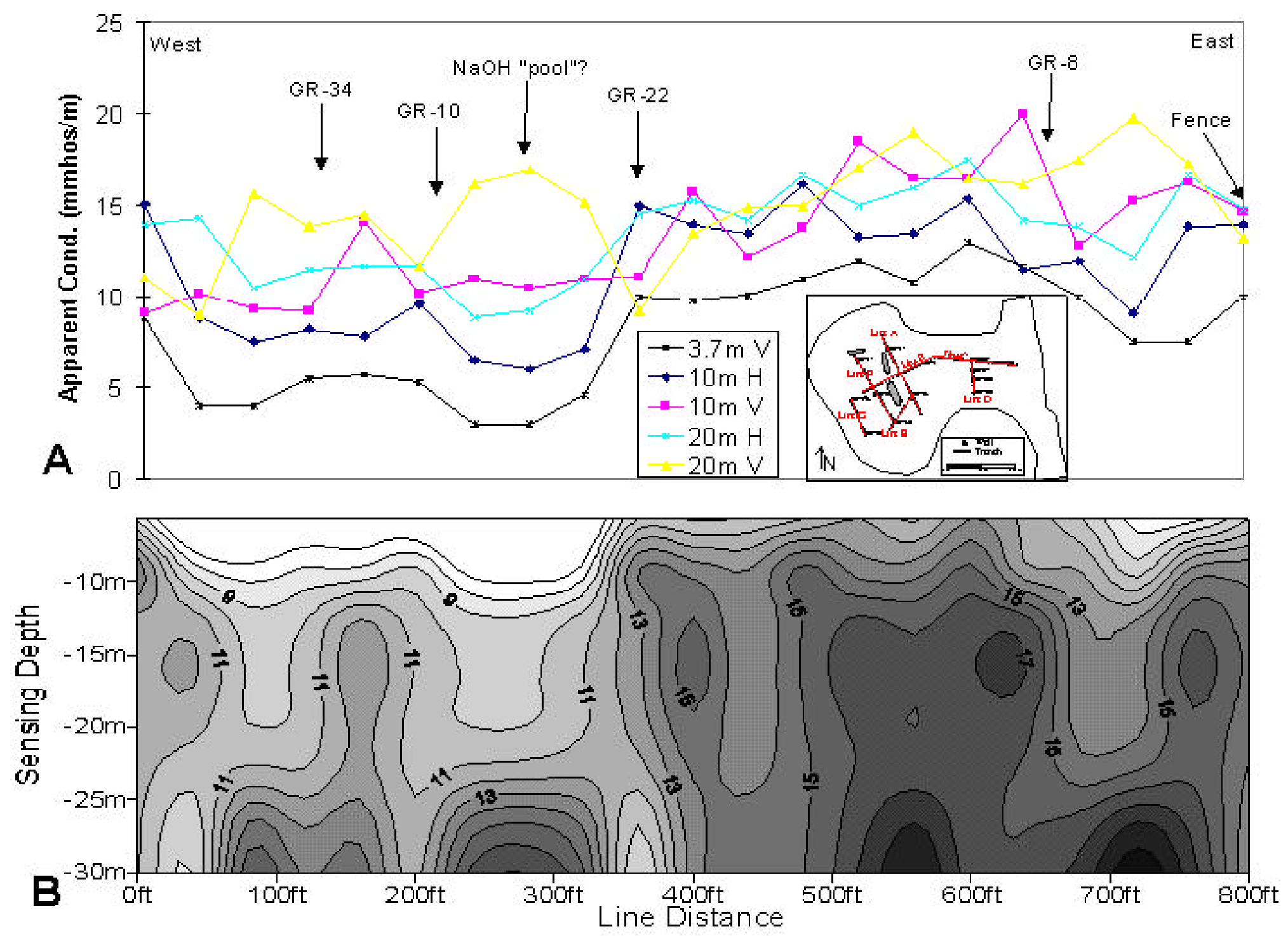

Figure 22. Greer EM Line $C$, conductivity profile (A) and cross-section (B). 
Line D (Figure 23) runs north-south from GR-22 in the north to GR-19 in the south. This line crosses over an area near the injection of $\mathrm{NaOH}$ into GR-20. GR-20 is located at $\sim 180$ feet along the line and the downgradient direction is to the north towards GR-21 and GR-22. Water sampling of wells GR-20, 21, and 22 has shown that the injected $\mathrm{NaOH}$ moved at a much slower rate than expected (less than $1 \mathrm{~m} /$ day) making it plausible that residual high conductivity injection-related material may remain near the area of injection (GR-20). A high in the 20 meter vertical dipole reading is observed downgradient of GR-20 and appears as a 60-90 ft wide anomaly. This anomaly may be the result of earlier injections of $\mathrm{NaOH}$ into GR-20 and may represent a remaining "pool" of highly conductive solution in a depression on the pitfloor. It is important to note that no pre-injection measurements were made to track the changes in terrain conductivity due to the $\mathrm{NaOH}$ injection. Because of this, it cannot be said with certainty that the observed conductivity high is related to the injection

Line E (Figure 24) runs from southwest of GR-13 to GR-5 passing south of the larger, southern trench. This line lies near the highwall of the mine. The terrain conductivity profile does not show significant anomalies.

Line F (Figure 25) runs northwest-southeast along the top of the thickest part of the spoil from northwest of GR-11 to GR-13. To the southeast of GR-11 there are two deeper conductivity highs at $\sim 660$ and $\sim 540$ feet along the line. These may be sites of pooling were AMD and/or sludge within the spoil is present in significant quantities to be detected at the surface. At approximately 100 feet along Line F, the line nearly crosses the southwest corner of the southern trench. The EM response over this area reveals low conductivity near the surface and high conductivity at depth. These conductivity features 

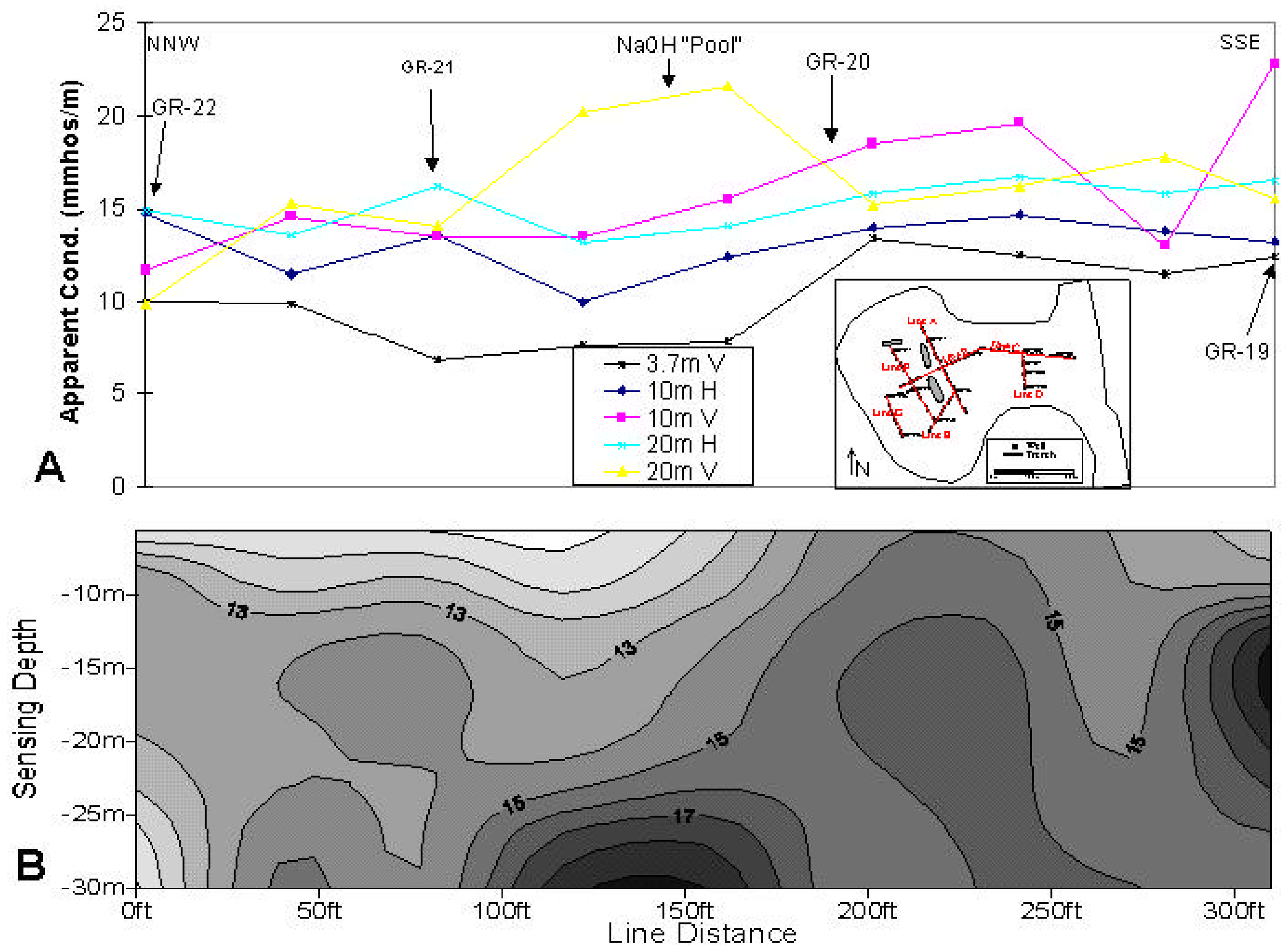

Figure 23. Greer EM Line $D$, conductivity profile (A) and cross-section ( $B$ ). 

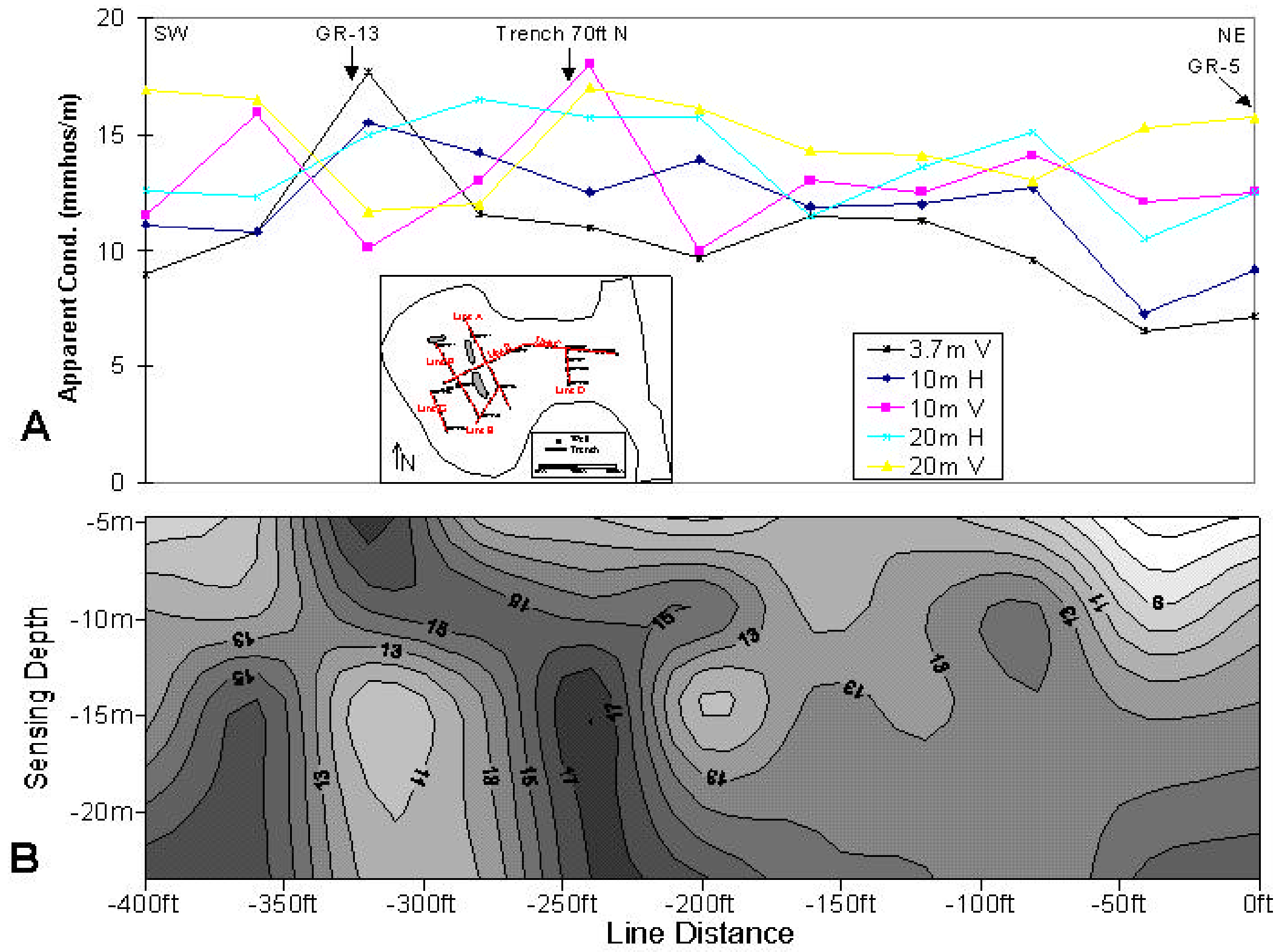

Figure 24. Greer EM Line $E$, conductivity profile (A) and cross-section (B). 

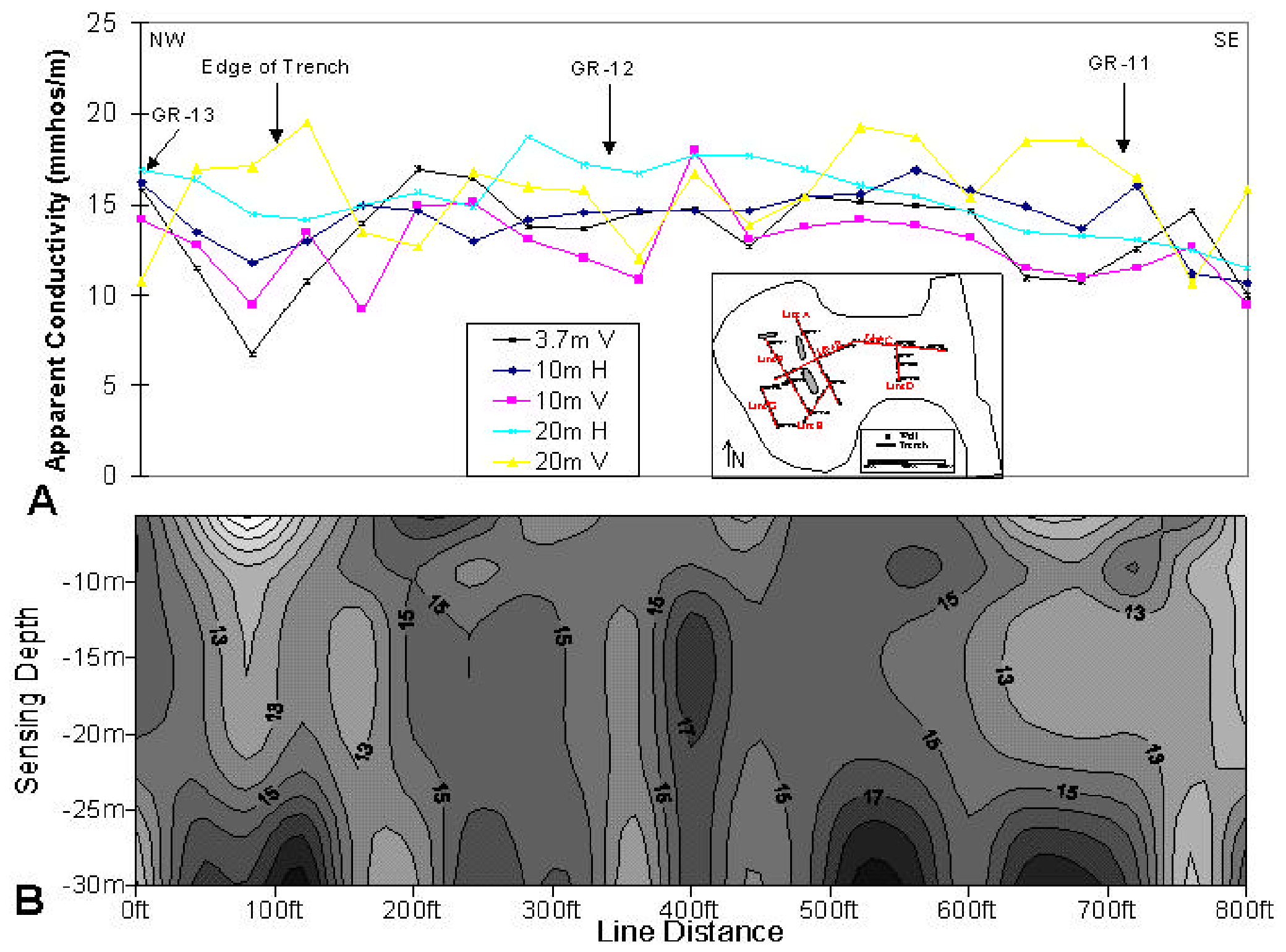

Figure 25. Greer EM Line $F$, conductivity profile (A) and cross-section (B). 
are interpreted to result from increased drainage into the trench at the surface and from the presence of sludge at depth respectively.

Line $\mathrm{G}$ (Figure 26) runs northwest-southeast over the western portion of the spoil below a topographic high (see Figure 5a for surface topography). From GR16 to GR-15 apparent conductivity values remain between 10 and $15 \mathrm{mmho} / \mathrm{m}$ except on the southeastern end of the line near GR-15 where more variability exists. This variation may be related to a zone of AMD production in the mine spoil but other explanations such as pooled AMD at the pitfloor are possible.

\subsubsection{Grid 1}

After completion of the profiles, the EM 31 was used to collect regularly spaced data in the area around the sludge filled trenches present at the site. The EM 31 was operated in the vertical dipole orientation which provides an optimal exploration depth of approximately 4.7 meters (15.2 feet). A $20 \mathrm{ft}$ grid spacing was used to collect the data and a fairly complete grid was collected in six field days. The location of this grid is represented by the red area labeled Grid 1 in the Greer Site Map (Figure 5d or top left of Figure 27). The EM 31 response over the grid along with individual station locations is shown in Figure 27. The plot shows distinct conductivity highs around the trenches extending outward; anomalies B and C from the northern trench and anomalies D and E from the southern trench. The location of anomaly $\mathrm{C}$ also correlates to a buried trench. An additional conductivity high is seen in the northeastern quadrant of the plot (anomaly A). This feature is relatively linear and is believed to be a coal refuse disposal pile.

Ackman (personal comm. 1999) notes that known surface and near-surface coal refuse 

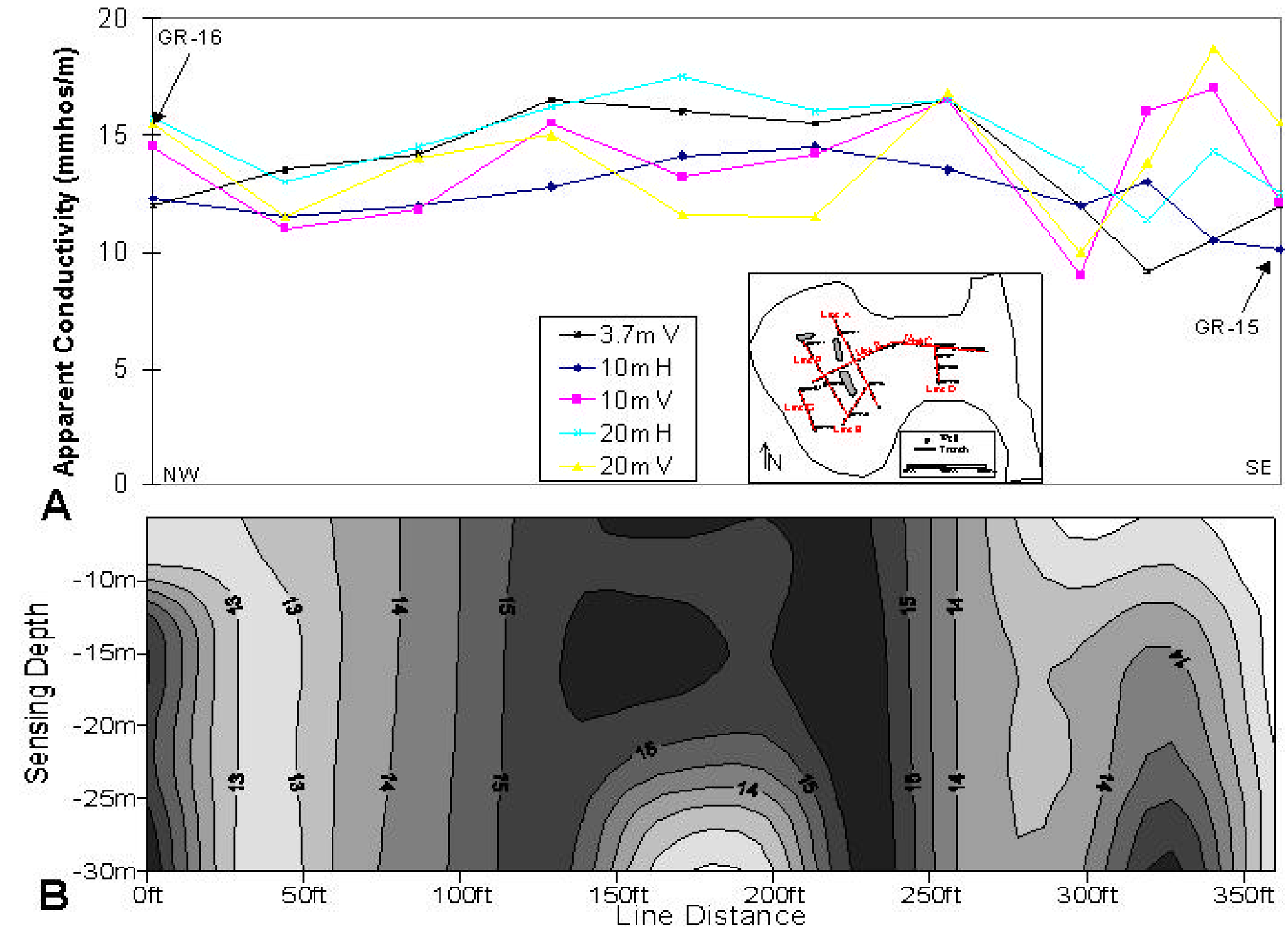

Figure 26 . Greer EM Line $G$, conductivity profile (A) and cross-section (B). 


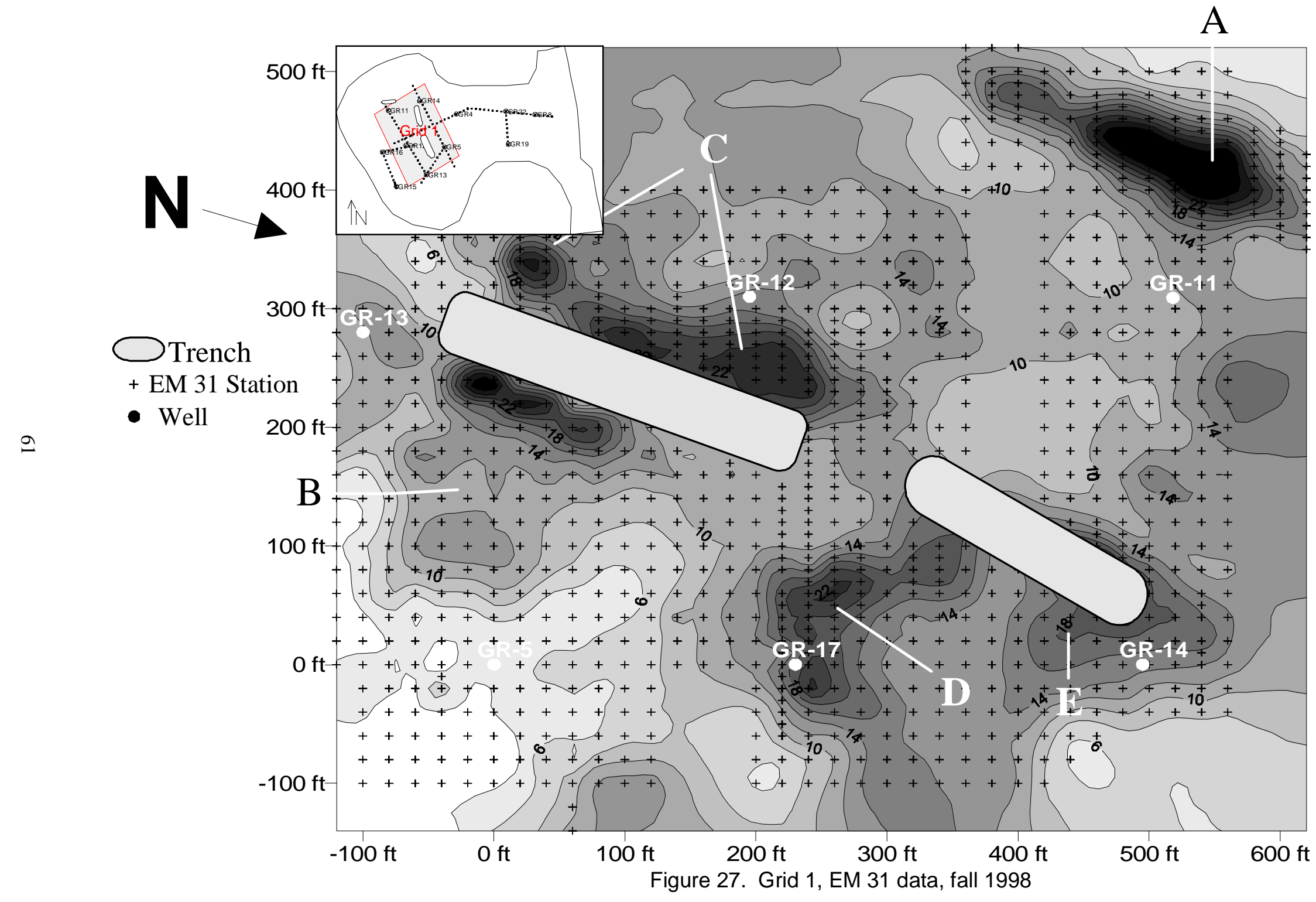


disposal piles appear as anomalously high regions at similar sites. This pile is believed to be near the surface rather than on the pitfloor and is believed to contain significant quantities of pyrite-rich, AMD-producing refuse. Mine employees note that a refuse pile in the area of anomaly A probably does exist. Detailed records of the reclamation of the site were not kept preventing further research into the site's history. A shallow $(<15$ feet) excavation or drilling of the spoil would be necessary to confirm that a coal refuse disposal pile does exist below anomaly A.

In March, 1999, the EM 31 grid was resurveyed to provide a time-lapse picture of the shallow subsurface in this area. Results of this second survey are shown in Figure 28. Comparing the two plots, one can see that the location and orientation of the anomalies

remain relatively unchanged. Anomalies A through E are all still present in March, 1999 and nearly identical in shape and intensity with the exception of anomaly B. Anomaly B appears to be of lesser extent and less intense in the March 1999 data. Anomaly B is interpreted to be associated with migration of sludge into the spoil from the south trench. The change in extent and intensity of the high is interpreted to arise from migration of sludge into the spoil.

\subsubsection{Grid 2}

A small grid of EM 34 data were collected from the site access road north to GR 22 and is represented by the blue area of Grid 2 in Figure 5d. This grid covers an area around the 1996-1997 injections of $\mathrm{NaOH}$ into GR 20. Data were collected in northsouth lines 50 feet apart at 25 foot intervals. Figures 29 and 30 show the data collected over the area. The location of the road is approximately equal to the location of a 
A

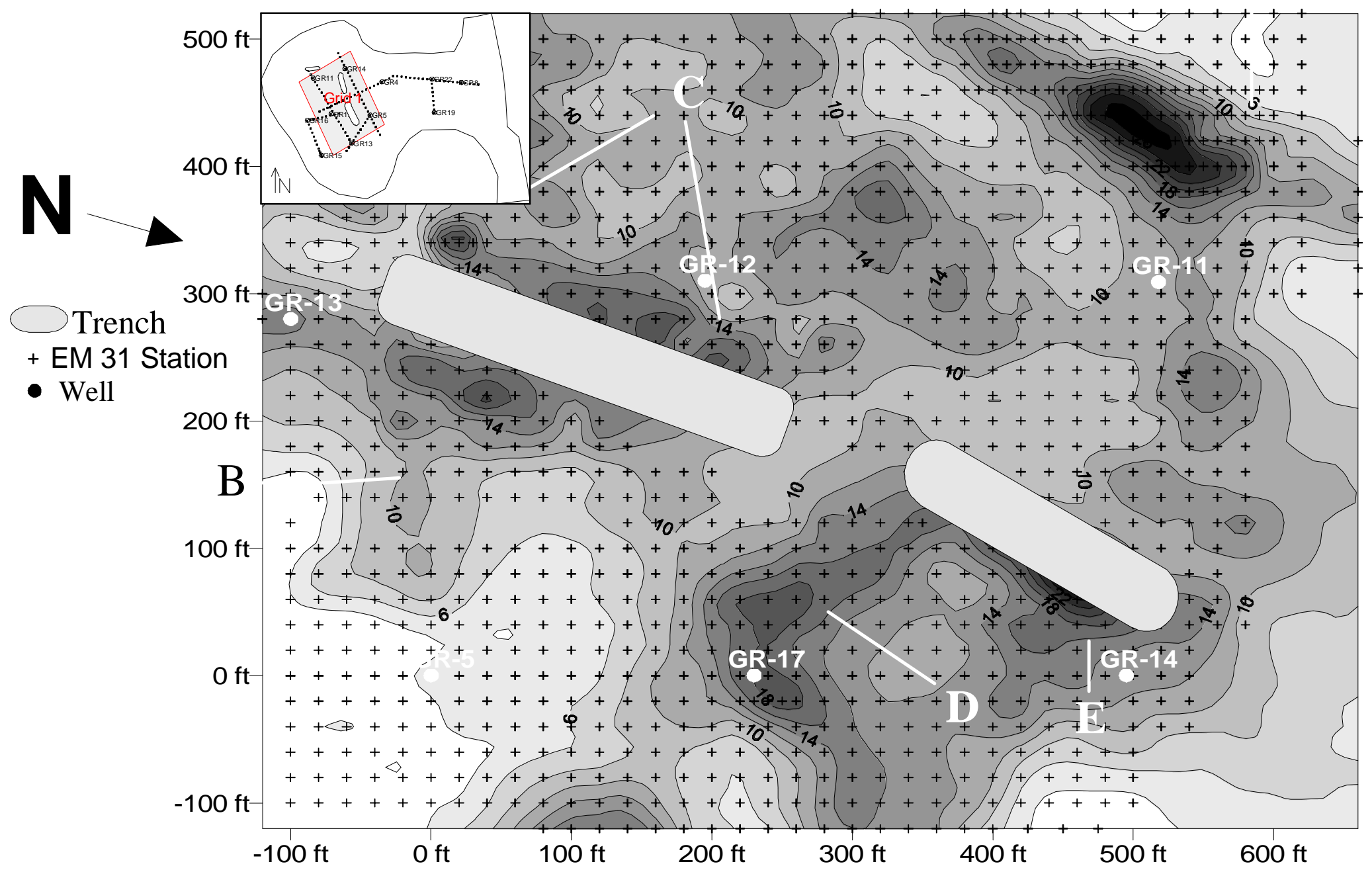

Figure 28. Grid 1, EM 31 data, spring 1999. 


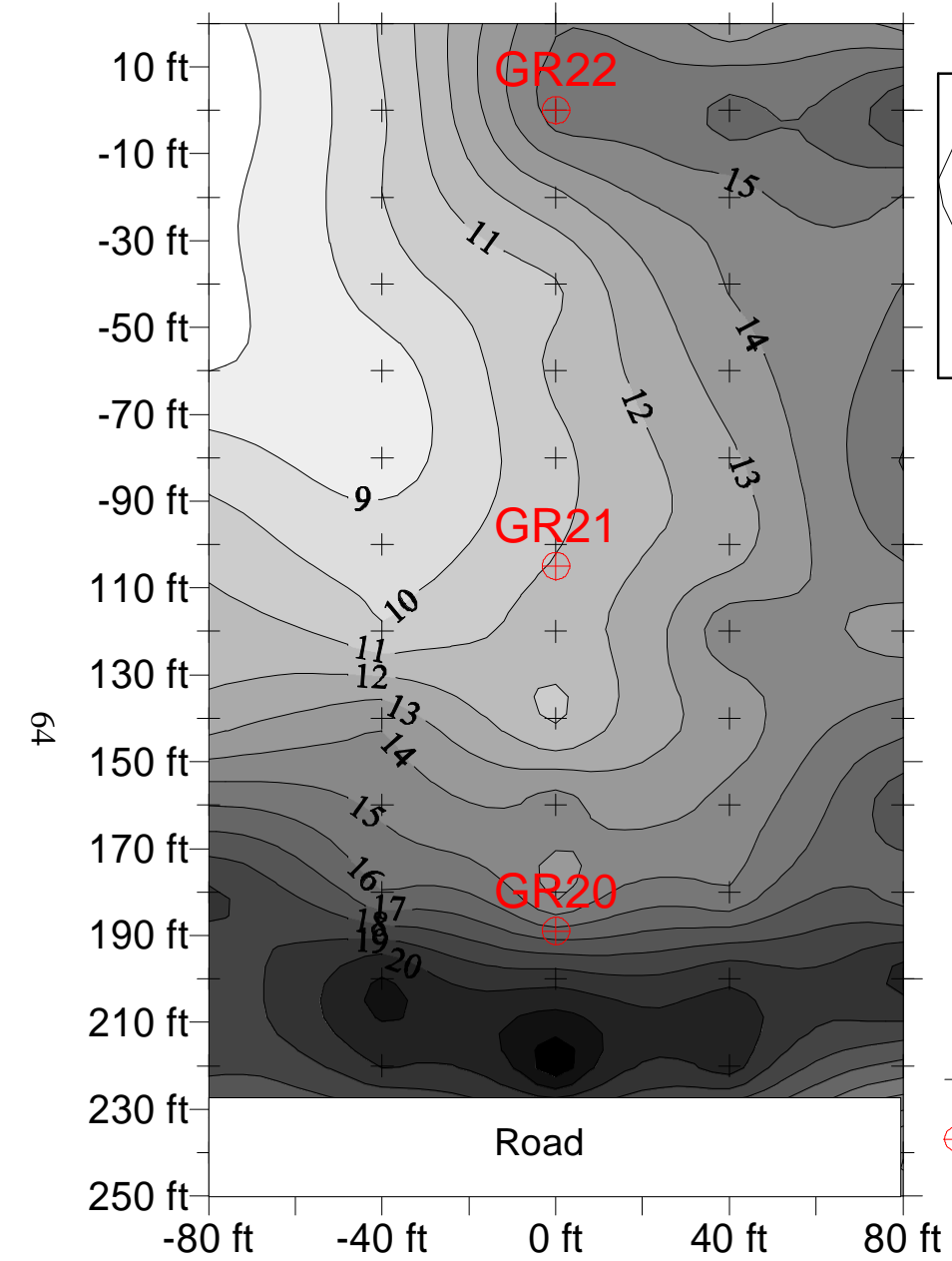

A. 10 meter Horizontal

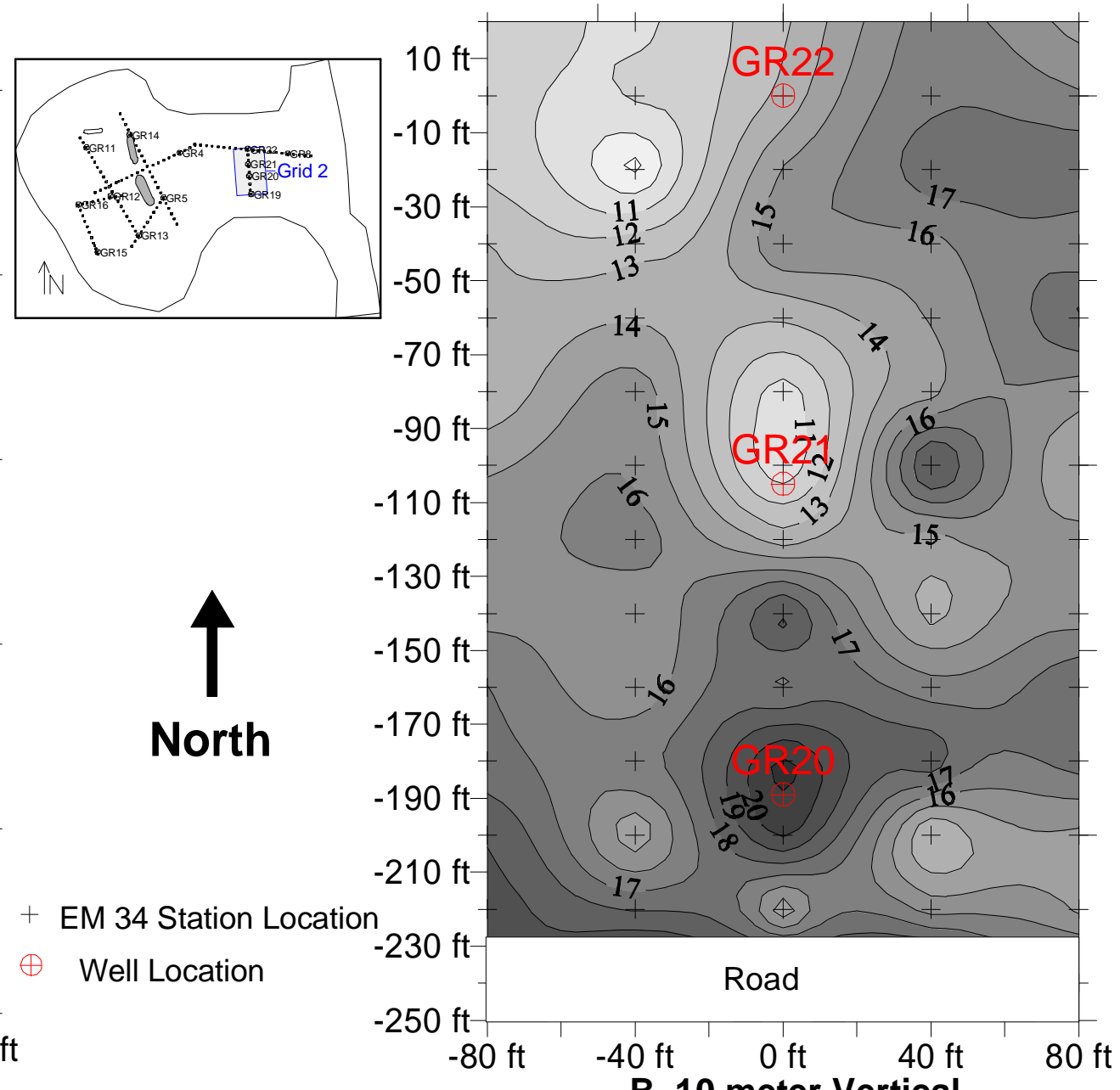

B. 10 meter Vertical

Figure 29. Grid 2, EM 3410 meter data over GR20 injection well. 

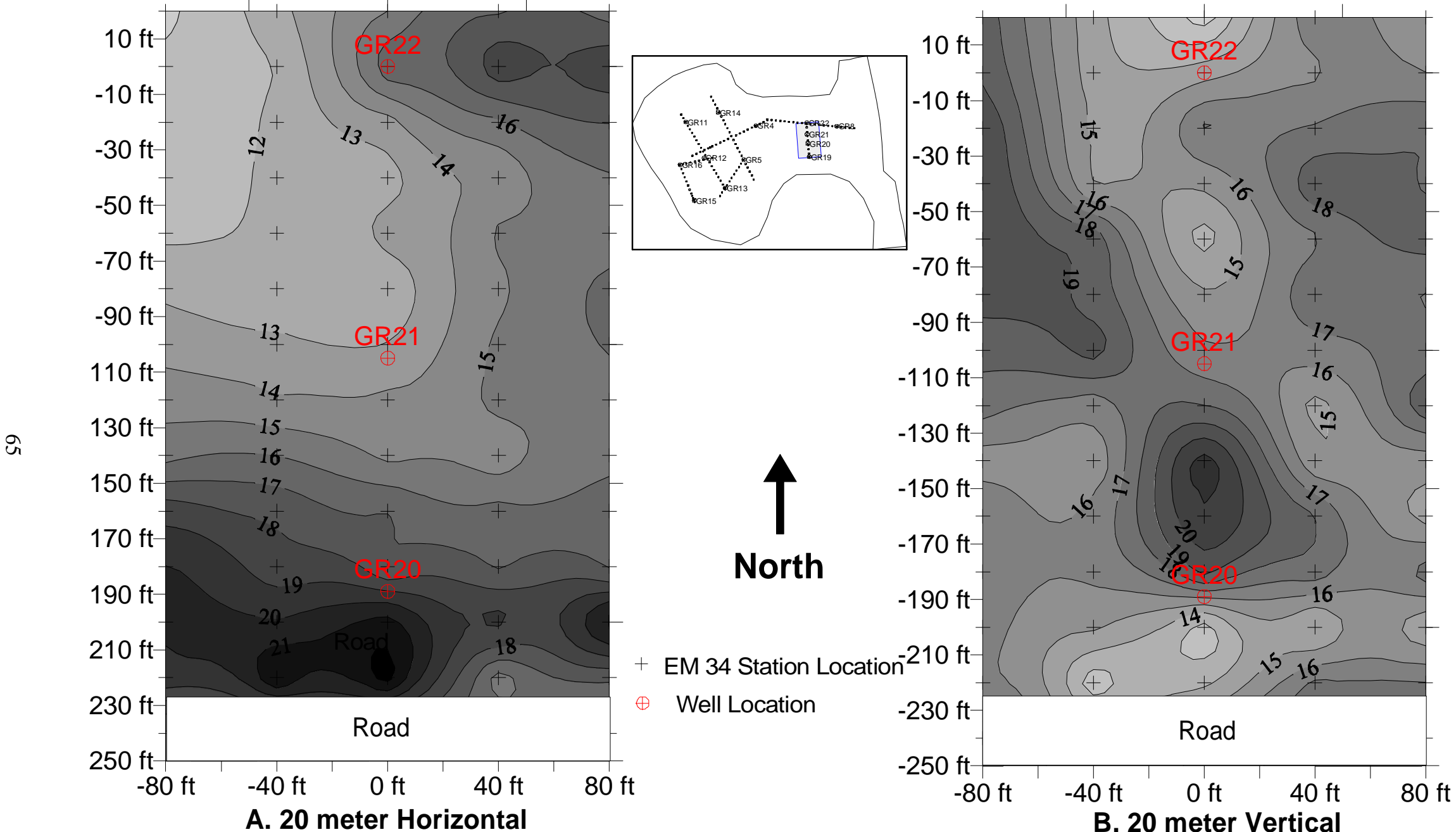

Figure 30. Grid 2, EM 3420 meter data over GR20 injection well. 
highwall with separate mine spoils draining to the north and south of the road. A shallower conductivity high north of, and parallel to, the road is seen in the 10 and 20 meter horizontal dipole readings. This high conductivity region is thought to be related to AMD-producing zones where water is present but not normally flowing and is highly conductive. The 20 meter vertical plot shown in Figure 30B represents the deepest sensing depth ( $~ 83$ feet) and best detects changes in conductivity at or near the pitfloor. In the 20 meter vertical plot, an apparent conductivity high is seen north of GR-20 where several injections of $\mathrm{NaOH}$ took place in 1996 and 1997. This anomaly appears to extend to the northwest at 335 degrees. Sincock (1998) indicated this is the approximate orientation of the mine's boxcuts. The presence of a deep high conductivity anomaly north of GR 20 extending northwest in the same orientation as the boxcuts suggests these features may be related to the migration of $\mathrm{NaOH}$ or $\mathrm{NaOH}$ related sludge from earlier injections. Without a pre-injection "baseline" it is difficult to confirm whether this anomaly is associated with the treatment.

\subsubsection{Grid 3}

In anticipation of a new trench being dug in the northwestern portion of the Greer site, a third terrain conductivity grid was surveyed. The location of this grid is shown as the green area in Figure 5d (Grid 3). This grid was surveyed three times, once before the trench was dug, once during the first application of lime slurry (initial state), and once after three lime slurry additions, one week after filling began. This series of three measurements allows for a distinction between static mine spoil features and transient features related to the movement of added solutions within the mine spoil. 
The grid surveyed before the trench was dug covers a slightly different area than the other two grids because the exact location of the trench was not known before digging began. Plots of the pre-trench survey are shown in Figures 31 and 32 using the same grid coordinates as Grid 1. The 10 and 20 meter horizontal dipole measurements seen Figures $31 \mathrm{~A}$ and $32 \mathrm{~A}$ are similar in shape and intensity to each other and mimic the response of the EM 31 over the same area. The most distinct feature in these plots is the presence of an apparent conductivity high west of (above) GR-11. This high trends nearly northsouth and is the same prominent feature seen in the EM 31 grid as anomaly A (see Figures 27 and 28). The 10 and 20 meter vertical dipole measurements seen in Figures 31A and 32B are deeper sensing measurements and show some similarity to each other. In the deepest measurement (20 meter vertical) distinct north-south trending features appear in the data. The most prominent of these features is a low conductivity anomaly in the westernmost part of Grid 2 (at the top of the plot). The location coincides with the conductivity high observed in the EM 31 (Figure 28) and 10 meter horizontal (Figure 31A) plots. It is thought that this feature is a coal refuse pile, a shallow highly conductive (20-25 mmho/m) body. Figure 9 (page 27) shows that at such high conductivities the assumption of operation at low induction number is violated and that indicated conductivity over high conductivity areas are unreliable and may actually be negative. The highly conductive body may appear as a conductivity low over this area since the low induction number is violated. The linear highs running north-south may be zones of increased moisture and AMD production. It is hypothesized that their linear nature is related to the backfilling process along boxcut trends which took place at the site during mining. 


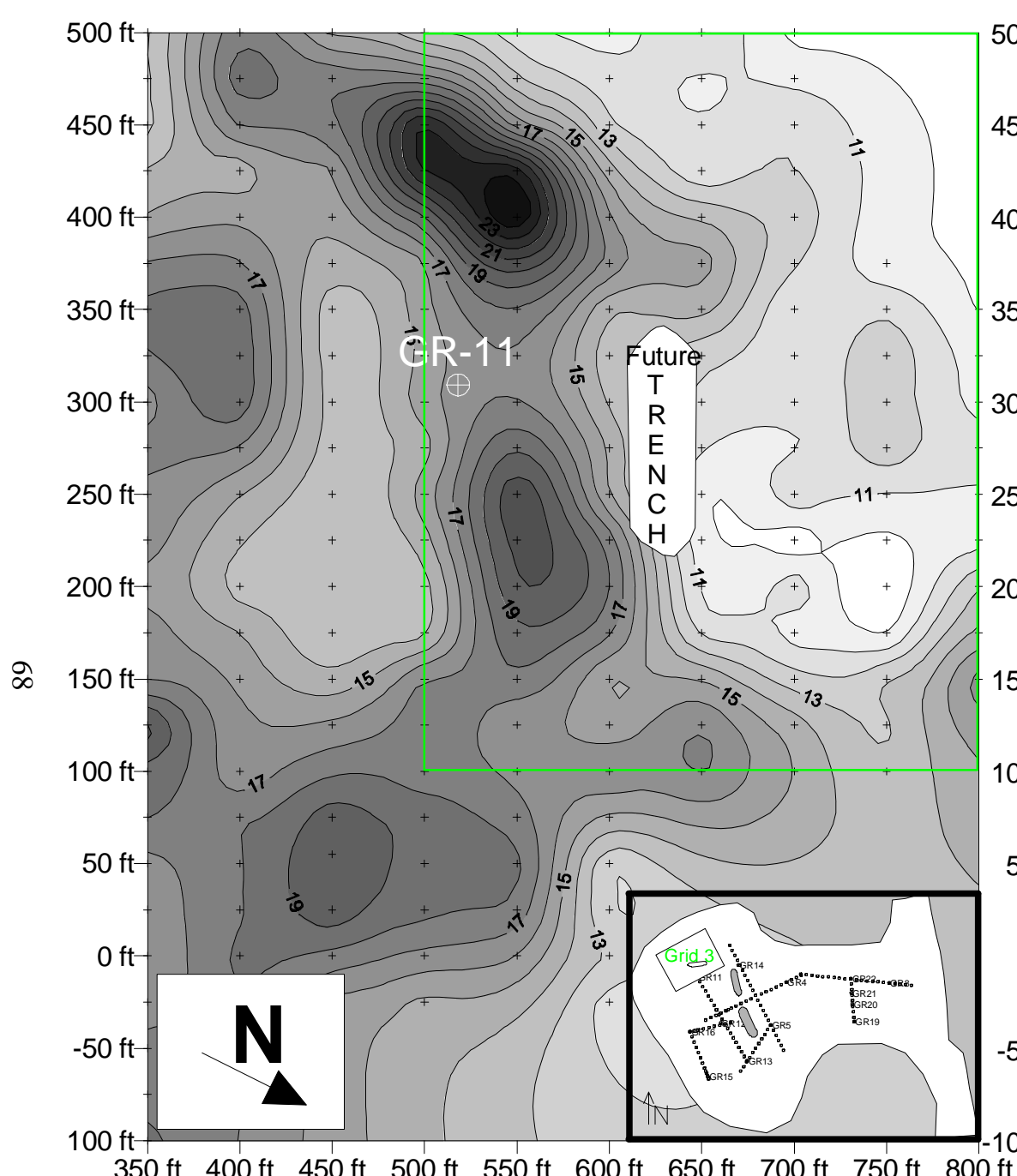

$350 \mathrm{ft} \quad 400 \mathrm{ft} \quad 450 \mathrm{ft} 500 \mathrm{ft} 550 \mathrm{ft} \quad 600 \mathrm{ft} \quad 650 \mathrm{ft} \quad 700 \mathrm{ft} \quad 750 \mathrm{ft} \quad 800 \mathrm{ft} \quad 350 \mathrm{ft} \quad 400 \mathrm{ft} \quad 450 \mathrm{ft} 500 \mathrm{ft} 550 \mathrm{ft} \quad 600 \mathrm{ft} \quad 650 \mathrm{ft} \quad 700 \mathrm{ft} \quad 750 \mathrm{ft} \quad 800 \mathrm{ft}$

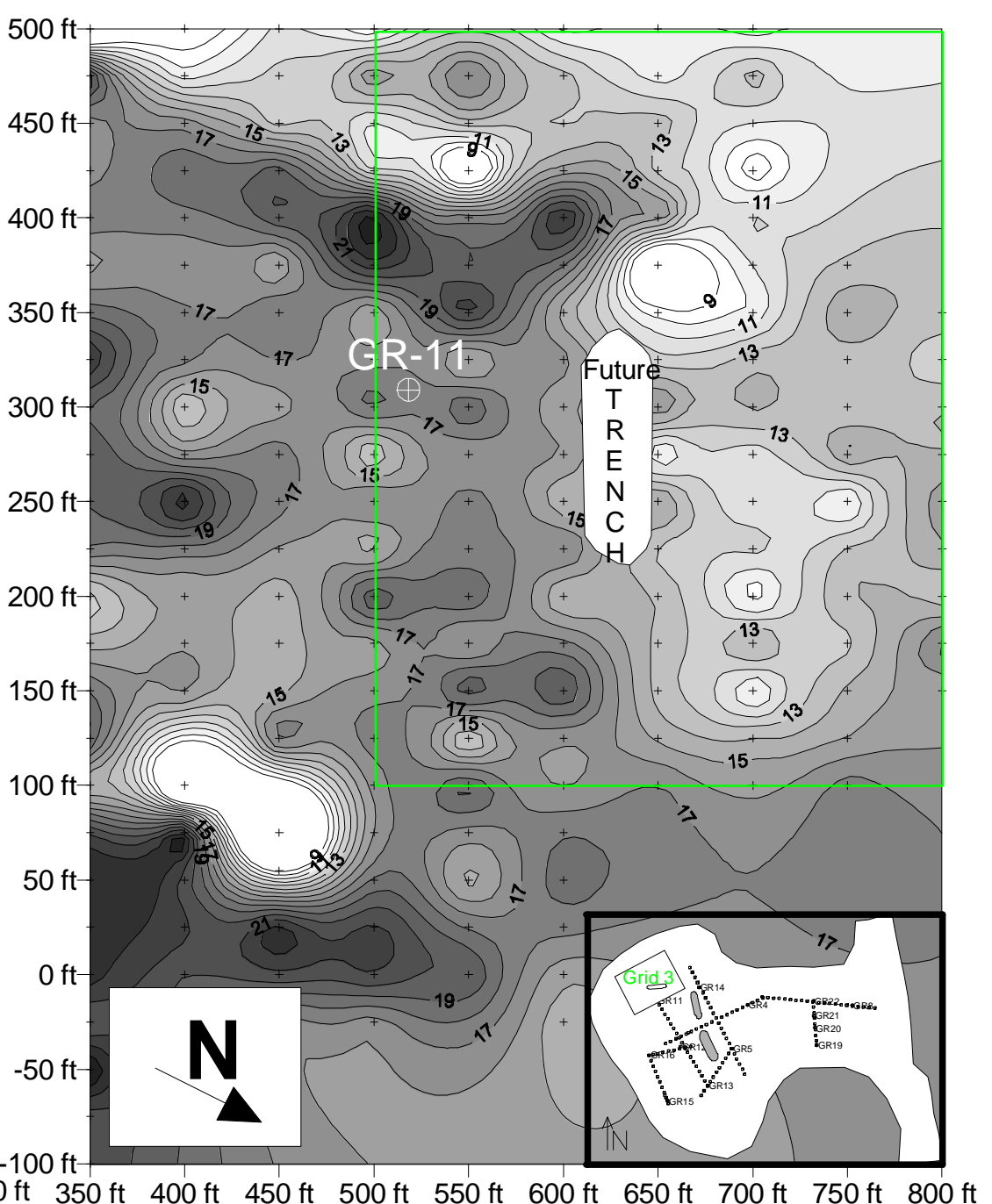

B. $10 \mathrm{~m}$ Vertical

Figure 31. Grid 3, 10 meter readings before the new trench. 


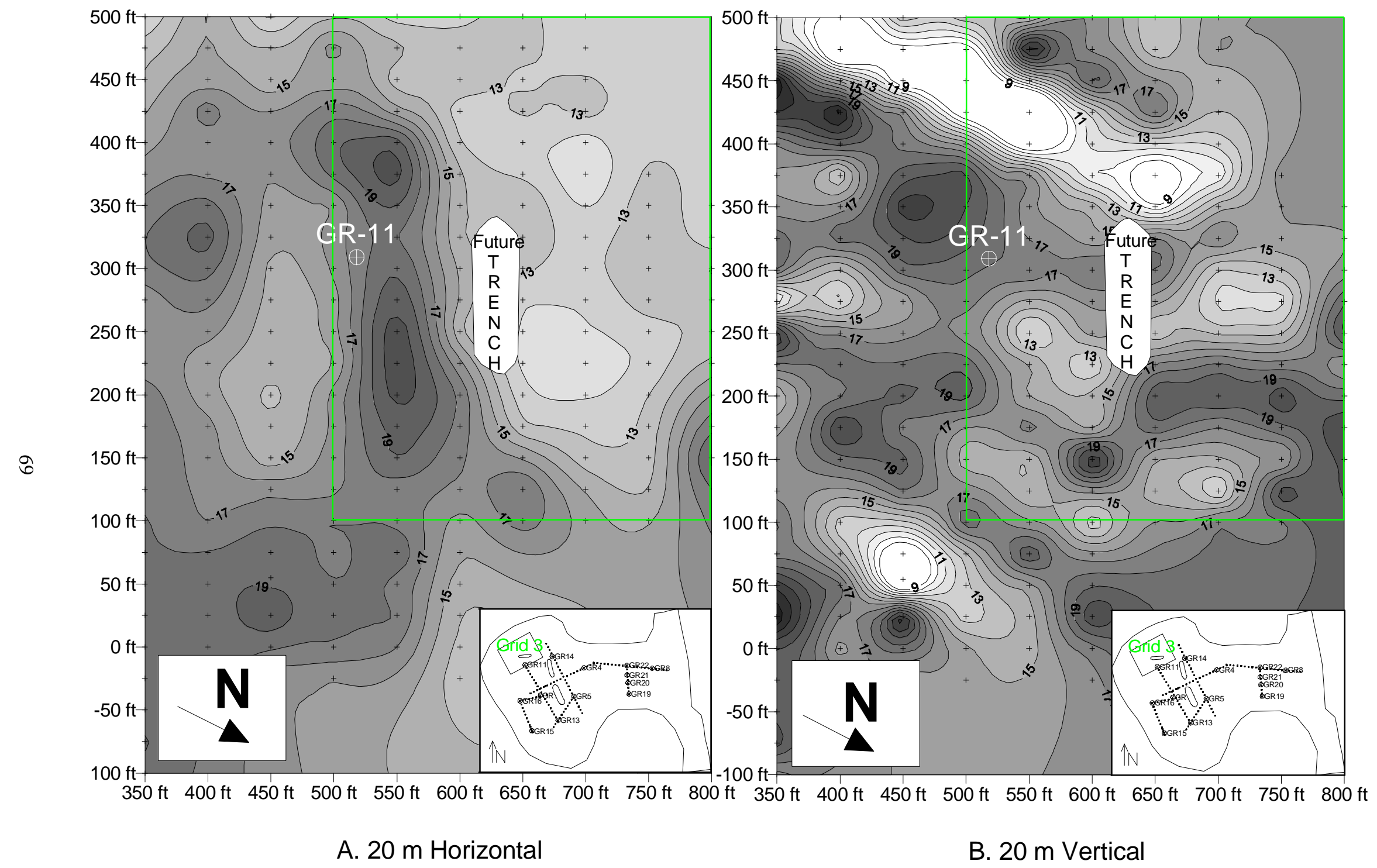

Figure 32. Grid 3, 20 meter readings before the new trench. 
Once the new trench was dug, a second set of EM 34 measurements was collected over approximately the same area as the previous pre-trench grid. Data collection took place concurrently with the first addition of lime slurry in the trench. Any material added had little time to migrate from the trench. The trench was filled with a powdered limestone $\left(\mathrm{CaCO}_{3}\right)$, water, and ammonia mix. This mix raised the conductivity at the surface in unrecorded test measurements over the area of application when first added. Data from this second survey is shown in Figures 33 and 34. Location and orientation of significant features did not change significantly over much of the area even after the trench was dug and surface was altered by movement of the topsoil. One area where values appear to be somewhat different is west of (above) GR-11 where a coal refuse pile is thought to exist. Grid values from the after survey were subtracted by the before survey to create difference maps (Figures 35 and 36). These difference maps show changes in apparent conductivity that took place from digging and initial filling of the trench. Highs represent increases in conductivity of the later survey, while lows represent decreases from the before survey.

The 10 and 20 meter horizontal difference plots (Figures 35A and 36A) show small changes less than $+/-3.5 \mathrm{mmho} / \mathrm{m}$ over the grid area. The decreases north and west of the trench in Figure 35A correspond to additions of low conductivity topsoil over these areas. The two areas where the conductivity increased in Figure 35A are at the eastern end of the trench and over Area A. The increase at the eastern end of the trench is thought to be related to the filling which was taking place as measurements were made. Observations of the filling process showed that most of the liquid added ran toward the topographically lower eastern end of the trench. Observations of the trench before filling 

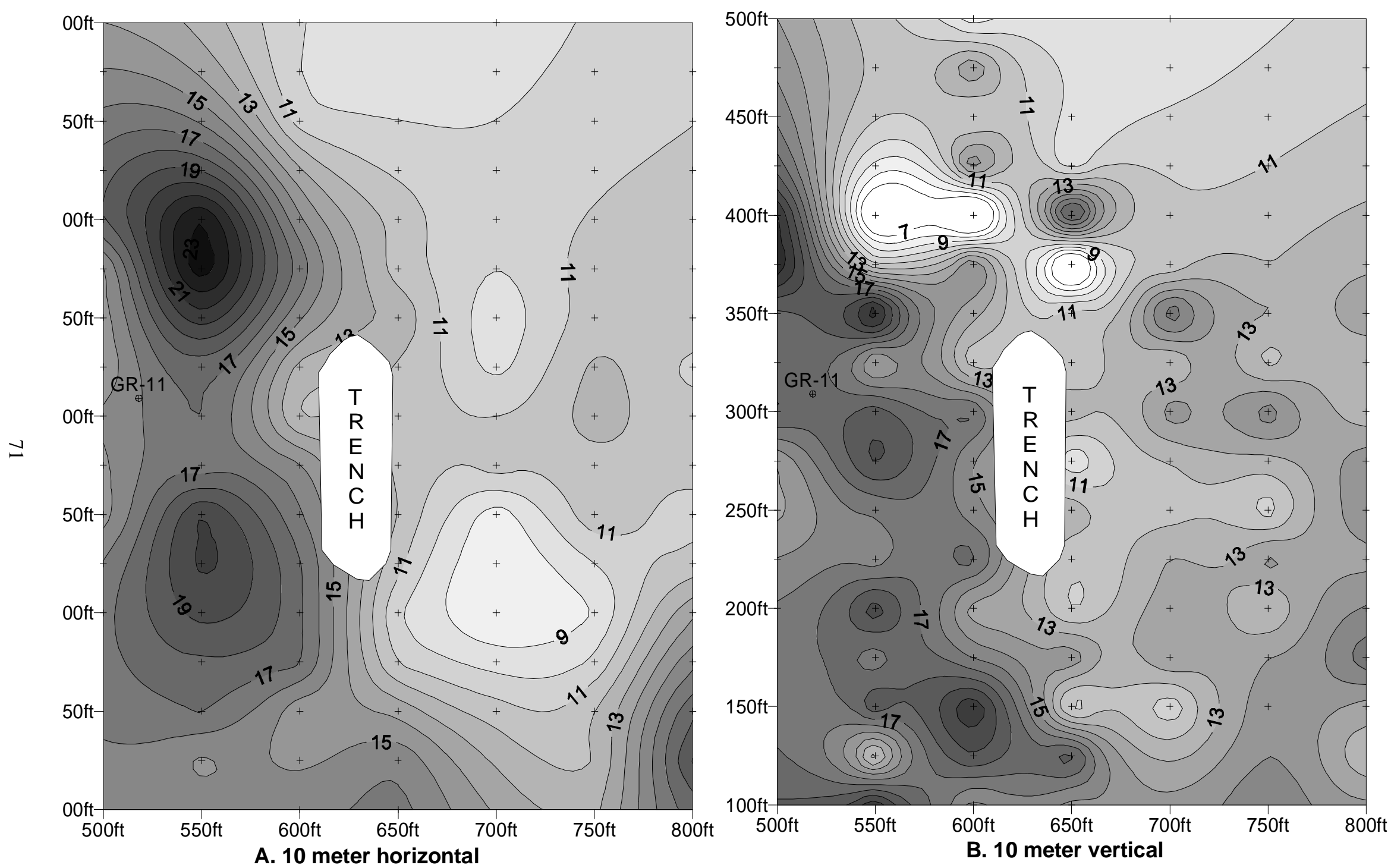

N

Figure 33. Greer Grid 3, 10 meter data after one lime application. 


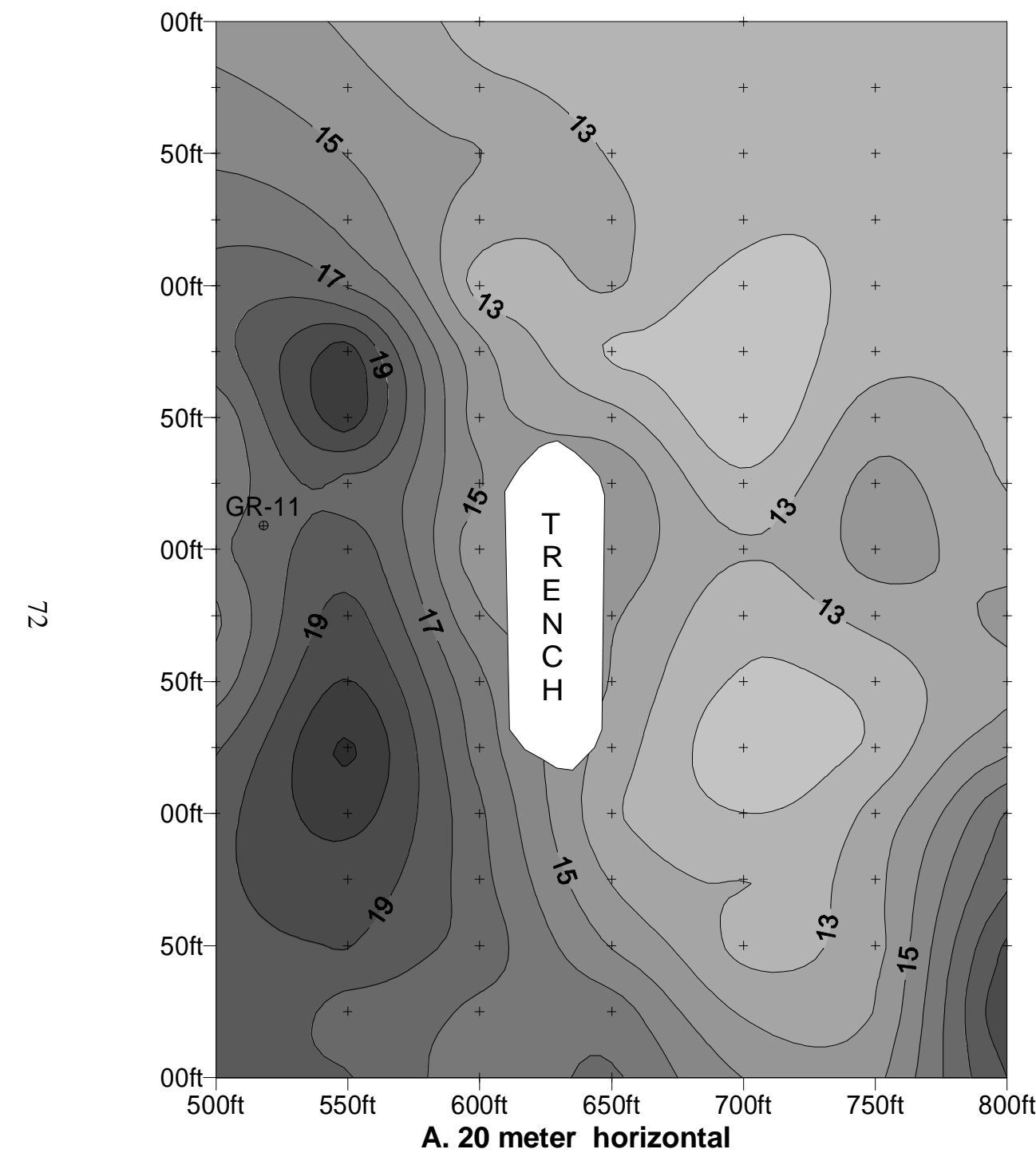

N

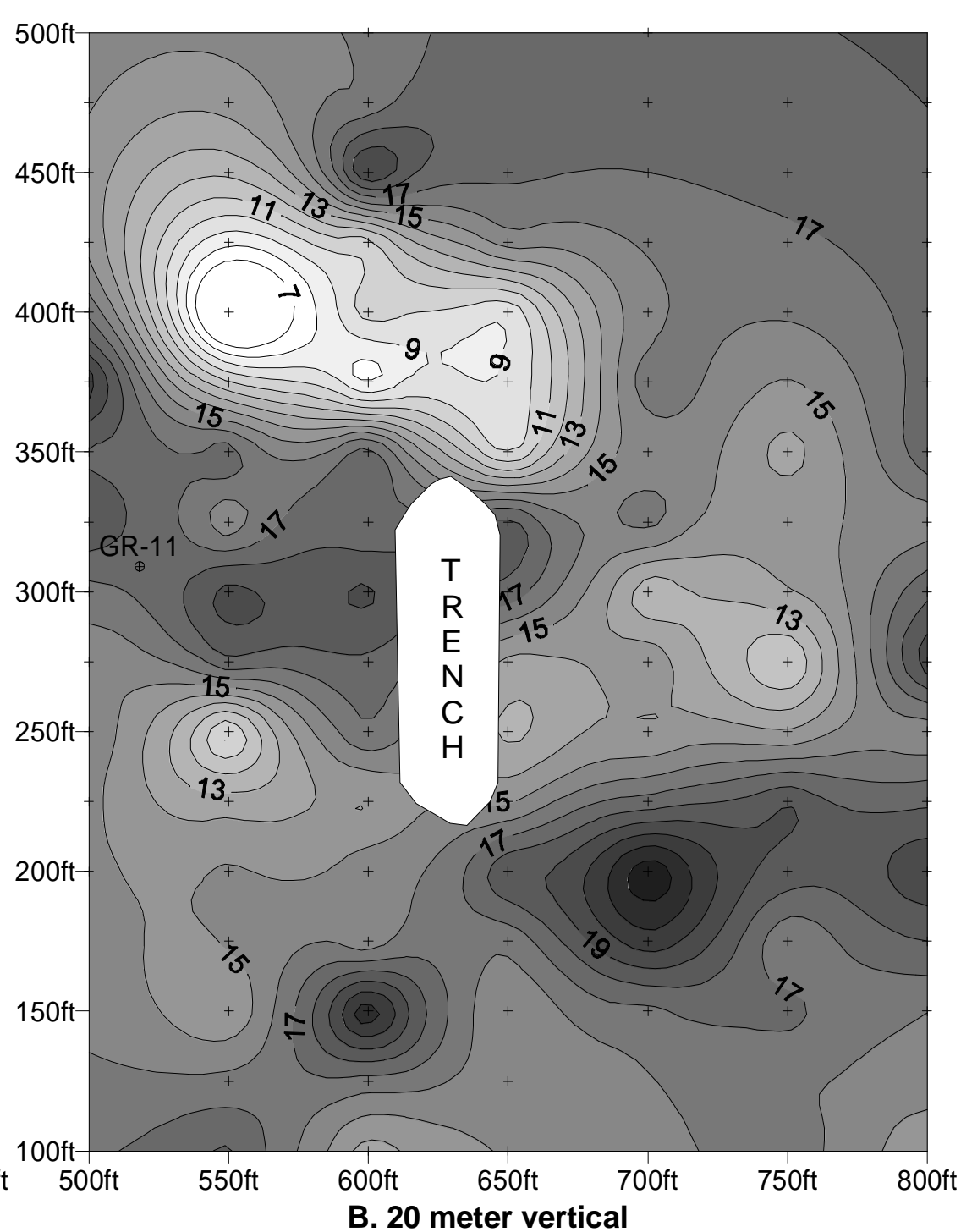

N

Figure 34. Greer Grid 3, 20 meter data after one lime application. 


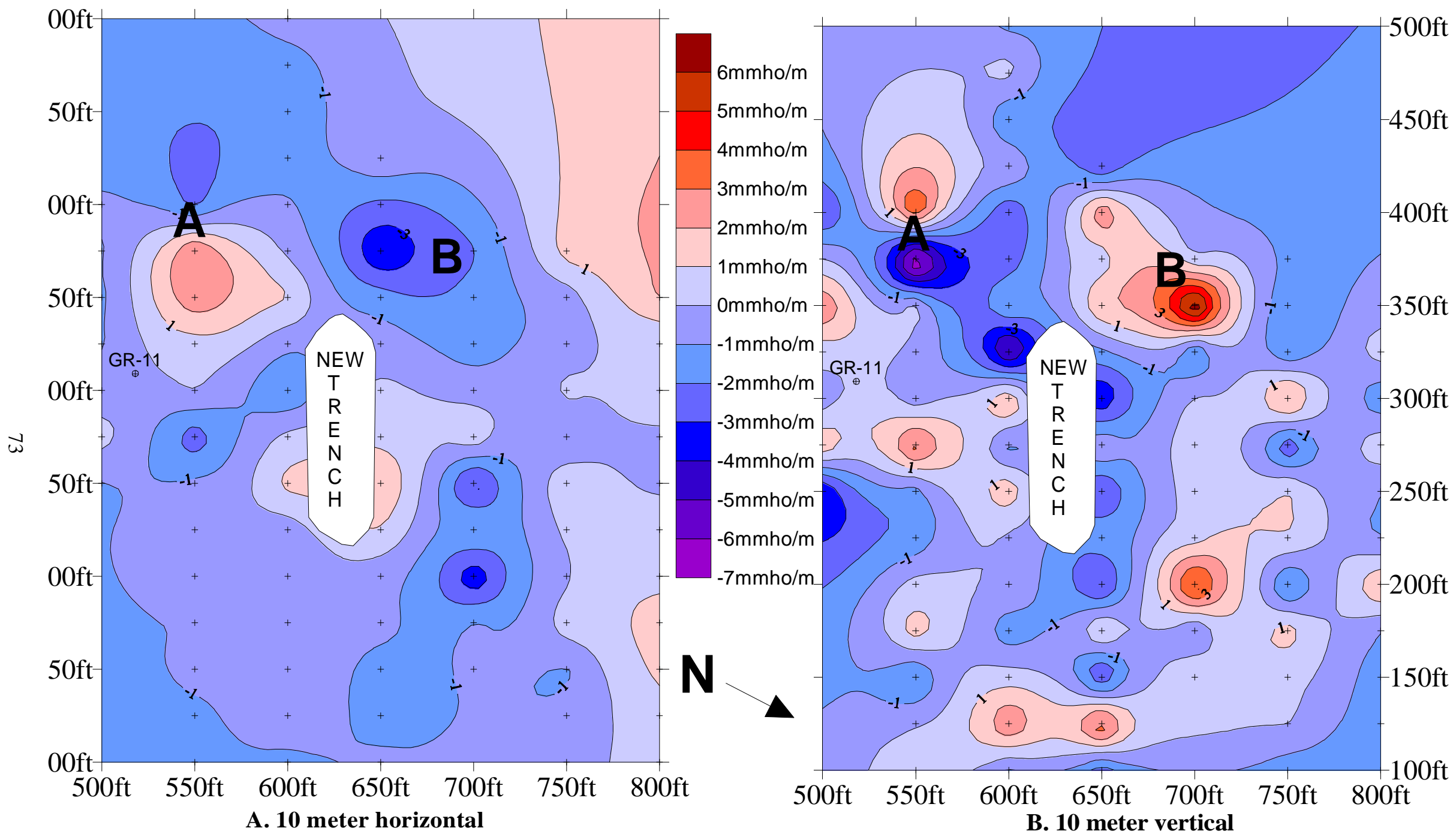

Figure 35. Grid 3, 10 meter difference one lime application - before digging. 


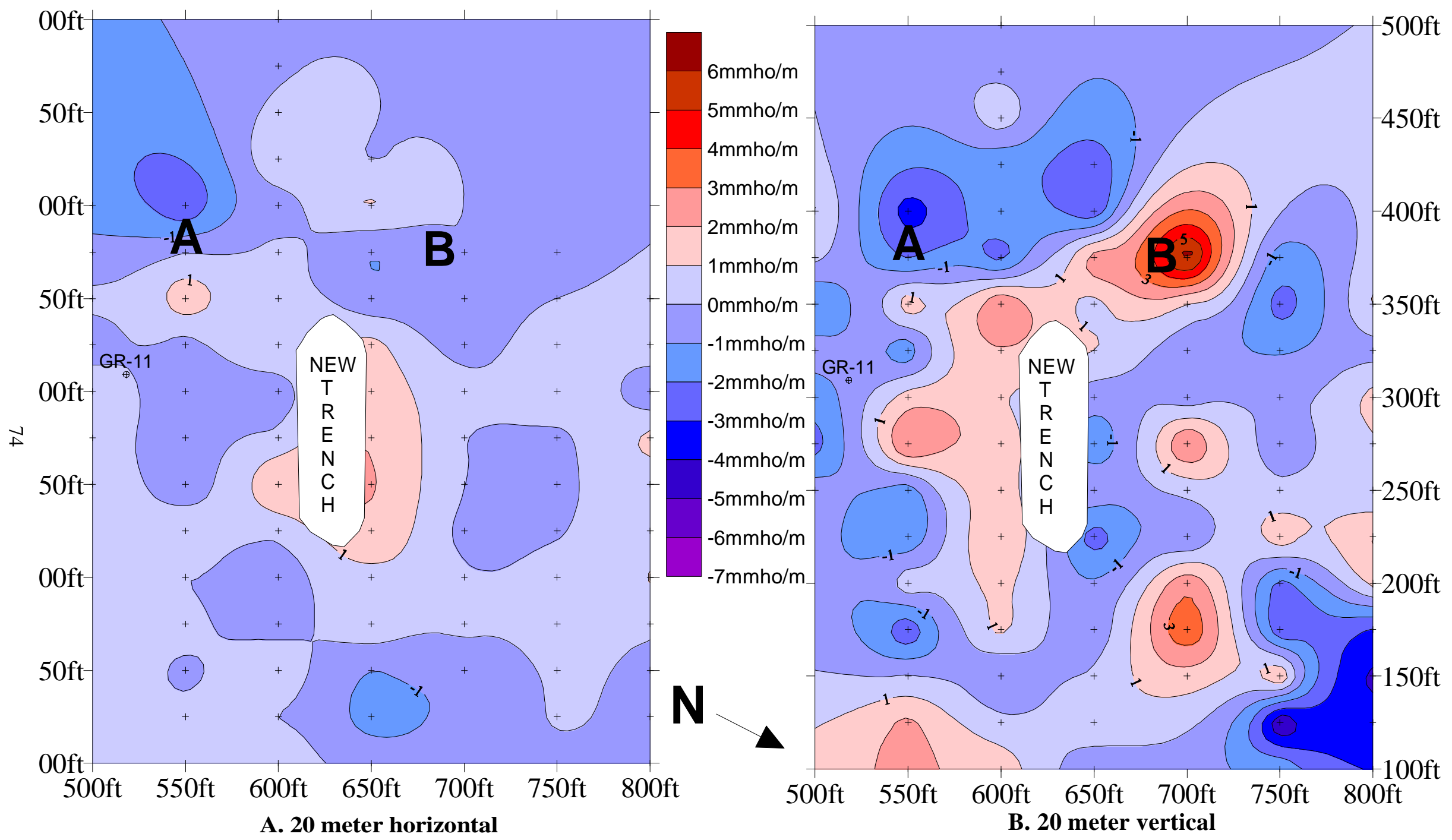

Figure 36. Grid 3, 20 meter difference one lime application - before digging. 
show the eastern end is also where particle size is largest and porosity most likely to be highest. The area "A" shows an increase in conductivity which may be related to small changes in the water content or water location of the refuse pile.

The 10 and 20 meter vertical measurements (Figure 35B and 36B) show greater variability $(+/-6 \mathrm{mmho} / \mathrm{m})$ in apparent conductivity over the grid area. The 10 meter vertical measurement (Figure 35B) shows a closely spaced increase and decrease in conductivity over area "A". This paired increase and decrease may be the result of drier near-surface conditions in the suspected coal refuse pile. Over area "B" the conductivity increased approximately $6 \mathrm{mmho} / \mathrm{m}$ in both Figure 35B and 36B. Changes in surface or subsurface conditions are not known over this area and such an increase was not expected.

Approximately a week after the trench was first filled a third set of EM 34 measurements was collected over the same grid as the week before. The third filling of the new trench had just been completed and between 20,000 and 50,000 gallons of liquid additions from the first two fillings had completely drained from the trench into the spoil. Plots of apparent conductivity over the grid are shown in Figures 37 and 38. These plots are similar to the ones collected a week earlier to the west and east of the trench but significant changes are seen north of the trench and, to a lesser extent, to the south. Again, difference plots were made to better illustrate the changes in apparent conductivity over the grid area. The difference plots were generated by subtracting the "first-filling" readings from the third filling readings. Figures 39 and 40 show the difference in apparent conductivity between the second survey and third survey over the new trench. Again, highs indicate increases in conductivity from the previous survey. 

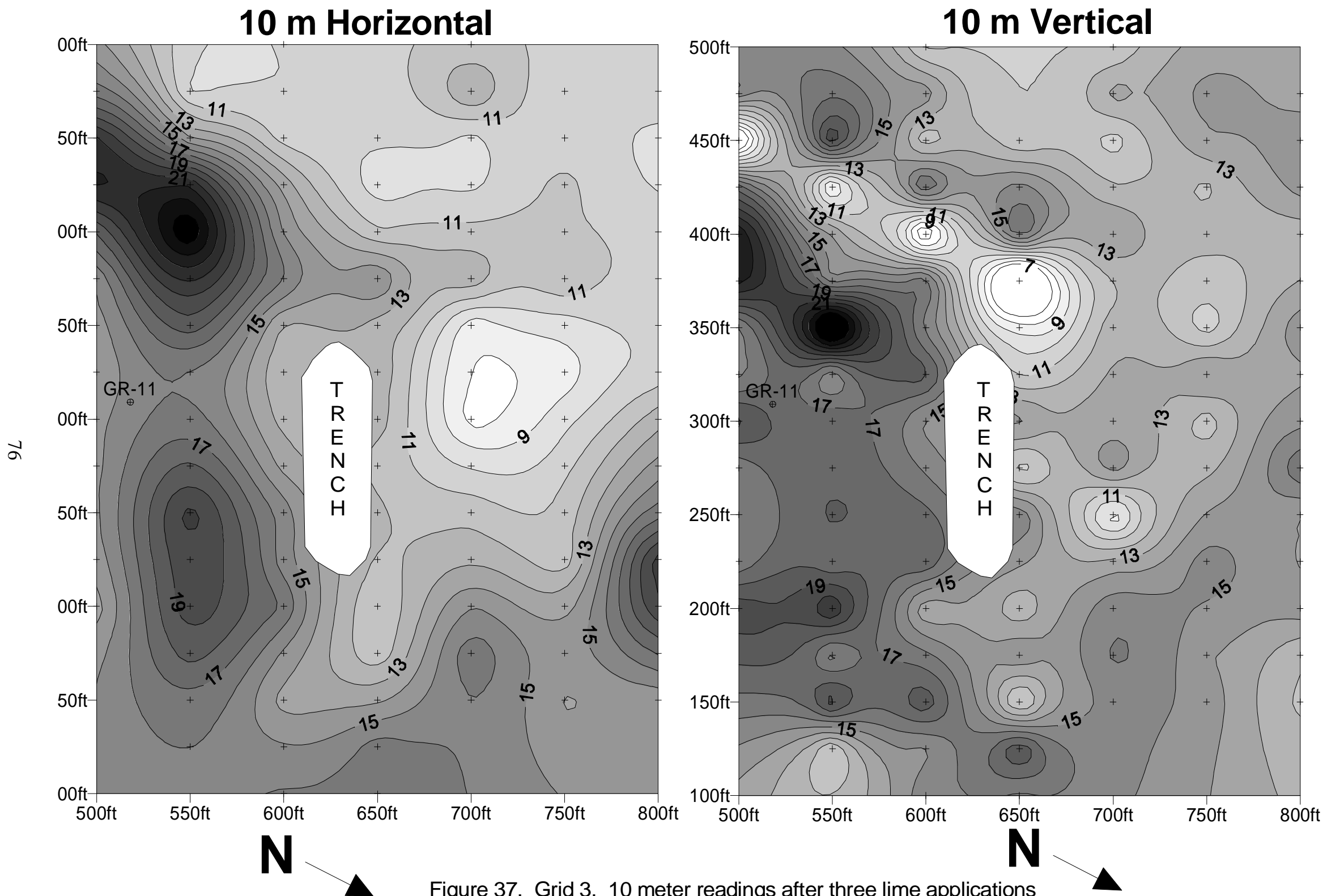

Figure 37. Grid 3, 10 meter readings after three lime applications 


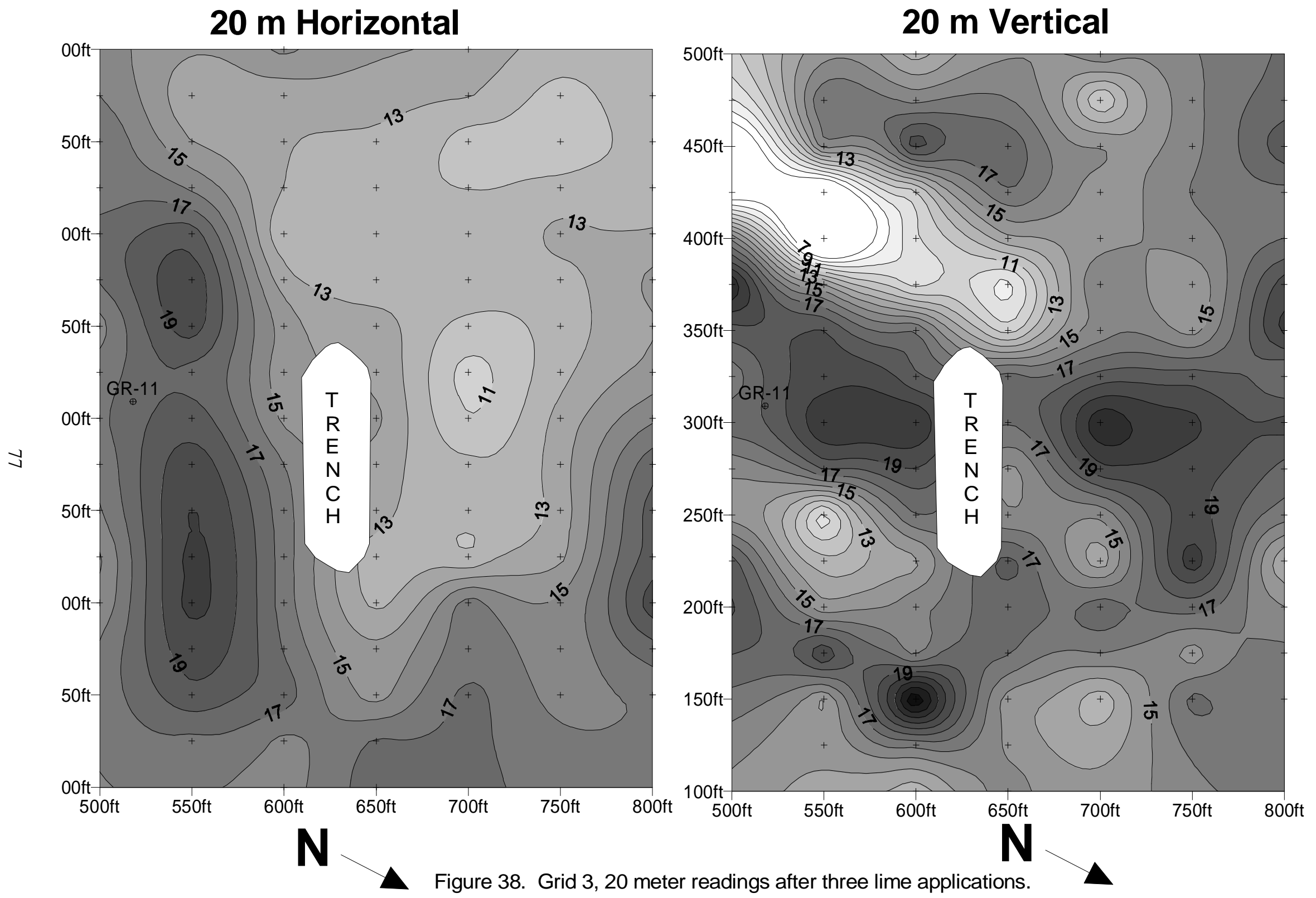




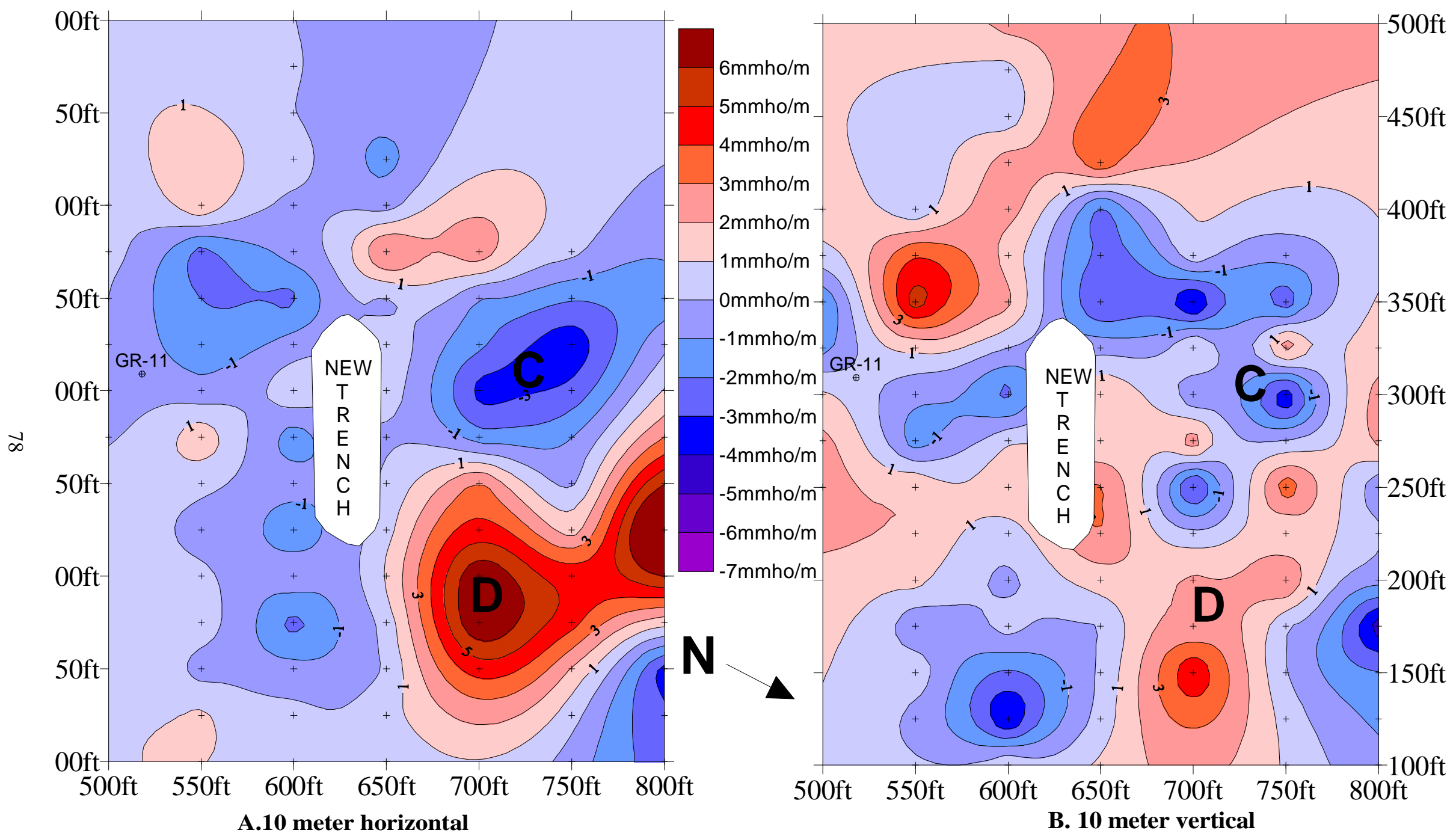

Figure 39. Grid 310 meter difference of three minus one lime applications. 


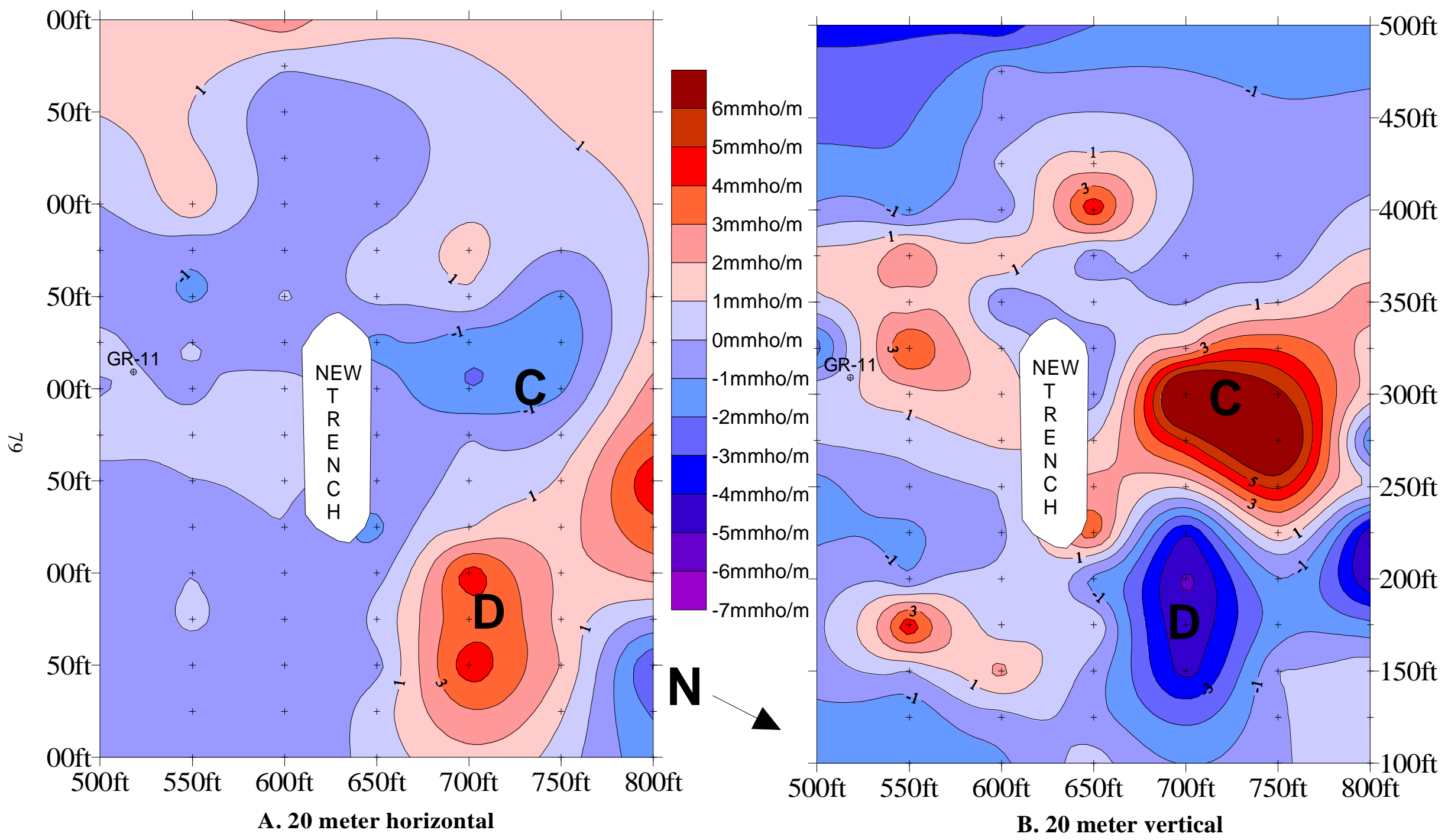

Figure 40. Grid 3, 20 meter difference of three minus one lime applications. 
The pre-trench survey is a poorer representation of the pre-injection state since the surface was disturbed between surveys by additions and removal of soil related trench construction. The surface was essentially undisturbed between the second and third surveys. Hence, the second survey was used as the "baseline" since it better represents "initial state" or pre-injection state over the new trench area.

Observations made with a 10 meter intercoil spacing in the horizontal dipole mode represent the shallowest penetration depth. The 10 meter horizontal response (Figure 39A) reveals a strong $(7 \mathrm{mmho} / \mathrm{m})$ increase in apparent conductivity north of the trench at area D. This area is downgradient and lower in elevation than the base of the trench. This anomaly appears to extend from the eastern end of the trench, increase in intensity to the north with a maximum increase about 100 feet from the trench. The anomaly appears to extend to the west of this high and continue beyond the bounds of the difference grid. On the same plot, an apparent conductivity decrease appears to extend northwest from the center of the trench with the most decrease occurring approximately 120 feet northwest of the trench (area C).

In the 20 meter vertical plot (Figure 40B), the deepest EM 34 difference plot, the response is nearly reversed from that of the 10 meter horizontal plot. Over area D a decrease in apparent conductivity appears to extend $90-100$ feet from the trench. This anomaly appears to extend west of the minimum another 100 feet to the edge of the plot Conversely, a strong $(8 \mathrm{mmho} / \mathrm{m})$ increase in apparent conductivity appears over area $\mathrm{C}$, the same area where a decrease in apparent conductivity is seen on the 10 meter horizontal plot. This increase appears to extend to the west from the eastern end of the trench before extending to the north and increasing in intensity. The 10 meter vertical 
and 20 meter horizontal plots show intermediate responses between the 10 meter horizontal plot and the 20 meter vertical plot.

In an effort to better visualize the changes in apparent conductivity with depth near the trench, two lines of data were plotted as cross sections of conductivity. The location of Line 3A and 3B is represented by the two yellow lines in Grid 3 of Figure 41. Lines $3 \mathrm{~A}$ and $3 \mathrm{~B}$ both transect the new trench area and were chosen for their distinct responses downgradient of the trench. Changes in apparent conductivity over the lines are shown in Figures 42 and 43. Only minor changes in apparent conductivity are seen from before digging of the trench to the first lime application in both the south-southeast and north-northwest sides of the line. One week after the first lime application significant changes in conductivity are seen north-northwest of the trench in both lines. Along the Line 3A (Figure 42) the area north-northwest of the trench does not show a high conductivity zone at depth before filling or during the initial application of a lime solution in the trench. However, after a week, a high conductivity zone at depth appears and extends to the edge of the line. Along Line 3B (Figure 43) the higher conductivity region at depth north-northwest of the trench is not as extensive and is of lower conductivity than before filling began whereas the surface conductivity over this area increased slightly. A discussion of these results appears in chapter 4, section 2 of this thesis. 


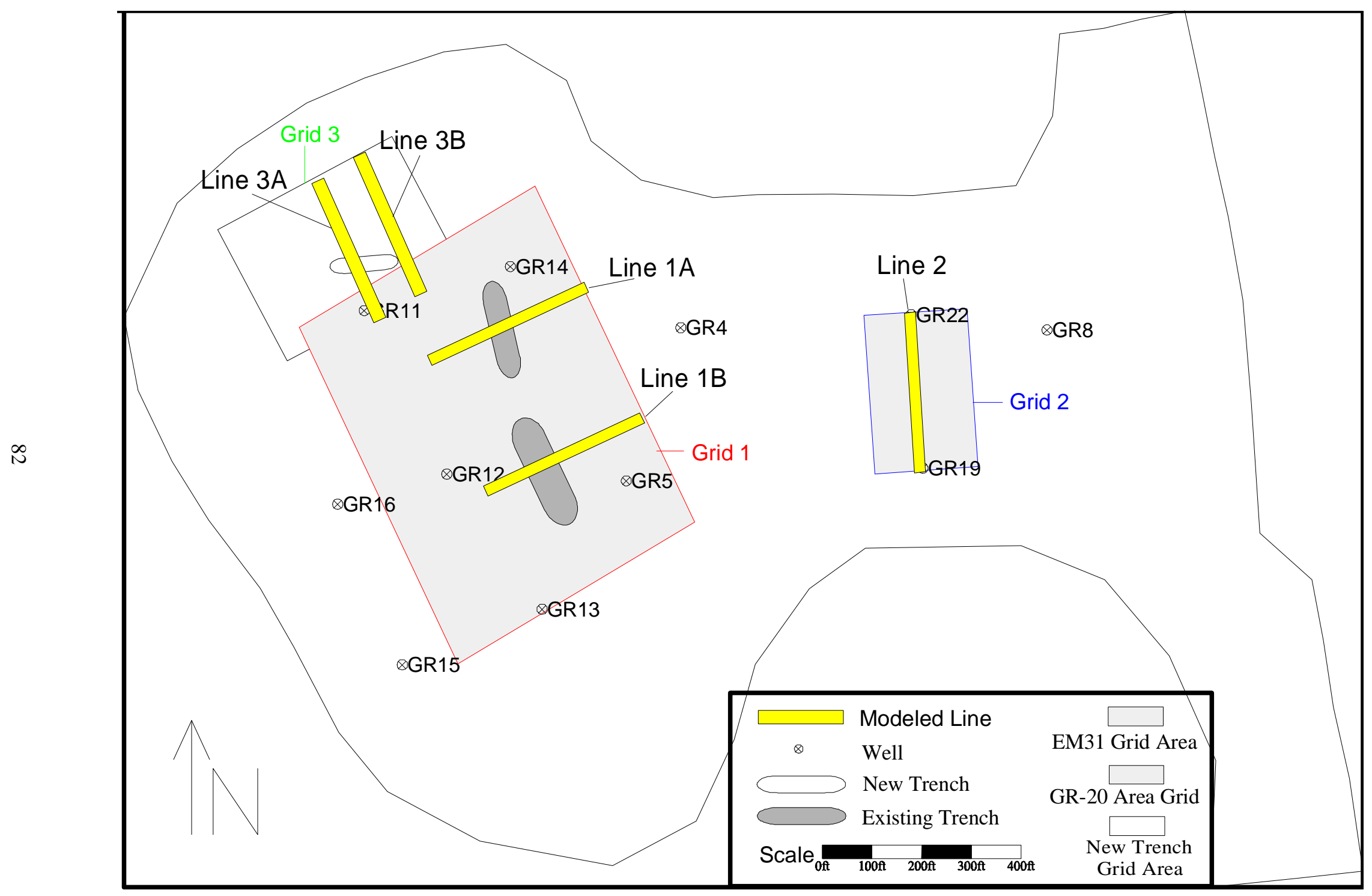

Figure 41. Greer site map showing modeled line locations. 


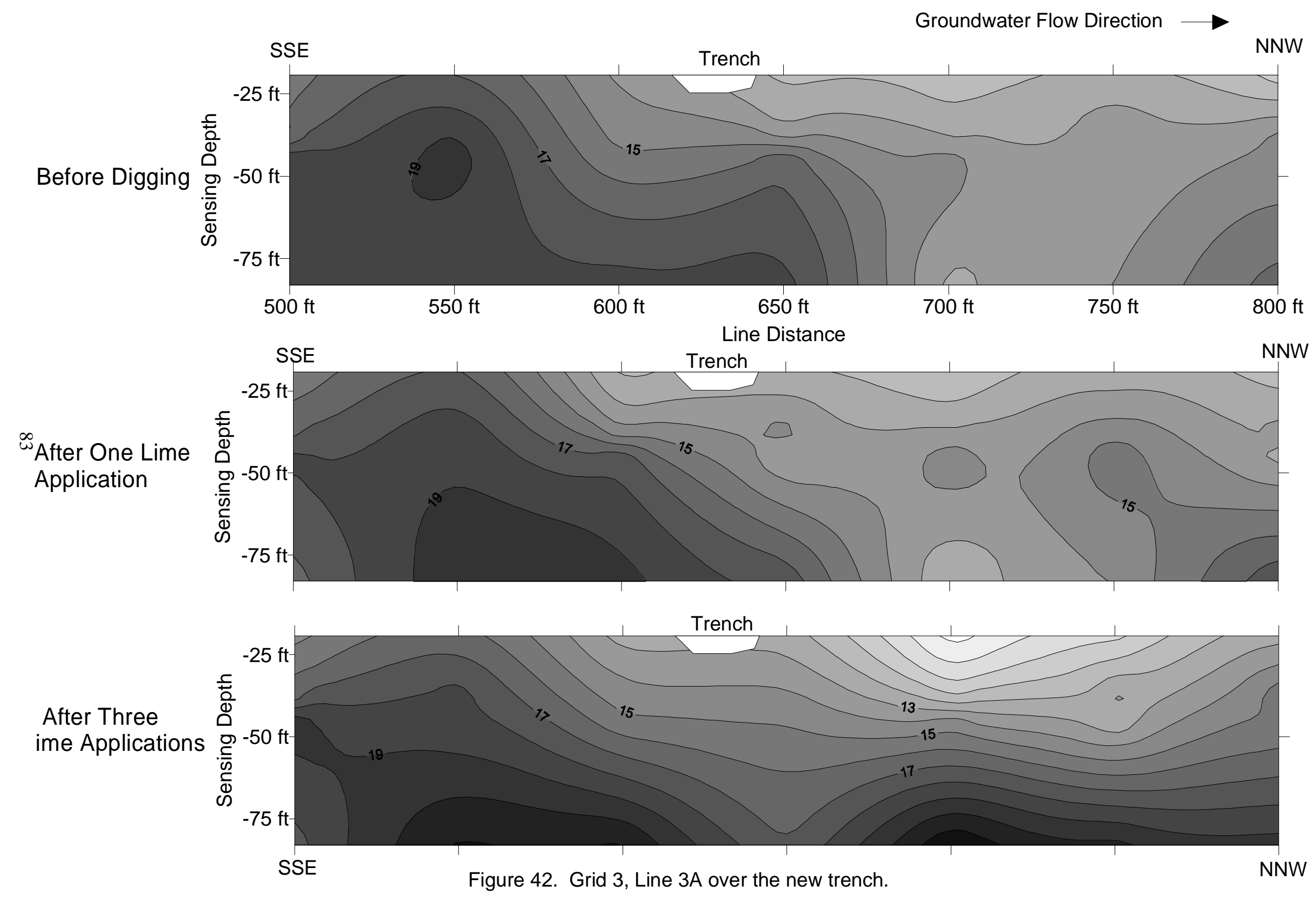




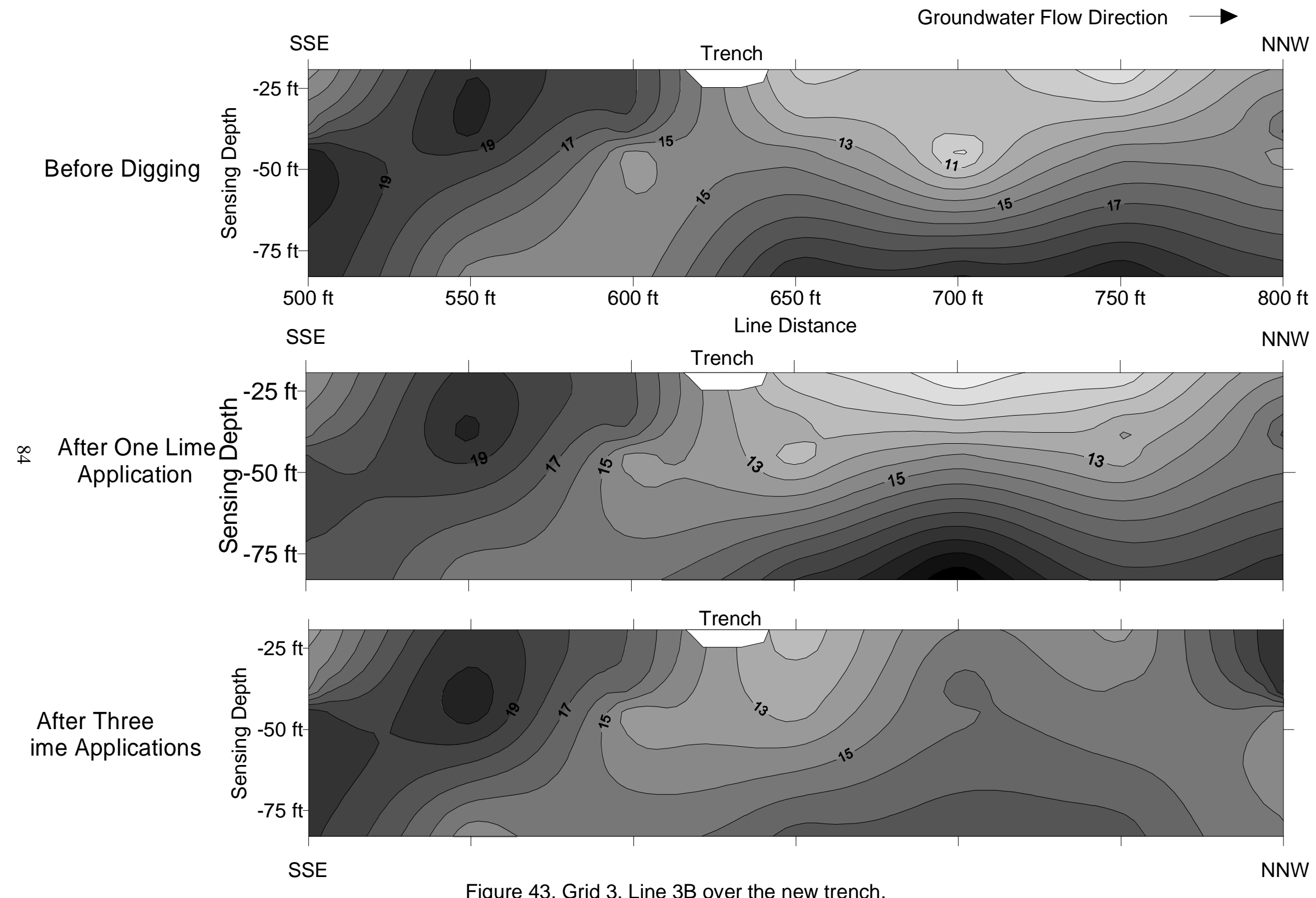




\subsubsection{Resistivity}

Five electrical resistivity soundings were made at the Greer Mansion site using a standard Wenner array. Results are shown in Figure 44 and indicate that the resistivity varies irregularly with depth throughout most of the site. Resistivities range from less than $1,000 \Omega$-ft $(0.3 \mathrm{mmho} / \mathrm{m})$ to over $5,000 \Omega$-ft $(0.06 \mathrm{mmho} / \mathrm{m})$ and average about 2,000 $\Omega$-ft $(0.015 \mathrm{mmho} / \mathrm{m})$. These values were more resistive than expected and do not agree with the terrain conductivity data. These data were to be used to better define the terrain conductivity models made but the inconsistency between the two techniques prevented this. Soundings 1 and 4 show a drop in resistivity at the 108 foot depth which may be the result of pooled AMD within the mine spoil while soundings 2 and 3 show an increase in resistivity at the 108 foot depth, possibly related to dry conditions at and below the pitfloor. As at the Irish Ridge site, the apparent resistivities are anomalously high and may be due to the fact that water was not used to improve ground / electrode coupling. Given the drought-like conditions present during the time of survey it is unlikely that this would have provided the desired coupling. 


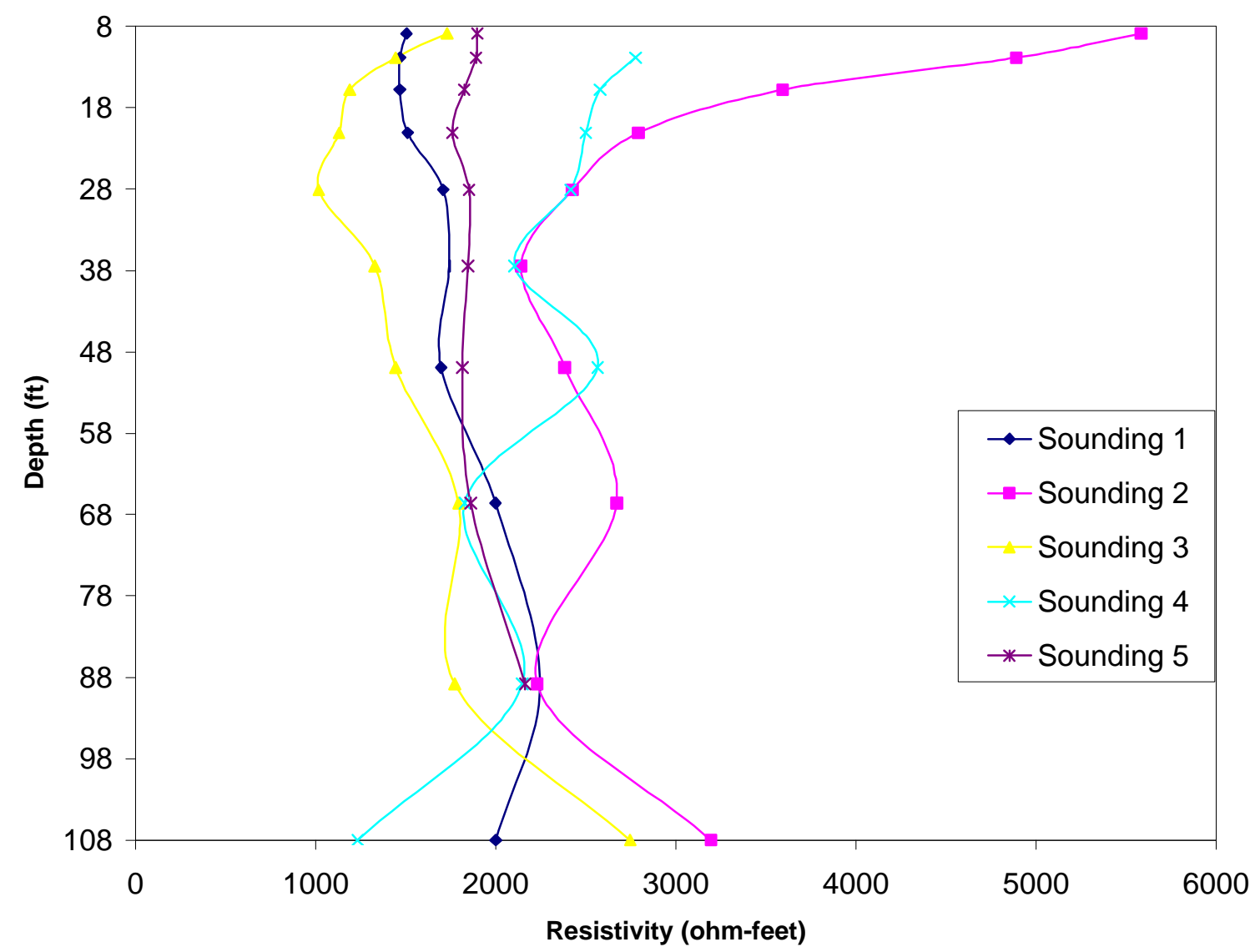

Figure 44. Greer Resistivity Soundings

\subsection{Long Ridge}

At the Long Ridge site, three EM 34 measurements, 10 meter vertical, 20 meter horizontal and 20 meter vertical, were made at each of the 340 station locations. Data from each measurement was contoured in Surfer. Three contoured plots of EM 34 data collected at the site are shown in Figures 45, 46, and 47. The three plots reveal relatively minor differences in apparent terrain conductivity as a function of coil spacing. A quick look at the contoured conductivity maps (Figures 45, 46, and 47) reveals the presence of three features of interest: a broad increase in conductivity in the western portion of the 


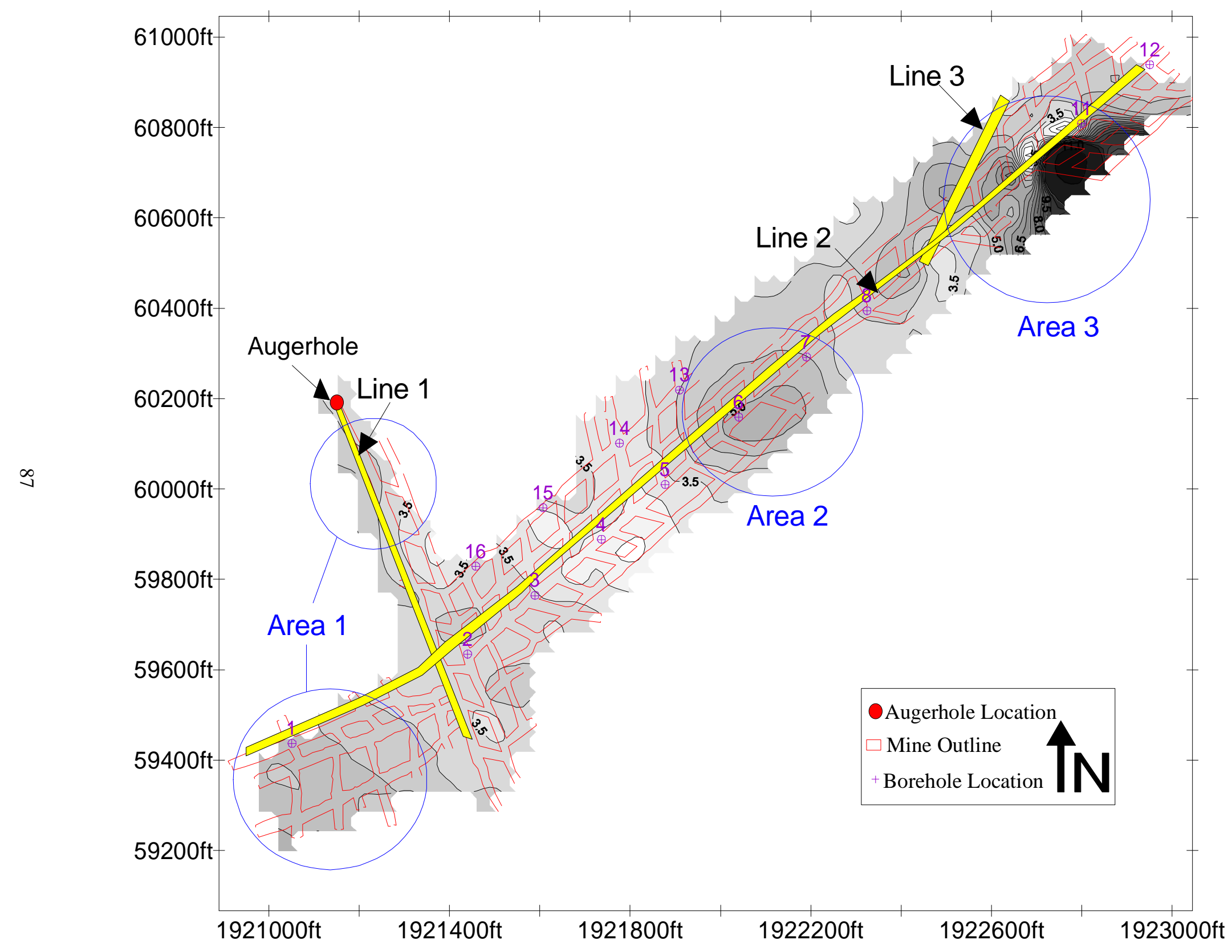

Figure 45. Long Ridge 20m horizontal data, 39 foot sensing depth, $0.5 \mathrm{mmho} / \mathrm{m}$ contour interval. 


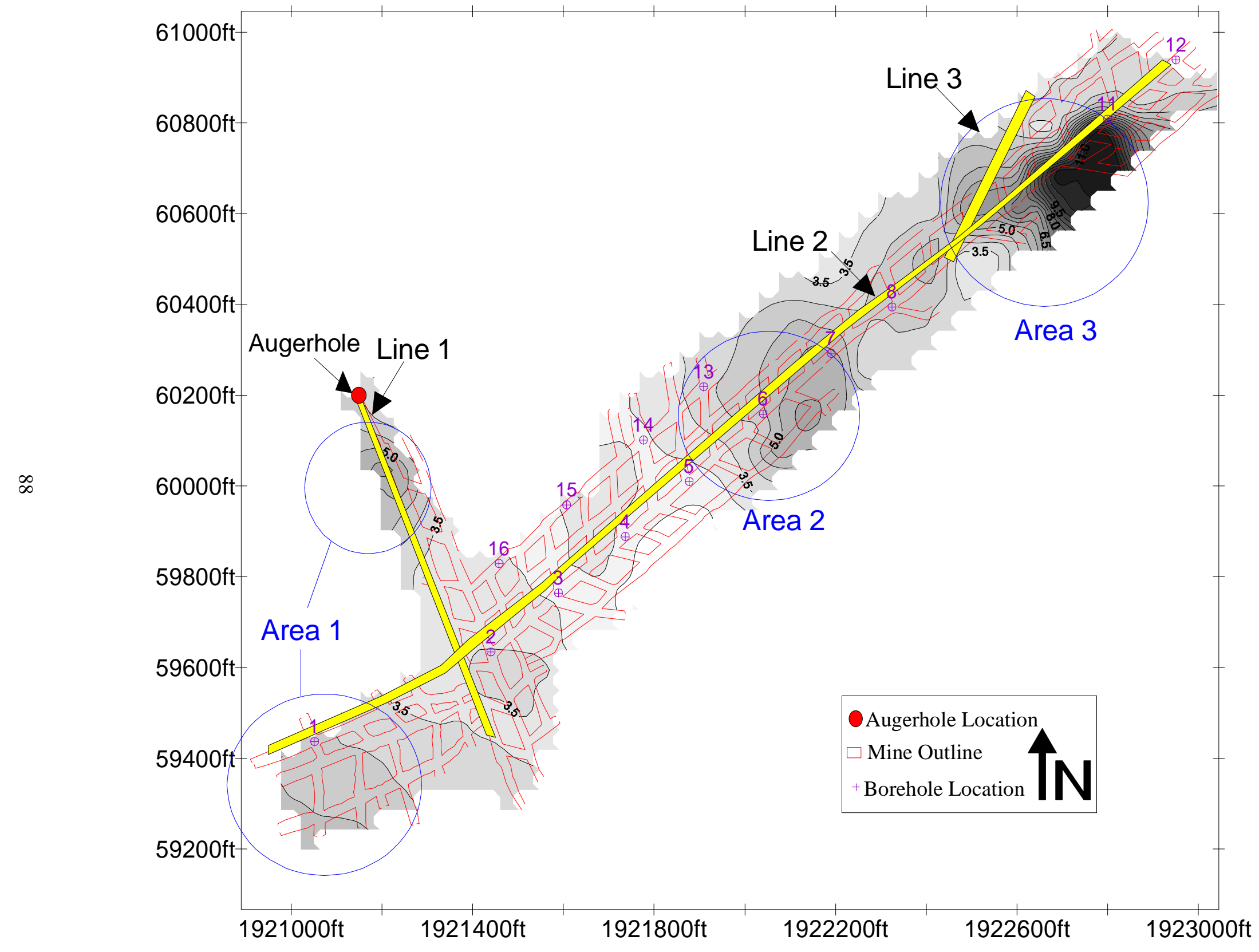

Figure 46. Long Ridge 10m vertical data, 41 foot sampling depth, $0.5 \mathrm{mmho} / \mathrm{m}$ contour interval. 


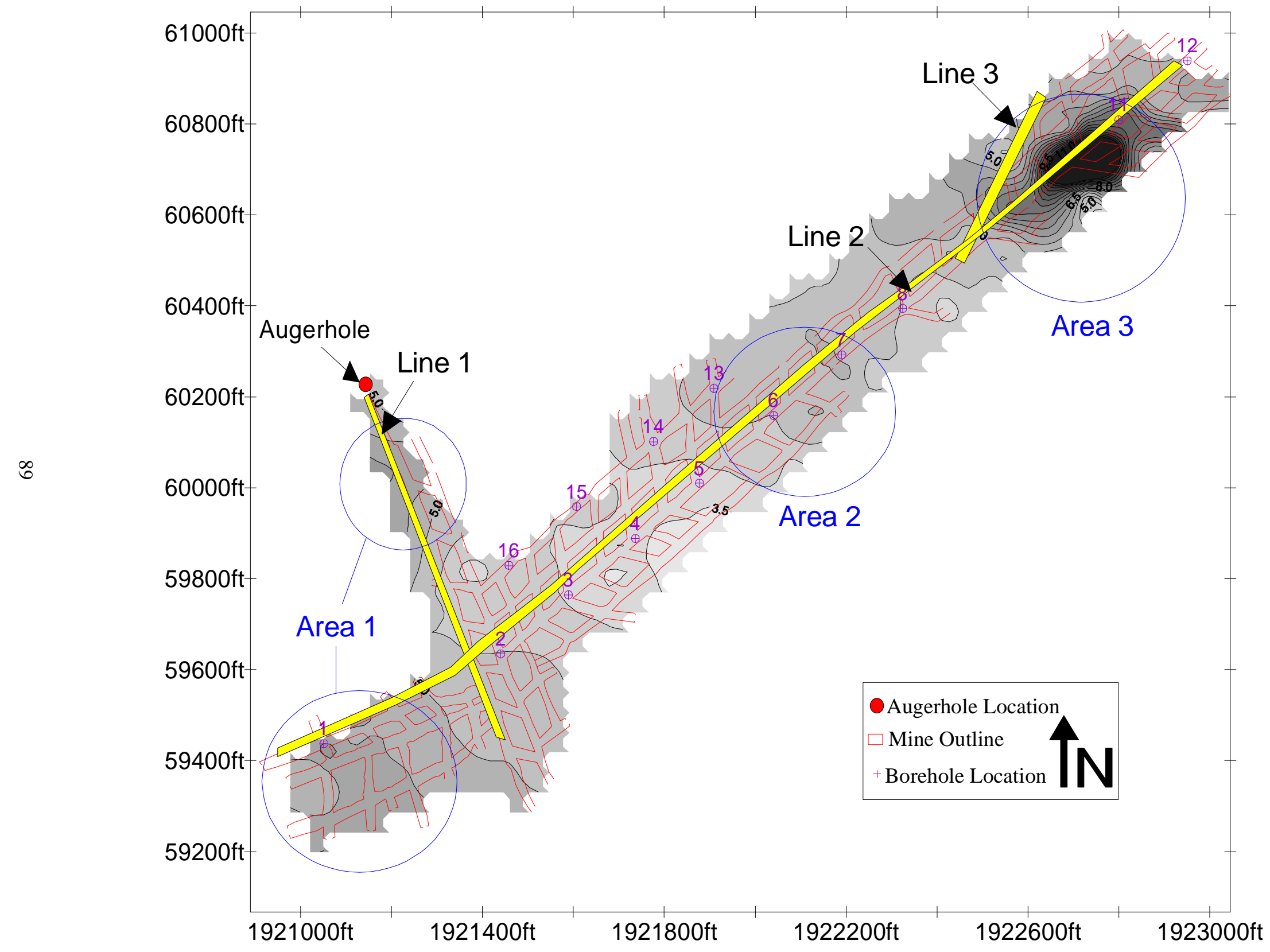

Figure 47. Long Ridge $20 \mathrm{~m}$ vertical data, 83 foot sensing depth, $0.5 \mathrm{mmho} / \mathrm{m}$ contour interval 
mined area (Area 1), a weak anomaly southwest of borehole 7 (Area 2), and a strong anomaly in the northeastern portion of the mined area (Area 3).

\subsubsection{Area 1}

The broad increase in ground conductivity in Area 1 of Figures 45, 46, and 47 occurs over areas where the thickness of the low conductivity sandstone unit thins and the depth to the more conductive coal and underclays decreases. Variations in apparent conductivity follow variations in depth to the coal seam over the southern and western portions of the mined area. If the mined interval is assumed, overall, to be a zone or layer of higher conductivity then its influence will be to increase apparent conductivity in areas where it is closer to the surface. This depth effect is best seen in the northern circle of Area 1 where a high conductivity zone correlates well with a topographic low (at about 360000 feet north). It should be noted that this topographic low is an intermittent stream valley and that increases in apparent conductivity in this area may also be related to increases in water saturation in the near-surface and at depth.

\subsubsection{Area 2}

The weak anomaly southwest of borehole 7 (Area 2) stands out as a region where the ground conductivity is somewhat higher than the surrounding areas (Figure 48C, center). A look at the topography in this small area reveals it is nearly flat (Figure 48A) with relief of less than 10 feet across nearly 500 feet. Unlike the rest of the study area, the surface dips at only $1.2^{0}$ and is not as well drained. Evidence of this could be seen in early August 1999 when drought conditions left most of the surface of the site dry while 
this area remained moist. The slightly higher ground conductivity in this area may be from an increase in moisture content in the subsurface resulting from poorer drainage at this flat bench. Because ground conductivity is controlled by the total dissolved solids

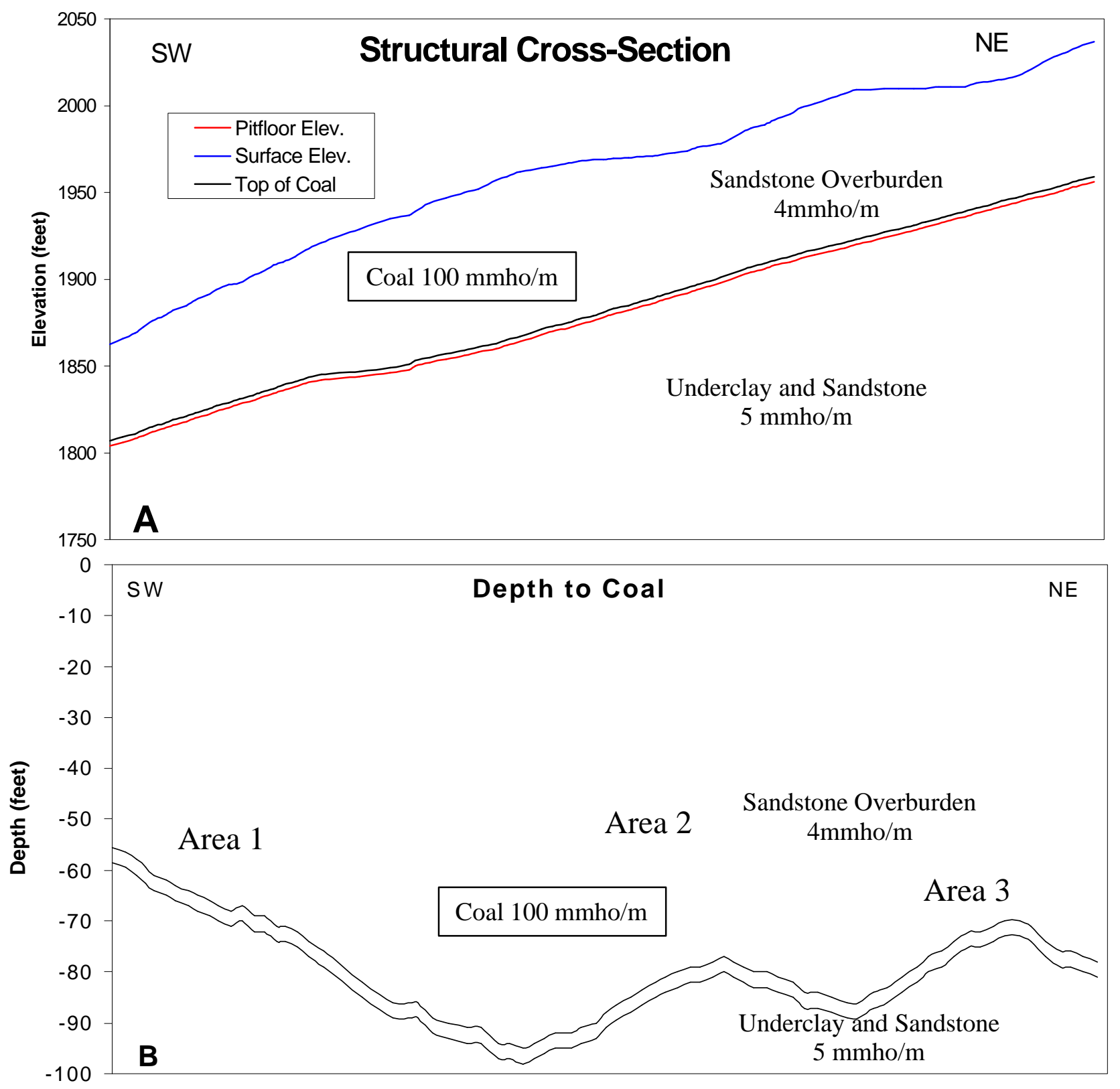

Figure 48. Long Ridge cross-section over area 2. 
and indirectly by the quantity of water in the subsurface, an increase in water content of both the thick sandstone unit and the underlying coal seam would result in an increase in apparent conductivity measured at the surface. Pitfloor data from Anker Energy does not show any change in pitfloor slope or orientation in this area, however, because the slope on the pitfloor surface is only about $2^{0}$, debris from collapse or similar sources could pond conductive mine water and create pools deep enough to account for increases in apparent conductivity at the surface.

\subsubsection{Area 3}

In Area 3 (Figures 45-47), a strong anomaly in the northeastern portion of the study area, is centered over a large pile of fly ash and "kiln dust" at the surface of the site. Smaller scale color contour plots of the northeastern portion of the mine were made to more accurately investigate the anomalous area. These $1 "$ to $125^{\prime}$ scale plots are presented as Figures 49, 50, and 51. The gray rectangle in Figures 49-51 shows the approximate bounds of the piles. Although there are no known studies of fly ash or "kiln dust" influence on ground conductivity, elevated ground conductivity readings over both the fly ash pile and kiln dust pile at the Long Ridge site strongly suggest that sizable piles of fly ash and kiln dust in an open field environment produce conductivity highs and are substantially more conductive than surrounding earth materials. When mixed in a grout and injected at depth, it is expected that fly ash and kiln dust grouts would make and excellent terrain conductivity target. At this site, most of the near-surface (upper $75 \mathrm{ft}$ ) is composed of low conductivity sandstone (see Figure 7 for stratigraphic column), any 


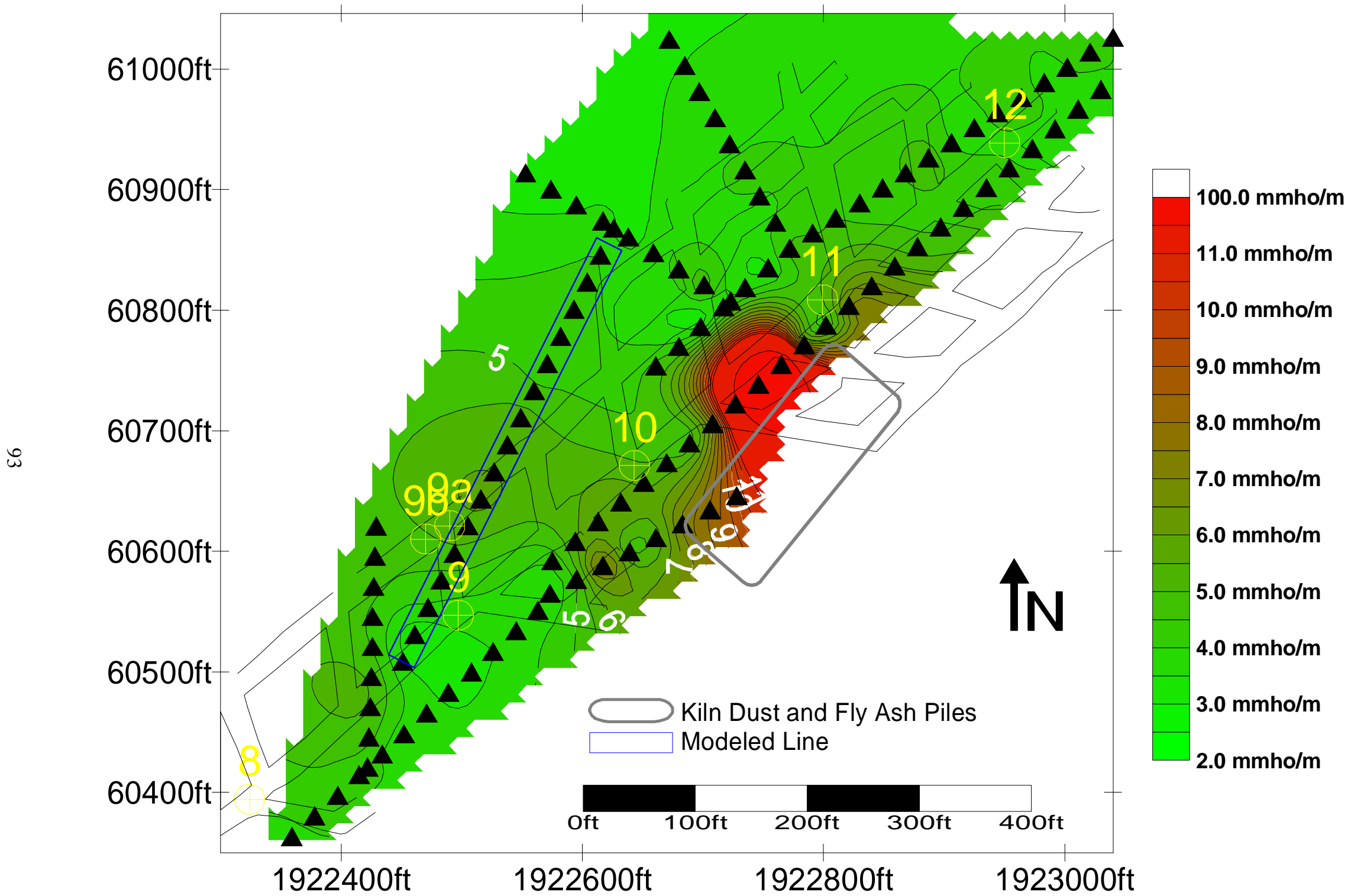

Figure 49. Long Ridge Area 3 enlargement, $20 \mathrm{~m}$ horizontal data, $0.5 \mathrm{mmho} / \mathrm{m}$ 


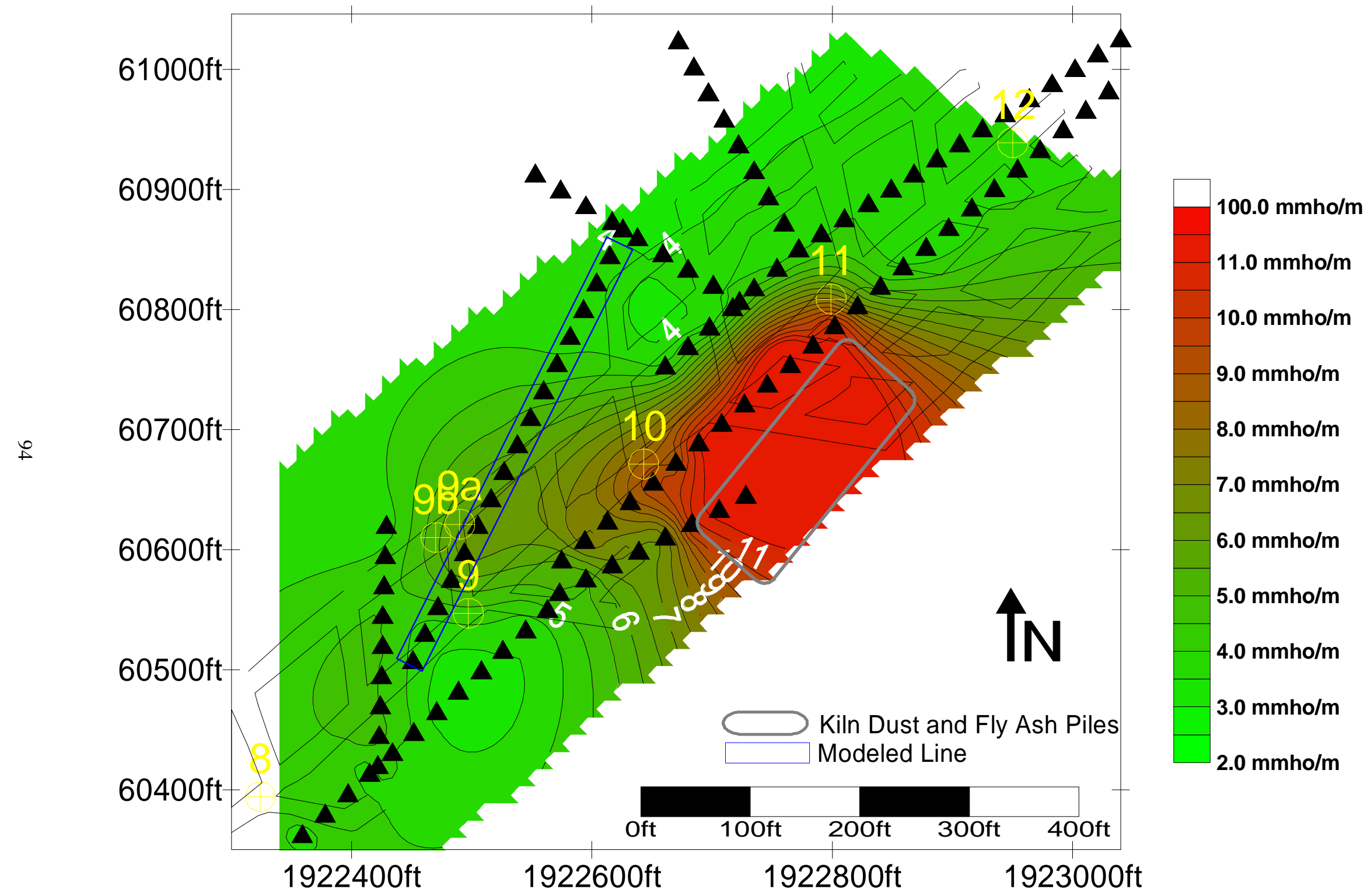

Figure 50. Long Ridge Area 3 enlargement, $10 \mathrm{~m}$ vertical data, $0.5 \mathrm{mmho} / \mathrm{m}$ contour interval 


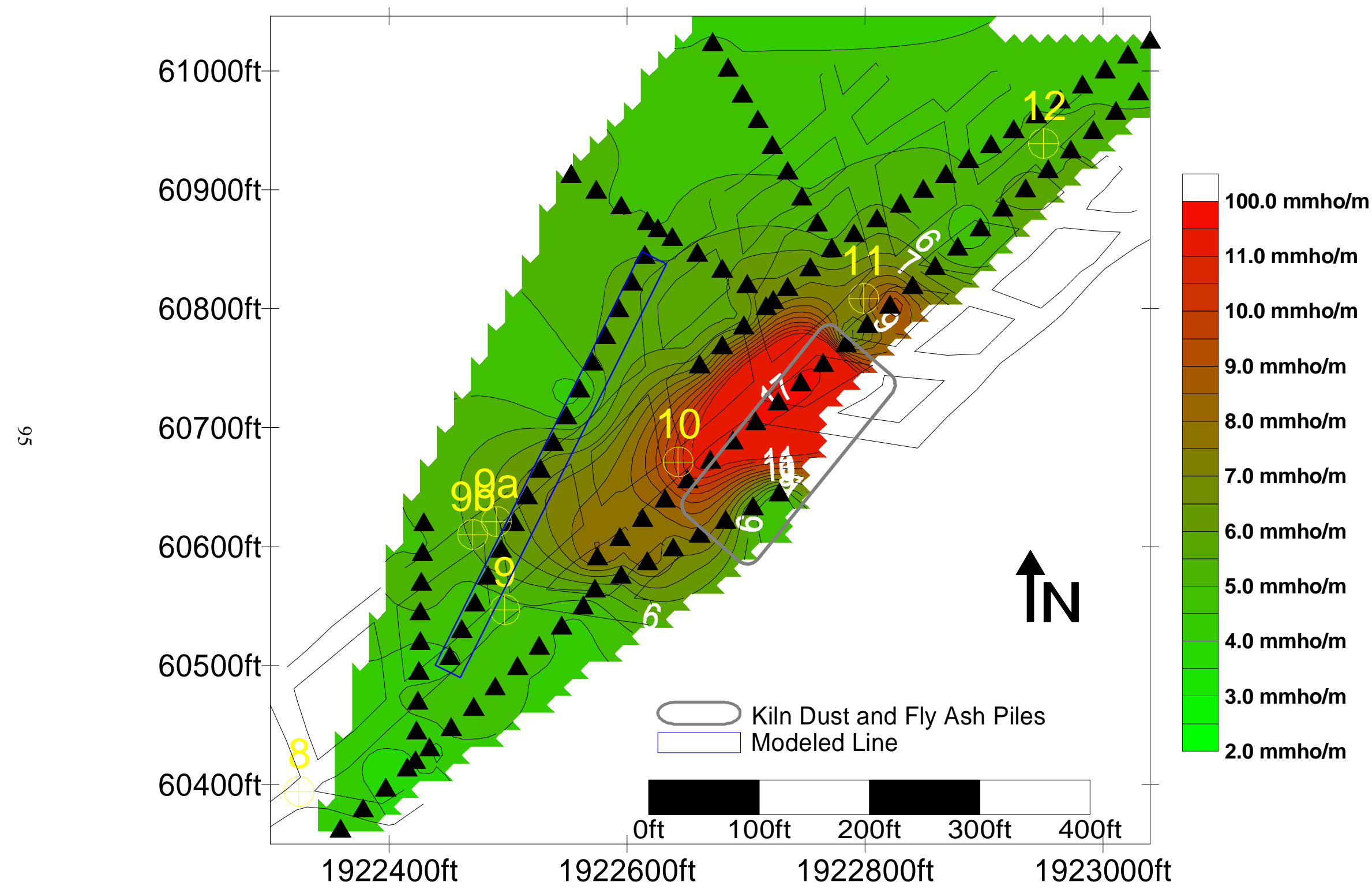

Figure 51. Long Ridge Area 3 enlargement, $20 \mathrm{~m}$ vertical data, $0.5 \mathrm{mmho} / \mathrm{m}$ contour interval 
high conductivity zones at or near the surface would have a more pronounced response due to the large contrast in conductivity.

The pile of fly ash in the region of this anomaly is roughly oval in shape, 220 feet long and 105 feet wide. Given this geometry, an oval "bulls eye" type anomaly would be expected over the pile. The resulting contour plots indicate an anomaly that follows this pattern near the pile, extending beyond it nearly 100 feet in most directions. In the west-southwest direction the conductivity high extends nearly 200 feet beyond the pile (see Figures 49-51). Because of this anomaly pattern, it is thought that the anomaly in this area is due to the fly ash pile and a second source. Observations at the surface during the time of the survey do not indicate anything anomalous at the surface in this area. In addition, the pitfloor in this area is relatively uniform in dip and orientation. The source of the anomaly may be due to pooled AMD at depth, resulting from the grouting efforts at drillholes 9,9a, and 9b. An additional possibility is that high conductivity metals have carried from the fly ash pile into the near-surface of the surrounding areas by rainwater, increasing the near-surface conductivity. Results of modeling efforts over area three are shown and discussed in chapter 4 . 


\section{CHAPTER 4 - Modeling Results and Discussion}

\subsection{Irish Ridge}

Data from the Irish Ridge site were originally collected in a north-south grid pattern without respect to mine geometry or borehole locations since information about the mine was not provided. Upon collection of geophysical data, areas of interest were identified and the anomalies in these areas were analyzed and modeled. Two areas of particular interest were chosen for modeling efforts. The first feature of interest, labeled $\mathrm{A}$ in Figures 52A and $\mathrm{B}$, is a prominent north-south trending high conductivity feature observed in the terrain conductivity data. A second anomaly, labeled B in Figure 52B and $\mathrm{C}$, is observed along Line 2 located in the northwestern portion of the survey area where a mine pool was reported to exist at depth (Black, personal communication, 1999). Models were constructed along profiles across each anomaly.

\subsubsection{Line 1}

Feature A appears as a linear conductivity high with approximately north-south trend in the terrain conductivity data (Figures $52 \mathrm{~B}$ and C). This anomaly is thought to be the result of a partially water-filled vertical fracture zone for three reasons: it has a linear nature, overburden cracks have been observed in the far east end of the mine (extending to the north along this anomaly trend), and high conductivity is observed. This feature is most prominent to the south at approximately $-500 \mathrm{ft}$ (Figure 52). Observed terrain conductivities along Line 1 across the feature were entered into Interpex Ltd 's EMIX34P modeling software. A three layer inverse model was generated (Figure 52). Layer conductivity was fixed for two layers in this model and layer thicknesses were freed and 


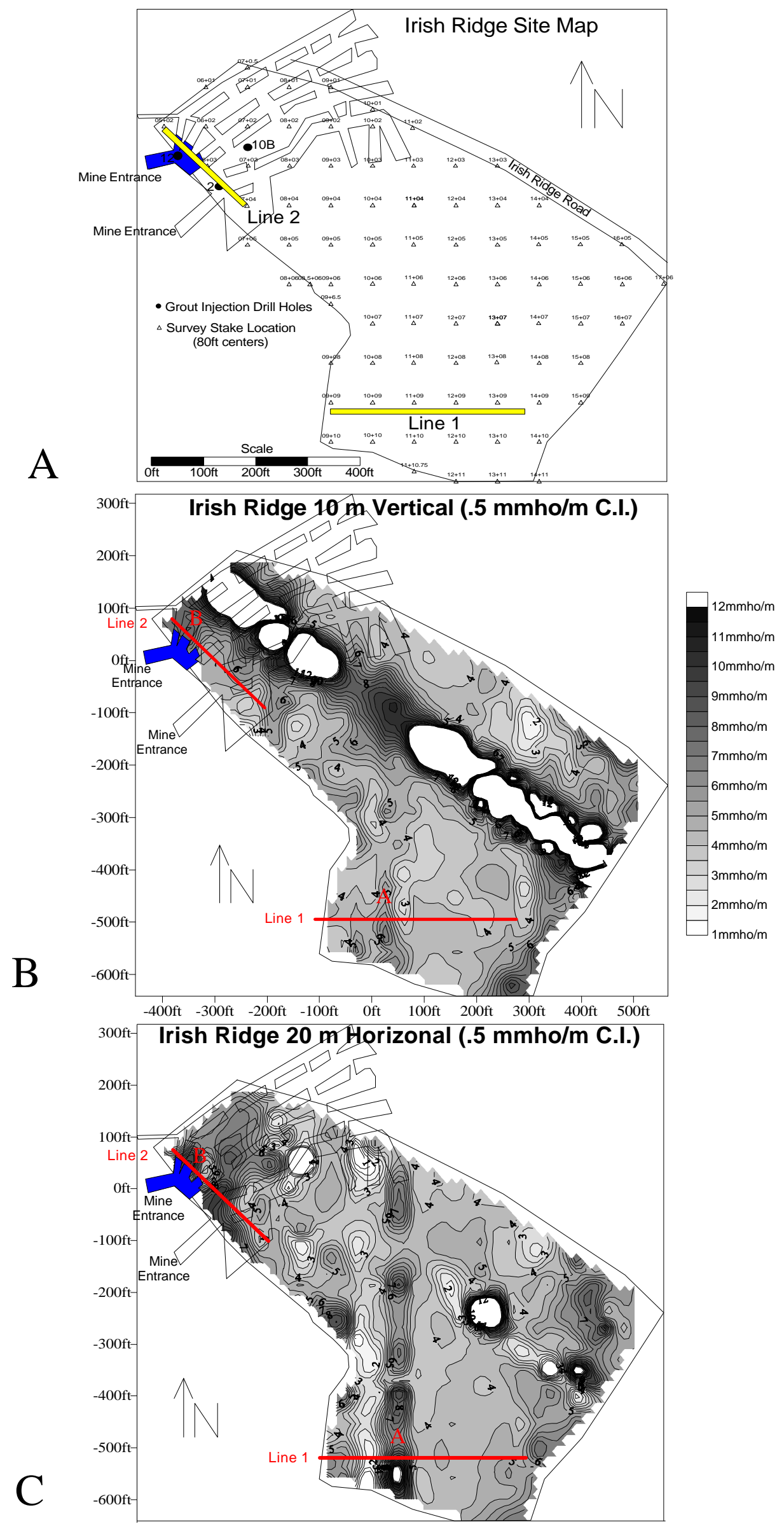

Figure 52. Irish Ridge site and conductivity maps. 
an optimal configuration was determined iteratively by the software to minimize the error between calculated and observed conductivities. The upper layer was assigned a 4 mmho/m conductivity based on shallow EM 34 terrain conductivity data collected at the site. The lower layer was assigned a $5 \mathrm{mmho} / \mathrm{m}$ conductivity based on likely apparent conductivity values from an unsaturated sandstone-limestone lithology. The middle (AMD) layer was assigned an initial value of $25 \mathrm{mmho} / \mathrm{m}$ with the software free to vary the middle layer conductivity to obtain the best fit to the observed data. This conductivity value is consistent with the 1000 to $2000 \mathrm{mS} / \mathrm{m}$ water conductivity readings typically seen in Upper Freeport coal AMD affluent (Ziewkiewicz, personal communication, 1999).

Initial results of this modeling effort revealed an excellent fit over most of the line, however, a poor fit was obtained in the +45 to +85 feet interval. The model was modified between 45 and 75 feet to include a fractured sandstone surface layer. After trial and error the fractured sandstone layer was modeled as a $10 \mathrm{mmho} / \mathrm{m}$ layer extending from the surface to the top of the third layer. The physical model generated from this modified approach is seen in Figure 53A. The resulting geometry is generally consistent with what is known of the subsurface in this area (that a higher conductivity coal layer lies beneath a 40-60 foot thick sandstone layer). The conductivity of the middle layer varies from 18 to $36 \mathrm{mmho} / \mathrm{m}$ and lies generally about 45 feet below the surface. The middle high conductivity layer coincides with the Upper Freeport coal. The portion of the line from about +45 to +70 feet with a moderate conductivity zone extending to the surface approximates a vertical fracture zone. This location coincides with the linear conductivity high observed in Figure 52B and C. The modified model 

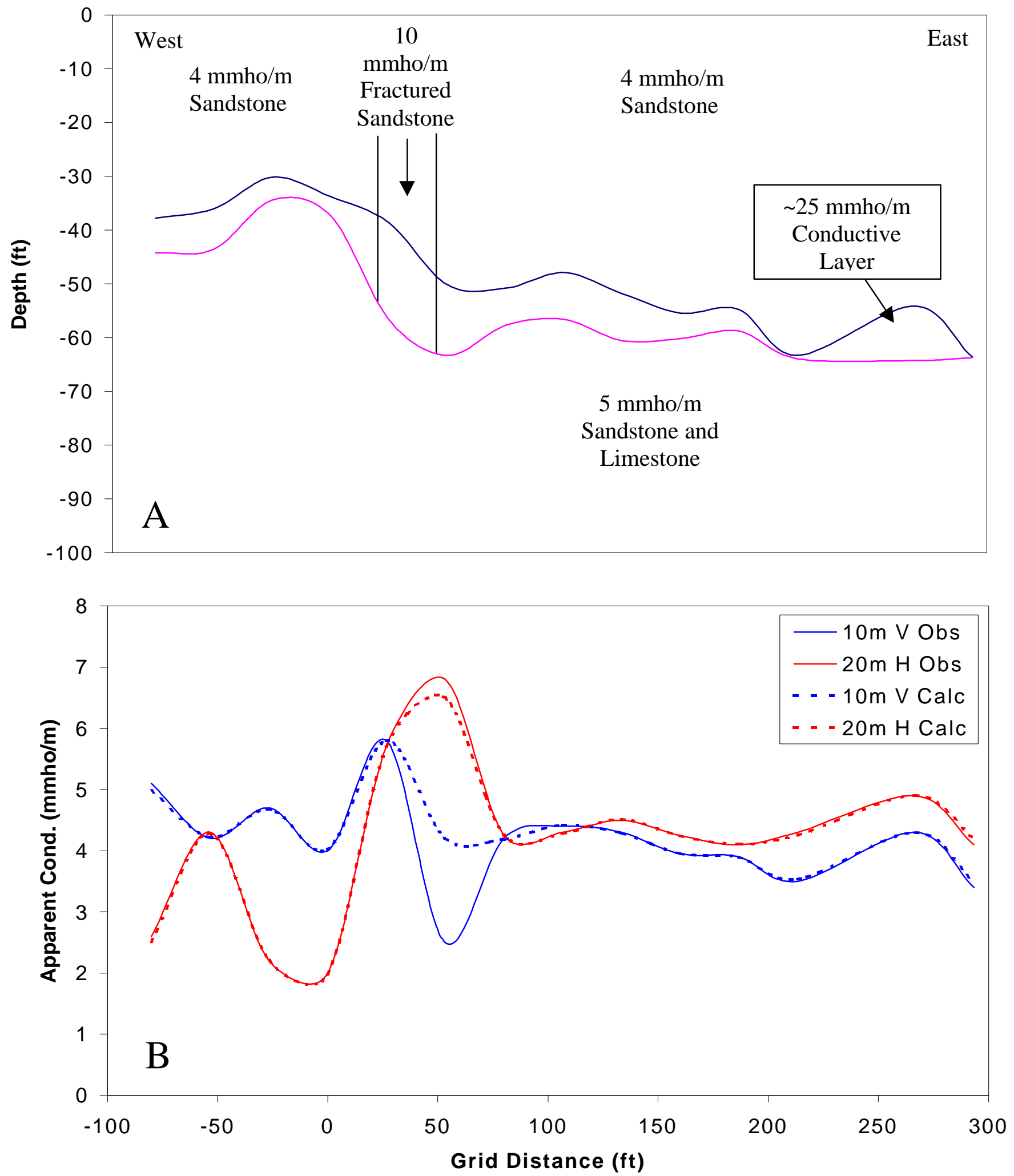

Figure 53. Irish Ridge modeled Line 1 results. 
with a fracture zone more accurately fit the observed data than the model without a fracture zone. In this model, the calculated response mimics the observed data over this area. While no evidence exists, it is possible an anomaly similar to that of line 1 could be generated from a small, highly conductive body, such as a buried pipe or wire. This body would appear as a linear terrain conductivity high in both shallow and deep readings since the assumption of operation at low induction number is violated over highly conductive bodies.

\subsubsection{Line 2}

The second area of interest (Area B, Figure 52) coincides with a pool of AMD in the mine mapped by NMLRC. An increase in apparent conductivity over this area is thought to be related to the pooled AMD at depth. A three layer inverse model was generated in a manner similar to that generated along Line 1 . However, in this case the depth of each layer of the model was fixed and only the conductivity of the middle layer was allowed to vary in the inversion process. A model with a 47 foot thick, $4 \mathrm{mmho} / \mathrm{m}$ layer as the top layer, a 3 foot thick middle layer of variable conductivity, and a 5 $\mathrm{mmho/m}$ infinitely thick lower level was constructed to represent the subsurface over the modeled line (Figure 54A). The approximate geometry of the model including approximate room and pillar locations is shown at the Figure 54A. Since this line is mapped as crossing three mine headings, one would expect to observe three peaks in middle layer conductivity where the line crosses water-filled mine headings. Modeled

conductivity of the middle, 3 foot thick layer is shown in Figure 54B. The results show 

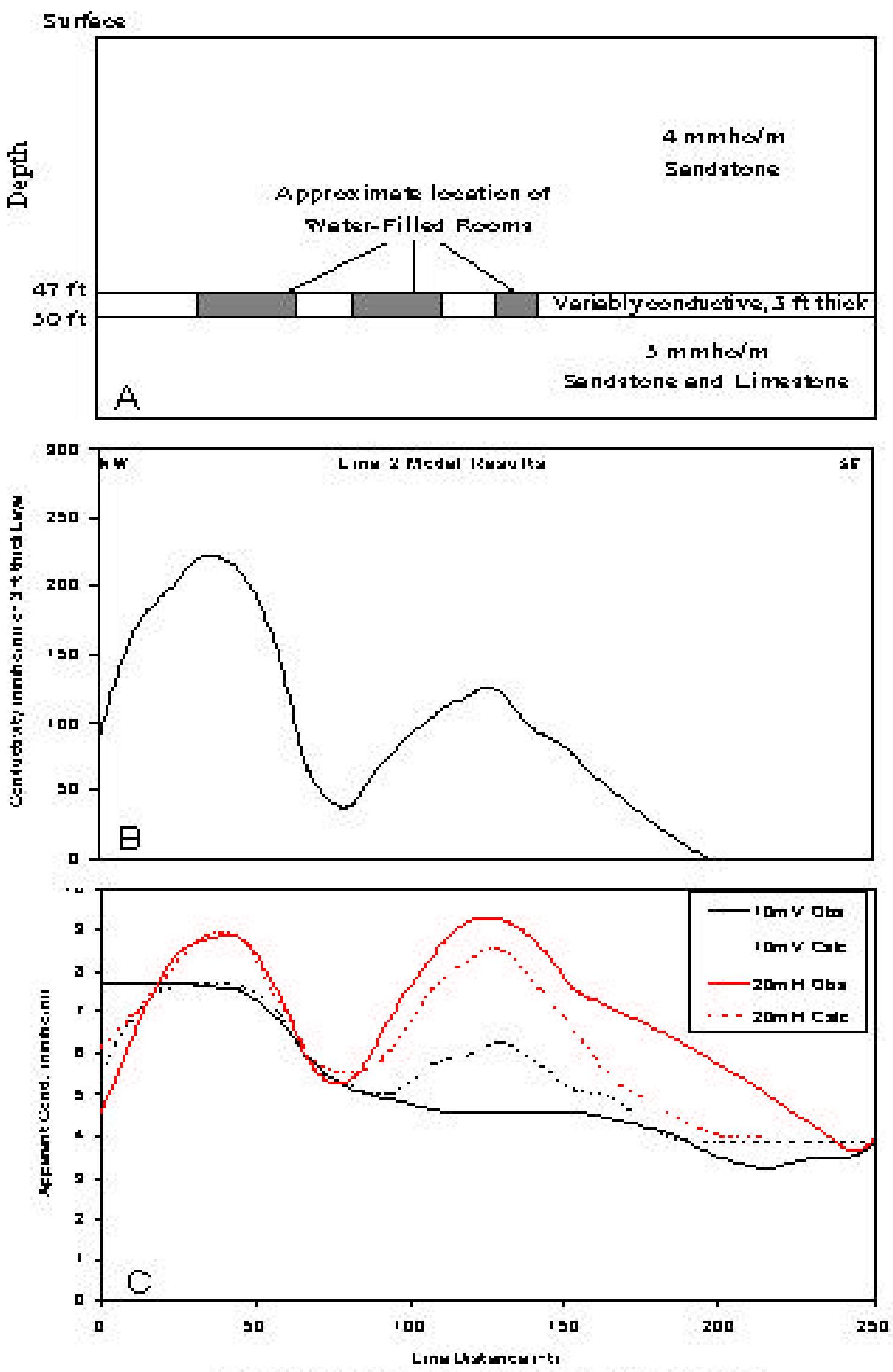

F igure 54. Ir iah fidge, Line z model end result. 
two peaks in middle layer conductivity centered over $\sim 35$ and $\sim 125$ feet along the line.

These peaks appear to be located above the western-most water-filled room and the room that passes below stake $07+02$ (Figure 52A). The stronger response on the northwest side of the line corresponds to deeper water in the mine. Ziemkiewicz (per. comm., 1999) notes the accuracy of the mine map is questionable making it likely that the modeled response best represents the location of flooded mine headings and that the discrepancy in modeled verse expected response is related to a variation on the order of $15 \mathrm{ft}$ in one direction or another of the mine map orientation to the geophysical survey map.

While it appears that changes in apparent conductivity along Line 2 can be explained using this model, it is important to note that the modeled solution is nonunique. Other factors, such as variations in subsurface water content and contaminate concentration could create variations in apparent conductivity along observed Line 2.

\subsection{Greer}

\subsubsection{Grid 1}

Data collected over three separate areas at the Greer site were modeled using the EMIX34P software. Selected profiles (lines) of data were used to represent the response of each area. The location of these lines on the spoil can be seen in Figure 41 (page 82). The first line of data modeled (Line 1A) transects the northern trench in Grid 1. This line was modeled to evaluate the possibility that plumes of sludge migrate down and out from the surface trenches as suggested in earlier discussion (see section 3.2.2.). In this model the conductivity of the spoil was set at $6 \mathrm{mmho} / \mathrm{m}$ (the approximate lowest reading of the EM 34 over the site, representative of dry spoil) with a fixed depth of $20 \mathrm{~m}$ (66 feet) over the line. An infinitely thick $10 \mathrm{mmho} / \mathrm{m}$ layer lies below the spoil. Within the spoil a high 
conductivity $(100 \mathrm{mmho} / \mathrm{m})$ variable thickness plume of sludge was assumed to be present. This conductivity value comes from water conductivity data collected by Eb Werner from the sludge solution in GR 17. The trench that this line transects was no longer being filled with sludge. The resulting three layer model, where the thickness and depth of the sludge were varied, was derived through inversion to best fit the data.

The model obtained through inversion is shown in Figure 55A. A comparison of observed and calculated values is shown in Figure 55B. The resulting model (Figure 55A) suggests that the higher conductivity zones near the trench are related to sludge applications at the surface. It also suggests that high conductivity sludge plumes are still present in the subsurface near the northern trench and that they extend to the pitfloor. The model derived plumes come to within two meters of the surface beneath the trench. The slightly irregular geometry of the plumes suggests preferred flow paths may be present in the spoil.

Line 1B (Figure 41) transects the southern trench in Grid 1 and runs parallel to Line 1A. This line was also modeled using an inverse modeling approach where observed conductivities were entered and a layered model generated. This trench was actively being filled at the time data was collected and a plume extending from the surface to the pitfloor was assumed to be in existence based on the presence of sludge in nearby well GR 17. Like the previous model, the conductivity of the spoil was set at 6 $\mathrm{mmho} / \mathrm{m}$. The depth of the spoil was fixed at $25 \mathrm{~m}$ ( $82 \mathrm{feet})$ over the line with an infinitely thick $10 \mathrm{mmho} / \mathrm{m}$ layer below. Again, a high conductivity plume (100 $\mathrm{mmho} / \mathrm{m}$ ) of sludge was assumed to be present within the spoil with its thickness and depth determined by the modeling software to best fit the observed data. 

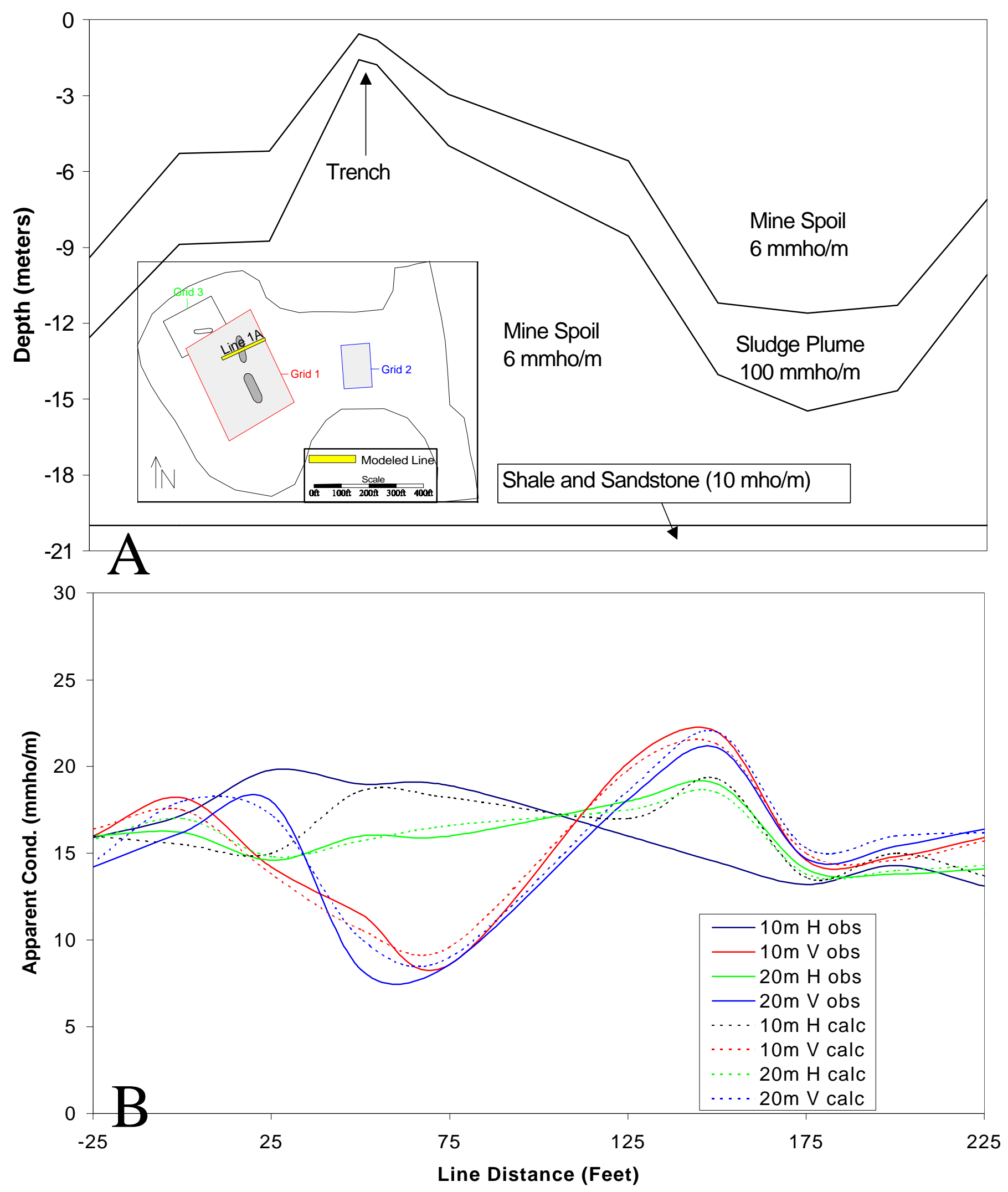

Figure 55. Greer modeled line 1A. 
Results of the model of Line 1B are shown in Figure 56. The resulting geometry (Figure 56A) is similar to that of Line 1A (Figure 55A). One exception is that the modeled plume extends to the surface in Line 1B. This may be due to the active filling of the southern trench. Again, the modeled results support the theory that the high conductivity zones extending from the trenches are due to sludge plume migration.

\subsubsection{Grid 2}

Another model was derived from data along Line 2 (Figure 57A). This line runs north-south through the middle of Grid 2 where $\mathrm{NaOH}$ was injected into GR20. Elevated $\left[\mathrm{Na}^{+}\right]$was seen in several weeks to the north (downgradient) of GR20 (Donovan and Werner, 1998). Elevated $\mathrm{pH}$ measurements in GR 21 confirm that effects from the $\mathrm{NaOH}$ injection extend to GR 21 (Donovan and Werner, 1998). This line was modeled to determine if terrain conductivity data show any evidence of earlier injections of $\mathrm{NaOH}$ or its migration. Several modeling approaches were taken to model this data, each with limited success. The main problem encountered with each of these approaches is that the terrain conductivity data modeled suggest the plume traveled to the northwest (see conductivity high in Figure 30B, page 65) not to the north. One approach used over Line 2, which uses a fixed geometry will be discussed here. In this approach, the subsurface below Line 2 was modeled with a homogeneous, $10 \mathrm{mmho} / \mathrm{m}, 40$ foot thick layer (representing unsaturated spoil) overlying a 10 foot thick, variable conductivity layer with an infinitely thick $10 \mathrm{mmho} / \mathrm{m}$ layer below (Figure 57A). The results of this model are expressed as the variations in conductivity of the 10 foot thick layer (Figure 57B). Geophysical data suggest that elevated conductivities from previous $\mathrm{NaOH}$ injections may have remained near the injection site along Line 2 . The modeled response varies 

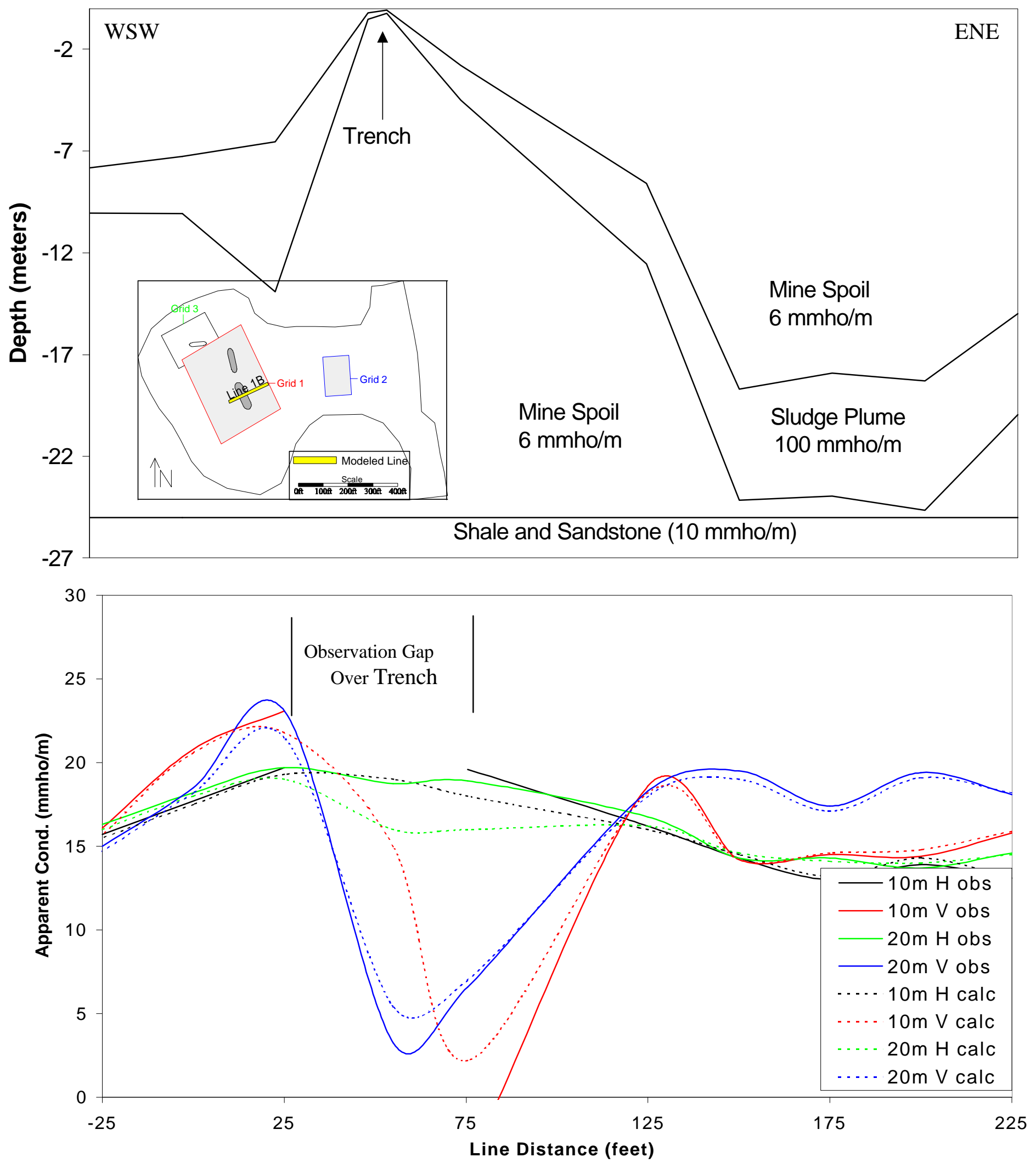

Figure 56. Greer modeled Line 1B. 

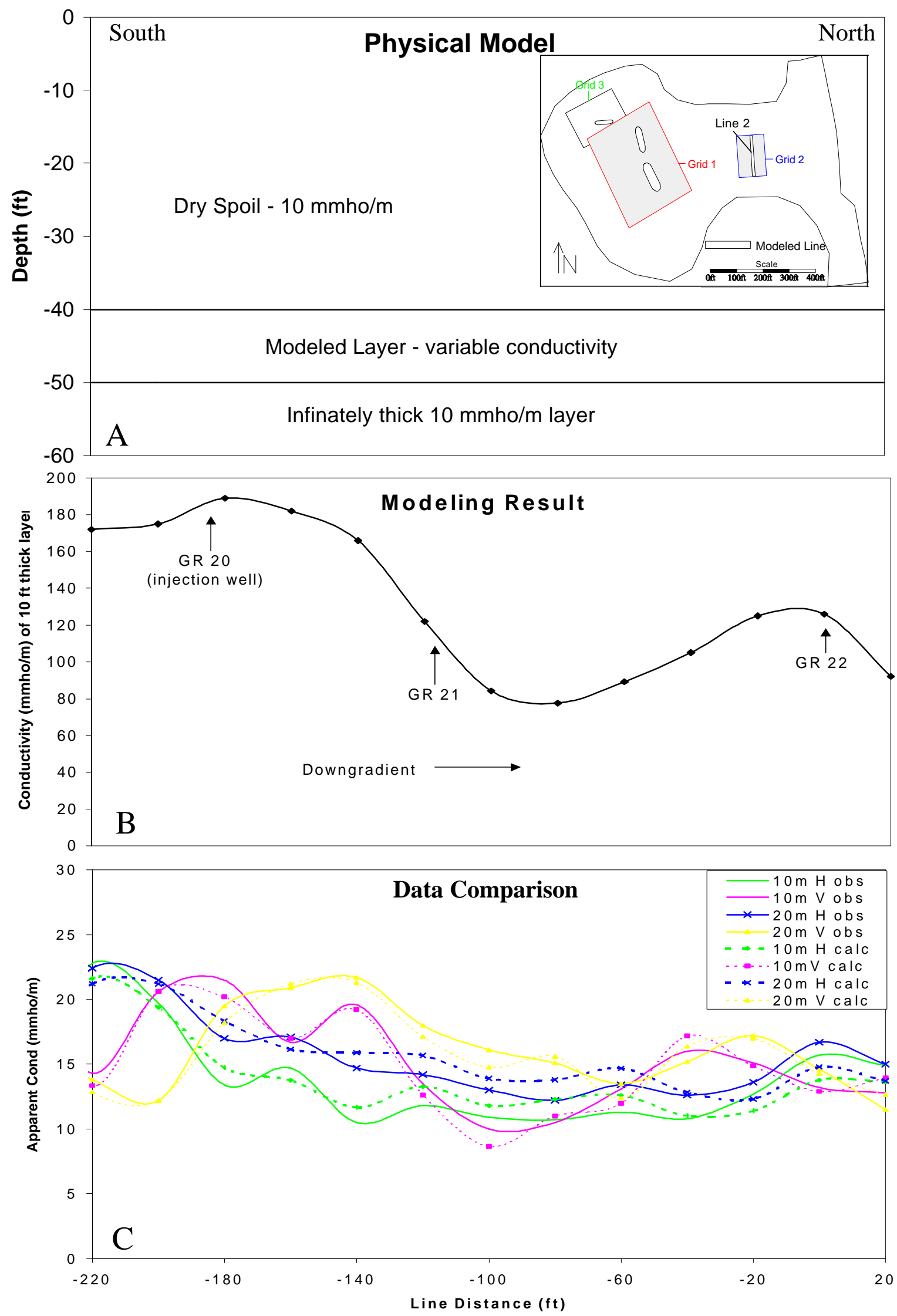

Figure 57. Greer Grid 2, modeled line 2 with fixed geometry. 
considerably from what would be expected if injected $\mathrm{NaOH}$ had migrated downgradient of the injection site (GR-20) along Line 2. Possible explanations for this variance include: the line of data does not follow a downgradient path from GR 20 since the effects of injected $\mathrm{NaOH}$ are actually in a different location than postulated (as stated earlier), or that variations in conductivity over the line are not related to subsurface injections of $\mathrm{NaOH}$ but other subsurface conditions (such as zones of AMD).

\subsubsection{Grid 3}

Two additional models were constructed along Lines 3A and 3B over Grid 3 (Figures 58 - 61). These lines were chosen because the conductivity variations observed in Figure 41 (page 82) suggest that lime slurry migrates through the spoil in two contrasting ways. Both of these lines were surveyed three times. Results from the first and second surveys are very similar, hence the post-filling survey (one week after filling) is referenced to the syn-filling survey to generate models. Several modeling approaches were attempted, each with limited ability to properly model the subsurface over this area.

A modeling approach similar to that used in Grid 1was first attempted. This approach uses a model with a fixed layer conductivity and variable layer geometry where the top and bottom layer conductivities are $10 \mathrm{mmho} / \mathrm{m}$ and the middle layer conductivity is $100 \mathrm{mmho} / \mathrm{m}$ (Figures 58B and 59B). The physical model generated for the first filling data is shown in Figure 58C for Line 3A and Figure 59C for Line 3B. Ideally, these models would show a fairly level, even conductivity, middle layer at $\sim 50$ feet representing AMD saturated or near-saturated spoil at the base of the spoil. In the after models (Figures 58D and 59D) some evidence of a migrating plume would be expected 

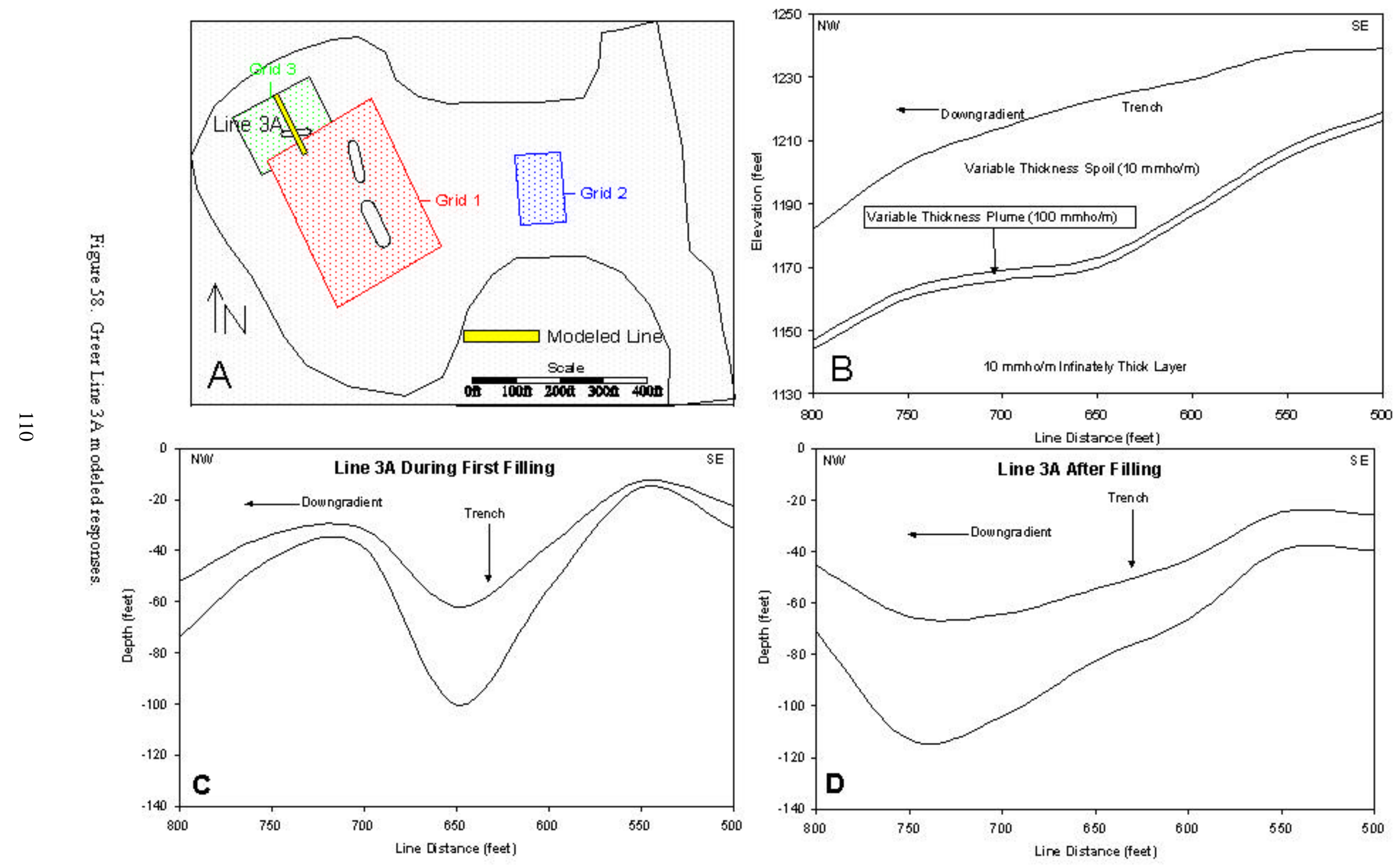

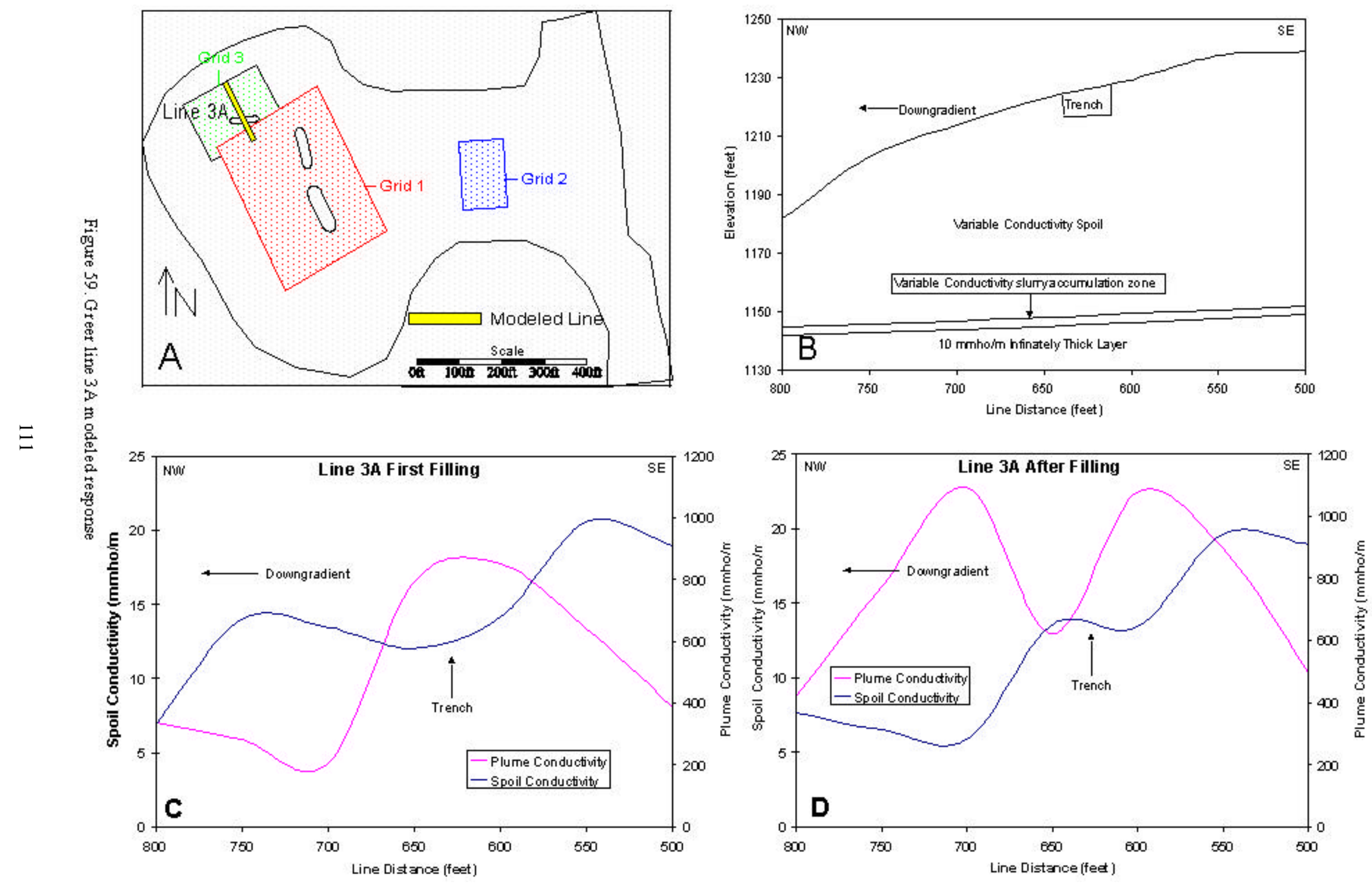

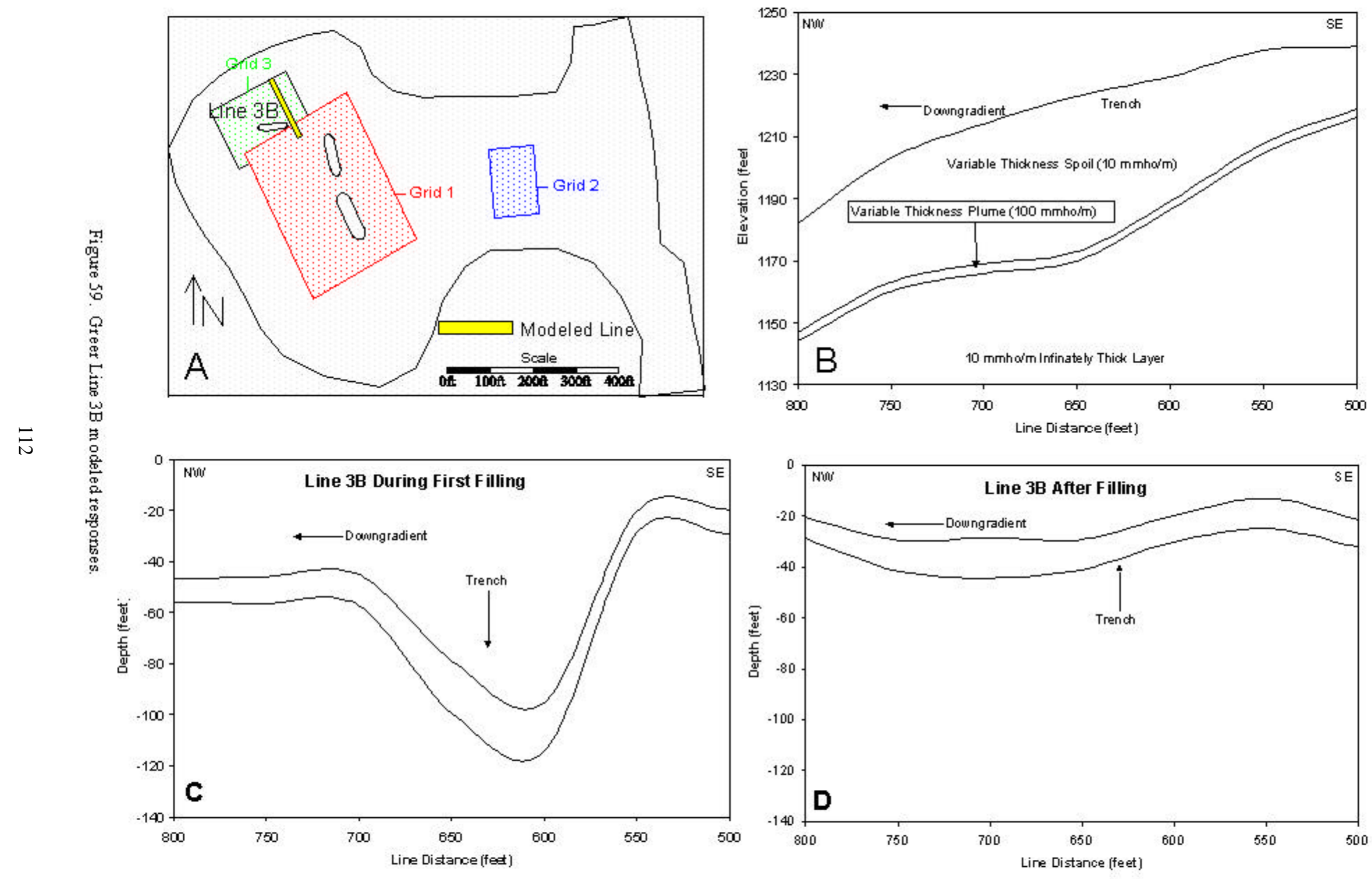

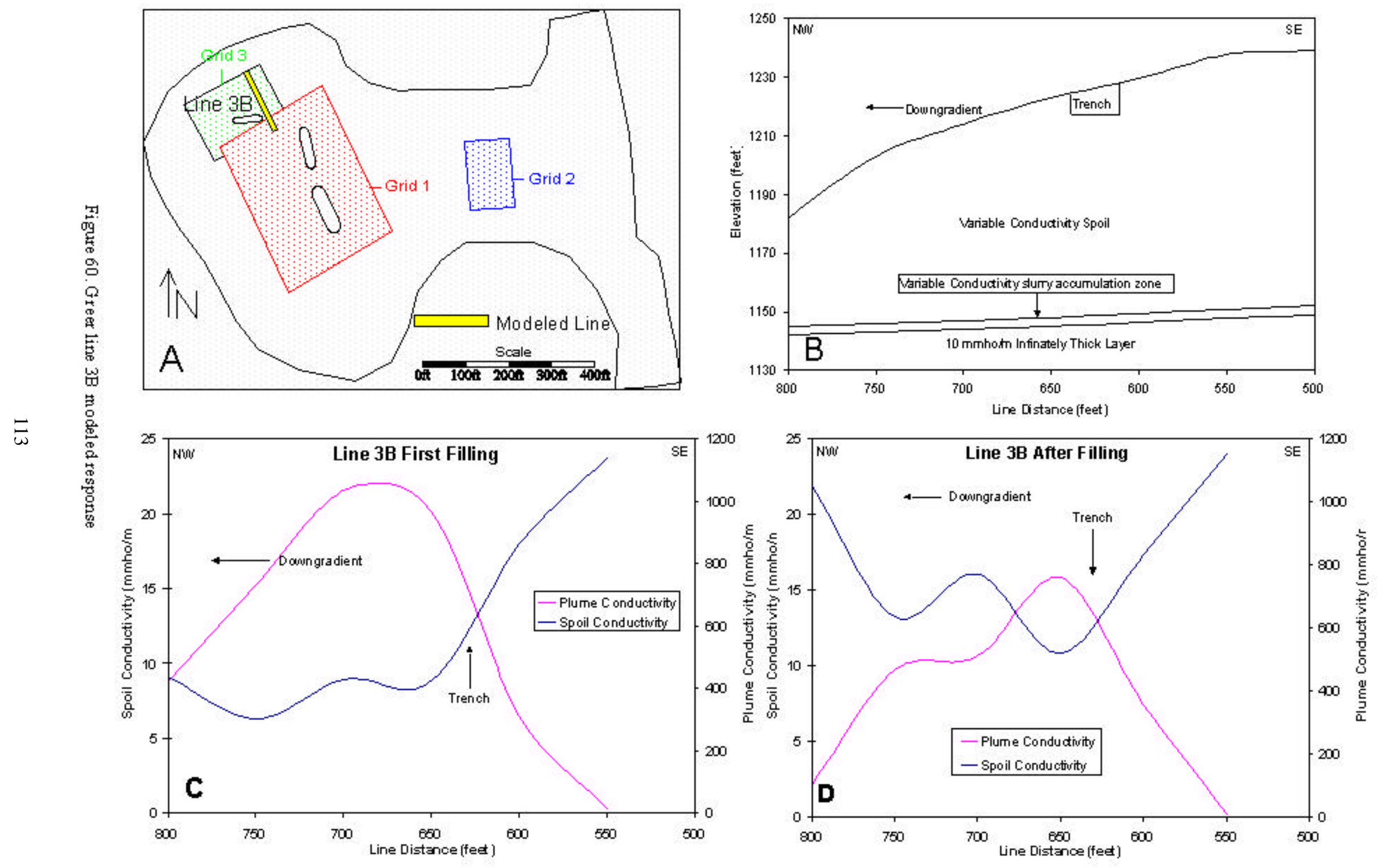
downgradient of the trench. Clearly the modeled response downgradient of the trench changes, but the model does not adequately represent these changes. Results of this model are shown to illustrate the shortcomings of this modeling approach.

A second modeling approach used fixed layer geometry and variable layer conductivity. In this model a homogeneous, 37 to 87 foot thick, variable conductivity layer (representing unsaturated spoil) overlies a 3 foot thick, variable (but high) conductivity layer (representing a zone of lime slurry accumulation) with an infinitely thick $10 \mathrm{mmho} / \mathrm{m}$ layer below (Figure 60B and 61B). This model does not take into account the variability in thickness or depth of the accumulation zone nor does it account for flow paths from the surface trench to the base of the spoil. The subsurface geometry for line $3 \mathrm{~A}$ and 3B models is shown in Figures 60B and 61B. Results are presented as plots of spoil and accumulation zone conductivity over the length of the line.

Figure $60 \mathrm{C}$ shows the modeled conductivity of Line $3 \mathrm{~A}$ during initial filling. The spoil conductivity (blue) line shows lower conductivity to the northwest, where the spoil is thinnest. Accumulation zone conductivity (red line) peaks over the trench between 600 and 650 feet along the line both before and during the first filling. One week after filling modeled conductivities vary significantly downgradient of the trench (Figure 60D). Spoil conductivity decreases from initial filling results downgradient of the trench while accumulation zone conductivity increases downgradient, peaking at about 700 feet.

Results of the same model over Line 3B (Figure 61) vary significantly from those of Line 3A. In the first filling model (Figure 61C) spoil conductivity decreases to the southwest as the spoil thins while the plume conductivity increases downgradient of the trench, peaking between 650 and 700 feet along the line. After three lime slurry 
applications (Figure 61D), results show the spoil (or near-surface layer) conductivity increases downgradient of the trench while the plume conductivity decreases over the same area. This may be explained by considering the possibility that the lime slurry plume is actually in the near surface over this line and does not extend to the pitfloor. The marked differences from line $3 \mathrm{~A}$ and $3 \mathrm{~B}$ could then be explained by differences in depth to flow paths within the spoil that allow the plume of slurry to move.

Neither of the modeling approaches presented here satisfactorily model the conditions in the subsurface around the trench in Grid 3. Little additional interpretation of this area can be made with the models generated. The inability to model this area in a straightforward way is an illustration of the limitations of modeling terrain conductivity data.

While the above models were of limited use for interpretation in Grid 3, interpretations of the after-before difference grids (Figures 39 and 40, pages 78 and 79) can be made. In the shallowest measurement (10m horizontal, Figure 39A), we see a strong increase in conductivity over point $\mathrm{D}$, extending from $\sim 100$ feet from the trench to the edge of Grid 3. This feature is interpreted to be lime slurry within the spoil moving downgradient and downward (toward the pitfloor) from the eastern side of the trench. As the slurry descends to the pitfloor, it is thought to be traveling northwest toward point $\mathrm{C}$. The 20 meter vertical reading, representing the deepest exploration depth, shows a high conductivity feature over point $\mathrm{C}$. This high is interpreted to be lime slurry reaching the pitfloor and accumulating. Higher porosity, stepped flowpaths from the surface to the pitfloor are assumed to exist to facilitate such flow. This interpretation of the terrain conductivity anomalies is generally consistent with what is known of the nature of the 
mine spoil and the lime slurry migration. Alternate interpretations of the terrain conductivity anomaly patterns can be made.

\subsection{Long Ridge}

\subsubsection{Area 1}

Using pitfloor and surface topography data from an Anker Energy Autocad file, a cross-section of Line 1 in Figures 8 and 45-47 was generated. Line 1 runs NNW-SSE over Area 1 and is approximately 800 feet long. A structural cross-section along the line (Figure 62) crosses the crest of Long Ridge at approximately 250 feet along the line and dips to the north and south. The Upper Freeport coal seam gently dips to the northwest at about $2^{\circ}$. To the north, an intermittent stream valley forms a topographic low which coincides with the location of an apparent conductivity high of northern Area 1. The depth to the coal seam was also determined from Anker's Autocad file and varies from 44 to 76 feet across the line.

A forward computer model of this line was generated to confirm that changes in overburden thickness could account for the variations in apparent conductivity (Figure 62). The model represents a three layer model closely following the actual geometry across the line. The surface layer is modeled as a homogeneous sandstone unit with a conductivity of $4 \mathrm{mmho} / \mathrm{m}$. The middle layer is a 1 meter (3.28 foot) thick high conductivity (100 mmho/m) layer. This may be interpreted as a wet layer of AMDproducing coal. EM 31 measurements collected directly over AMD seeps at a surface mine in Monongalia County were as high as, and in some cases, higher than 100 $\mathrm{mmho} / \mathrm{m}$. The lowest layer is a $5 \mathrm{mmho} / \mathrm{m}$ layer of underclays, limestone, and sandstone. 

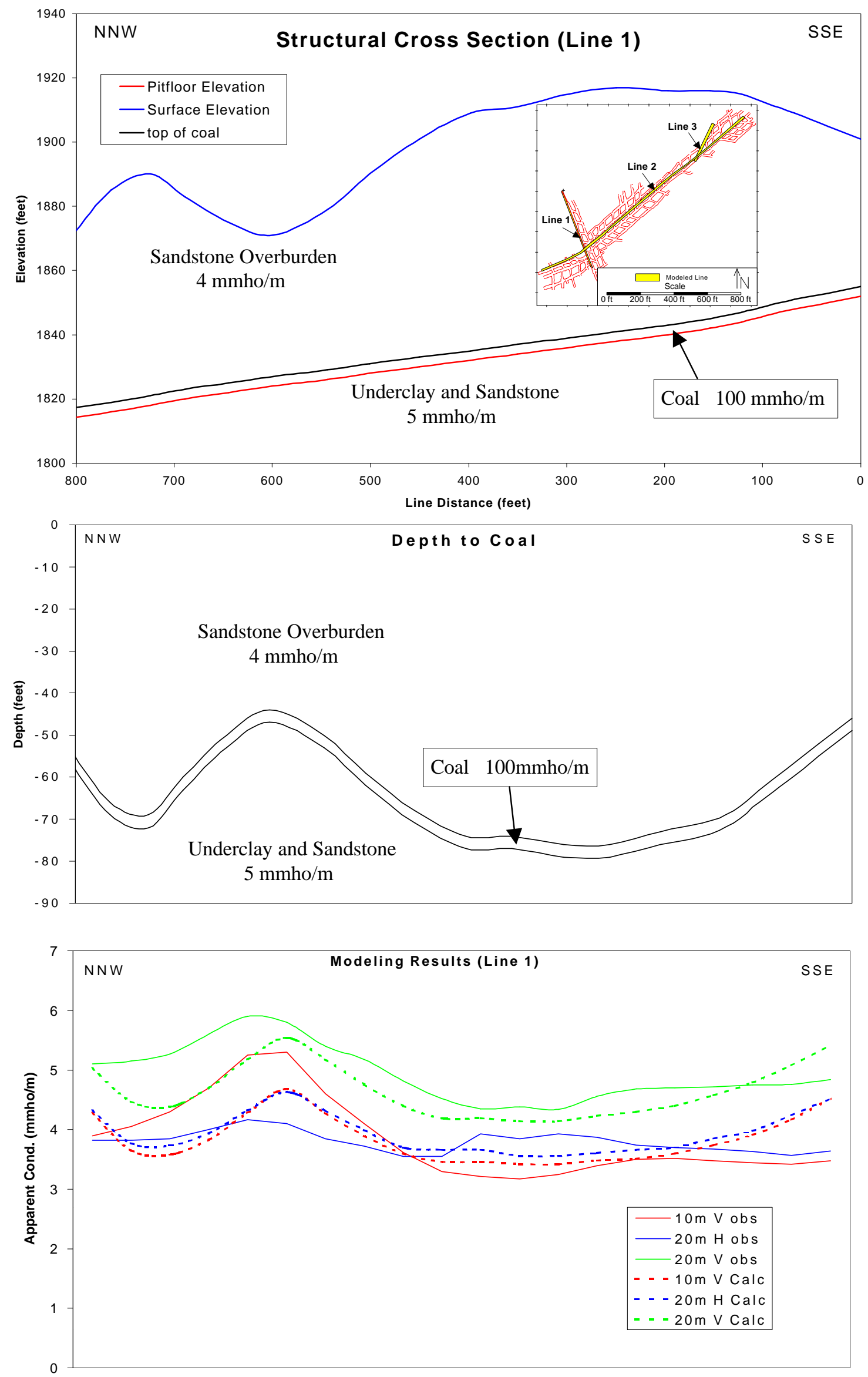

Figure 62. Long Ridge Line 1, structural effects model (Area 1). 
Results of the model along with observed values over the line are shown in Figure 62B. Results indicate a moderate increase in apparent conductivity as the higher conductivity layers get closer to the surface. At 600 feet along the line (corresponding to the topographic low near 360000 feet north) the depth to the pitfloor is approximately 44 feet and the observed conductivity is between 4.3 and $5.9 \mathrm{mmho} / \mathrm{m}$. Computed results yield values between 4.7 and $5.6 \mathrm{mmho} / \mathrm{m}$. In contrast, the depth to the pitfloor at the ridge crest near borehole 2 (250 feet along the line) is approximately 76 feet. Observed conductivity readings at the crest range from 3.3 to $4.4 \mathrm{mmho} / \mathrm{m}$. The computed conductivity values for this geometry range from 3.5 to $4.2 \mathrm{mmho} / \mathrm{m}$. The root mean square (RMS) error of the model varies from $4 \%$ to $8 \%$ across the line. This example shows that the increased conductivity values seen in Area 1 can be explained by variations in depth to coal where the coal is more conductive than the overburden. Ziemkiewicz (personal communication, 1999) has suggested that the mine may be flooded downgradient of the augerhole in the general region of Area 1. If this is the case, it is likely that the increased conductivity values seen in Area 1 are a result of both variations in depth to coal and increased conductivity from flooded conditions.

\subsubsection{Area 3}

In an effort to determine if the apparent conductivity increase seen over Line 3 could be attributed to suspected AMD at depth, computer modeling was done on a line of data collected away from the fly ash pile. Modeling of data collected along Line 3 (Figures 8, 45-47) was undertaken in order to compare the collected data to the theoretical response from a given geometry and to produce a physical model fitting the 
collected data. This line was chosen because it does not cross the fly ash pile yet it crosses the grout barrier between boreholes $9 \mathrm{~b}$ and 9 . Two approaches to modeling were taken, forward and inverse modeling.

Across Line 3, a grout barrier was assumed to be in place in the two main mine shafts around boreholes 9, 9a, and $9 \mathrm{~b}$ where fly ash grout was injected. The downgradient side of the barrier is modeled as a one meter thick layer with zero conductivity (a dry room) overlain by sandstone overburden 19 to 25 meters (63 to 82 feet) thick layer with $4 \mathrm{mmho} / \mathrm{m}$ conductivity throughout and underlain by an infinitely thick $5 \mathrm{mmho} / \mathrm{m}$ layer (Figure 63A). While no driller's logs were kept to confirm this stratigraphy, a continuous sandstone layer of this approximate thickness was reported to have been encountered during the drilling of all boreholes by one of the drillers and by Courtney Black of NMLRC. The upgradient side of the barrier was modeled using a similar geometry except the one meter thick layer was replaced with a fluid-filled, one meter thick, high conductivity layer $(100 \mathrm{mmho} / \mathrm{m})$ that thins to the northeast. This geometry simulates an AMD pool on a sloping pitfloor. This model could also simulate a sloping grout barrier if the barrier has an apparent conductivity signal similar to AMD (i.e. if the conductivity of AMD and grout is the same), since surface observations over the fly ash and kiln dust show both to be extremely conductive (relative to natural geologic features at the site). The physical model is shown in Figures 63A and 63B and the results of this model are shown in Figure 63C. Averaged results of this model agree with the collected data within 15 percent of the averaged observed data. This model demonstrates that, although a perfect fit was not obtained, there is the possibility that a pool of AMD or a mass of equally conductive grout from the barrier may be the source of 

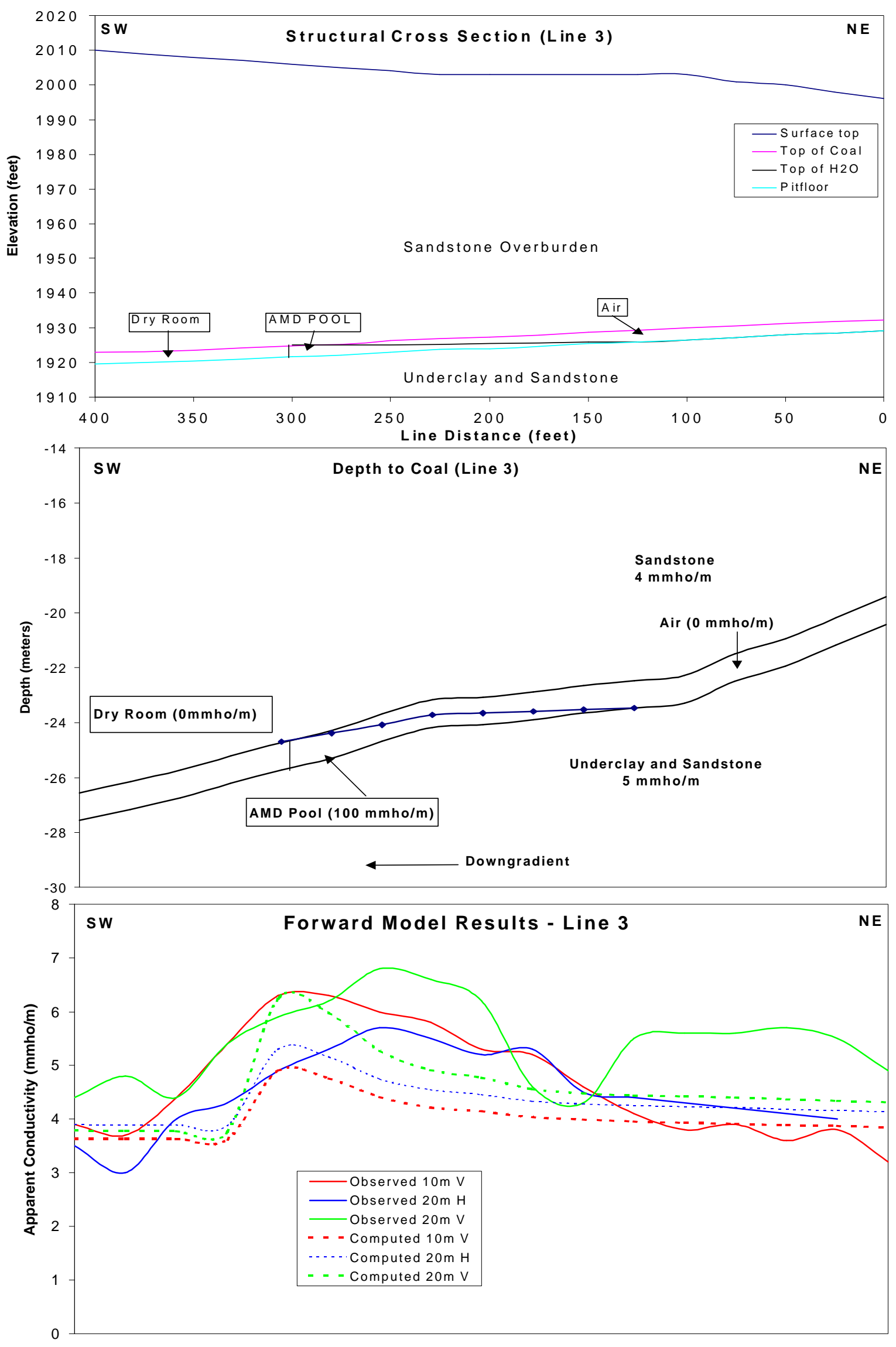

Figure 63. Long Ridge Line 3, forward model results. 
elevated conductivity measurements away from the surface ash piles. A closer fit to the observed data was attempted using the inverse modeling approach.

Data from the Line 3 was again used in to generate a three layer model. The inverse mode was generated from a starting model that consisted of a 14 to 25 meter thick homogeneous top layer with a conductivity of $4 \mathrm{mmho} / \mathrm{m}$. The middle layer was represented by a variable thickness $100 \mathrm{mmho} / \mathrm{m}$ layer, with the software free to vary the thickness of this layer through inversion to best fit the observed values northeast of 300 feet along the line. Again, an infinitely thick $5 \mathrm{mmho} / \mathrm{m}$ layer was assumed to underlie the middle layer. The resulting physical model is shown in Figure 64B and the observed and computed values of this model are shown in Figure 64C. The difference between observed values and computed values in this model varied between 2 and 12 percent.

This inverse model more closely fits to the observed data but contains the same underlying assumption that there is pooled conductive AMD at depth creating elevated conductivity readings at the surface. Both models support the assumption that the grout barrier is effectively pooling water behind it while preventing quantities of conductive water great enough to be measured at the surface using the terrain conductivity technique from flowing downgradient of the barrier. Neither model, however, is unique and other solutions and interpretations are possible. Because a set of measurements over the same area was not taken before grouting began, it is impossible to attribute the elevated conductivity reading to pooled AMD without speculating. 

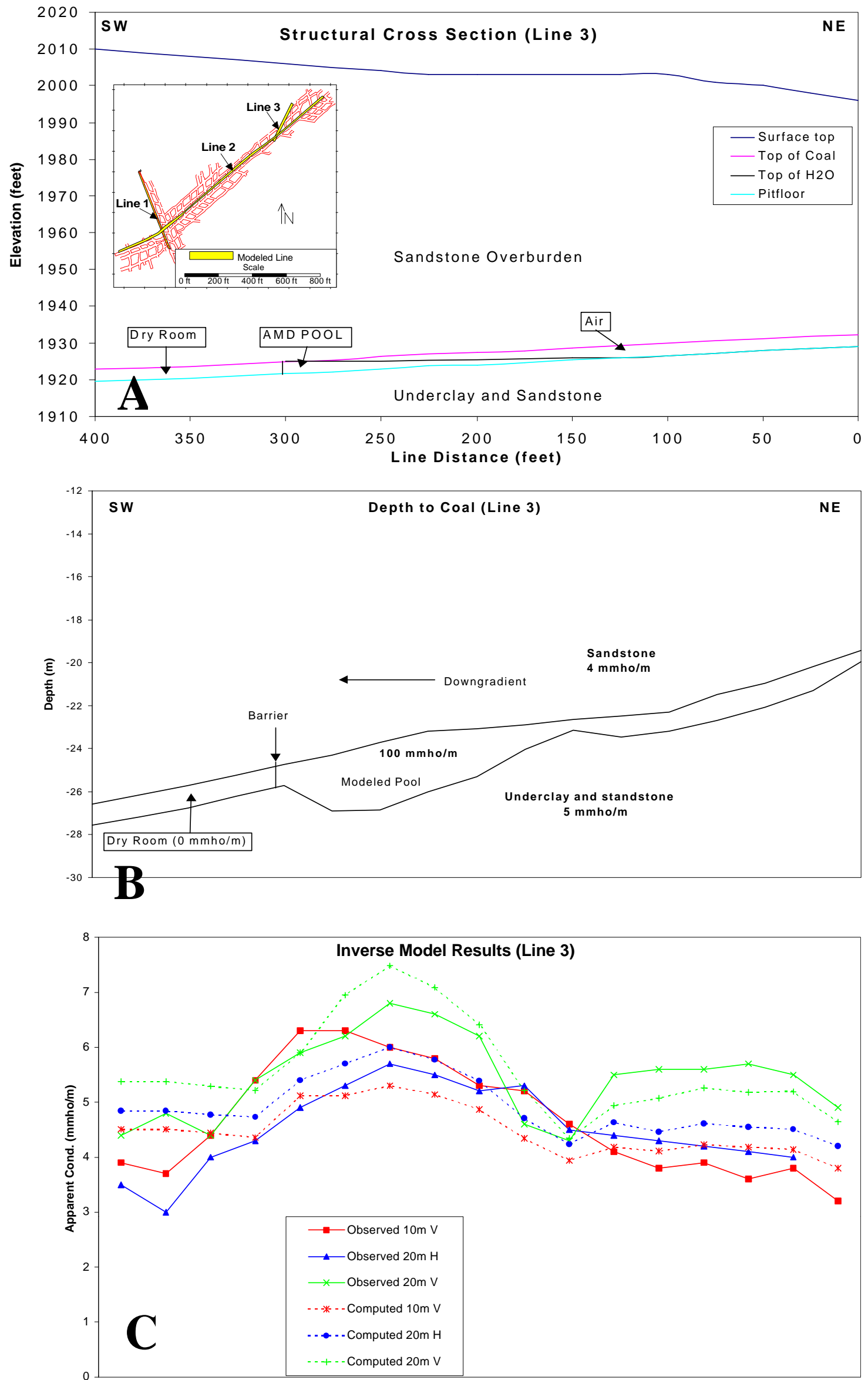

Figure 64. Long Ridge Line 3, inverse model results. 


\section{CHAPTER 5 - Conclusions and Significance}

\subsection{Key Findings}

\subsubsection{Irish Ridge}

Data collected across Line 1 at the Irish Ridge site (Figures 16 and 17) indicate the presence of a linear north-south trending terrain conductivity feature in the center of the site. This terrain conductivity high has been interpreted by the author as a partially water-filled fracture zone which is supported by modeling results and observations within the eastern portion of the mine, however, alternate explanations are possible. Data collected across the northwestern portion of the site (near Line 2, Figures 16 and 17) suggest that elevated terrain conductivity values observed at the surface may indicate the presence of water-filled rooms and may be used under careful conditions to map these flooded rooms.

Magnetic and terrain conductivity data distinctly show the presence of a nearsurface ( 3 foot depth) gas transmission line. The steel pipeline appears as a series of magnetic highs and lows in the magnetic surveys and as a conductivity high in the terrain conductivity surveys. Both geophysical techniques were able to determine the location of this transmission line. Although an interesting target, the pipeline at the Irish Ridge site acts as a source of interference in both surveys and hampered efforts to detect water-filled rooms and grout barriers.

\subsubsection{Greer Mansion}

At the Greer Mansion site, conductivity highs (seen in Grid 1, Figures 27 and 28) surrounding surface trenches filled with post-treatment sludge suggest sludge plumes can 
be detected using the terrain conductivity geophysical method. Elevated terrain conductivity readings (seen in Grid 2, Figures 29 and 30) observed downgradient of a previous $\mathrm{NaOH}$ injection site (GR-20, at the base of the spoil) suggest there may be longlived effects of the $\mathrm{NaOH}$ injection and that these can be detected at the surface using terrain conductivity measurements. Lastly, changes over time in terrain conductivity data collected over a new trench in which a lime slurry was applied (Grid 3, Figures 31-40) suggest that applications of lime slurry into surface trenches affect the terrain conductivity along the flow path of the slurry and that these flow paths can be detected using terrain conductivity measurements. Additional work is needed to determine how terrain conductivity responses relate to AMD, lime slurry, and sludge.

\subsubsection{Long Ridge}

At the Long Ridge site three separate anomalous areas were identified in the EM 34 data. A plausible interpretation for each anomaly is provided but it is important to recognize that other solutions exist and that EM data interpretations are non-unique. The increased conductivity values in Area 1, the western portion of the mined area, have been interpreted to be the result of a thinning of the sandstone overburden. In these areas, the depth to the coal seam, underlying clays, and potentially more conductive layers is decreased, increasing the apparent conductivity at the surface. Modeling a NNW-SSE cross-section through Area 1 yields computed values that support this interpretation. The moderate increase in apparent conductivity in Area 2, southwest of borehole 7, is interpreted to be the result of increased moisture near the surface. This interpretation is based on observations at the surface. Data provided by Anker shows no change in the 
nature of the pitfloor in this area However, a shallow AMD pool dammed by debris from collapse in the mine could exist in the area, accounting for the moderate increase in apparent conductivity in Area 2. The anomaly in Area 3 is the largest and most distinct of the three. This area is where grouting has taken place, pooled AMD is thought to exist, and where metal machinery and fly ash piles at the surface are located. With several possible sources for this anomaly it is impossible to separate possible deeper contributions to the terrain conductivity from the influence of the surface ash pile which is overwhelming. The origins of the smaller modeled anomaly and large anomaly in Area 3 cannot be fully resolved. The presence of highly conductive material at the surface is clearly a hindrance to interpretation and modeling efforts.

\subsection{Significance of findings}

This study provided an opportunity to evaluate the effectiveness of non-invasive geophysical techniques to delineate the layout and physical conditions of both underground and surface mine sites. These studies serve as a starting point to illustrate the potential benefits of geophysical surveys to mine site evaluation. This study may provide a way to better assess how well in-situ remedial techniques such as fly ash grouting, sodium hydroxide injection, and sludge additions are working. This study also provides evidence that geophysical techniques can be used during remedial efforts to target problem areas, site injection and monitoring wells, and better remedy the problems at a given site.

Although previous work has provided evidence of geophysical successes in this area, the widespread understanding and use of geophysics at mine sites undergoing treatment continues to be lacking. This study has contributed additional evidence that 
surface geophysical techniques can be used to more effectively remediate coal mine sites while showing the limitations of geophysics at these sites.

At the Irish Ridge site, anomalies in the terrain conductivity data suggest that water-filled mine rooms $40-50$ feet below the surface may be detected by terrain conductivity at the surface. Terrain conductivity data also suggest the presence of a fracture zone in the center of the site, where no mining is known to have taken place. It is important to recognize that no other subsurface data exist to support this hypothesis and that this interpretation is not unique.

At the Greer site, data suggest that the terrain conductivity geophysical technique may be used to detect applied post-treatment sludge and lime slurry. By monitoring the changes in terrain conductivity during and after applications of sludge and slurry, it appears possible to map the flow paths of this injected material. Additionally, data collected downgradient of an $\mathrm{NaOH}$ injection well appear to show elevated conductivity readings in at least some locations along the path of $\mathrm{NaOH}$ migration.

At the Long Ridge site, this study has provided the opportunity to evaluate how useful the terrain conductivity method is in detecting changes in the ground conductivity due to pooling AMD in an underground mine that has been grouted. Unfortunately, the existence of surface interference in the form of fly ash piles and metal machinery brought ambiguous results in the area of greatest interest.

\subsection{Suggestions for future work}

Future efforts at similar sites should include the use of geophysics in the planning and the initial stages of remedial efforts. Geophysical data collected in the early stages of 
a remedial effort provide baseline information on subsurface conditions at a site and can provide additional background information to be used to better plan future activities and target areas of interest or concern.

During the planning of remedial efforts, planners should consider avoiding possible sources of interference in geophysical surveys at a site. Removing or avoiding metallic objects is a necessity in magnetic surveys and often required in terrain conductivity surveys. The Long Ridge site demonstrates that location of fly ash piles and machinery directly over the mine should be avoided if geophysical evaluations are to successfully undertaken and tested at similar sites.

Geophysical efforts should include a time-lapse set of measurements. Beforeand-after surveys help to discriminate changes associated with remedial efforts from those associated with topographic effects, differences in depth to target, variations in near-surface geology, the influence of pre-existing fracture zones, etc. that produce conductivity variations across an area.

Lastly, future efforts should seek ways to improve modeling of terrain conductivity data and/or integrating multiple types of geophysical data. Terrain conductivity Models used in this study provide simplistic approximations of real world geometries and subsurface conditions. While useful, the current approach of combining one-dimensional models and are of limited use for more refined modeling. 


\section{References}

Ackman, T, Lyons, C., and Current, R., 1998, Post-Injection Geophysical Investigation of the Winding Ridge Site. Proceedings; Nineteenth Annual Surface Mine Drainage Task Force Symposium, Morgantown, WV.

Barker, B., 1998, Reaction Geochemisty of an Acidic Mine-Spoil Aquifer Following Well Injection of Sodium Hydroxide, Unpublished Masters Thesis, West Virginia University, Dept. of Geology and Geography, 121pp.

Black, D. C., 1999, Personal Communication, National Mine Lands Reclamation Center, Morgantown, WV.

Benson A.K. and Addams, C.L., 1998, Detecting the Presence of Acid Mine Drainage Using Hydrological, Geochemical, and Geophysical Data: Applications to Contrasting Conditions at Mine Sites in Little Cottonwood and American Fork Canyons, Utah. Environmental Geosciences, v.5, no. 1, 17-27

Donovan, J. J.; Frysinger, K. W.; Maher, T. P., Jr. 1997. Geochemical Response of Acid Groundwater to Neutralization by Alkaline Recharge. Aquatic Geochemistry, v. 2, n. $3,227-253$.

Donovan, J. J.; Werner, E. 1998. Variable-Density Flow Induced by Injection of Caustic Solutions into an Acidic Surface Mine-Spoil Aquifer. Abstracts with Programs Geological Society of America, v. 30, n. 7, 22.

Ebraheem, A.M., Hamburger, M.W., Bayless, E.R., and Krothe, N.C., 1990, A Study of Acid Mine Drainage Using Earth Resistivity Measurements, Ground Water, v. 28, n. 3, 361-368.

Fahringer, P.E. and Wilson, T.W., 1999, Geophysical Investigation of an Acid-Producing Surface Mine in Northern West Virginia,Abstracts with Programs - Geological Society of America, v. 30 (in press).

King, A.R. and Hynes, T., 1994, Applications of Geophysical Methods for Monitoring Acid Mine Drainage. Proceedings; International Land Reclaimation and Acid Mine Drainage Conference, Pittsburgh, PA.

Kirk, K.G. and Rauch, H., 1978, The Application of the Tri-Potential Method of Resistivity Prospecting For Ground-Water Exploration and Land Use in Karst Terrains. Proceedings of the International Assoc. Hydrology, Huntsville Conference, 285-299. 
Ladwig, K.J., 1983, Delineation of Zones of Acid Mine Drainage using Surface Geophysics. 1982 Symposium on Surface Mining Hydrology, Sedimentology, and Reclamation, Univ. of Kentucky, Dec. 5-10, 1982.

Ladwig, K.J., 1983, Electromagnetic Induction Methods for Monitoring Acid Mine Drainage. Groundwater Monitoring Review, v.3, winter issue, 46-51.

McNeil, J. D., 1980, Electromagnetic terrain conductivity measurement at low induction numbers; Technical Note TN-6, GEONICS Limited, Ontario, Canada, 15p.

McNeil, J. D., 1980, Electrical conductivity of soils and rocks: Technical Note TN-5, GEONICS Limited, Ontario, Canada, 22p.

Merkel, R. H., 1972, The Use of Resistivity Techniques to Delineate Acid Mine Drainage in Ground Water: Ground Water, v. 10, no. 5, 38-42.

National Mine Land Reclamation Center, 1996, Final Report WV102 "Determination of Engineering Requirements and Cost for Pneumatically Stowing Advanced Coal Combustion Ash in an Underground Mine."

Parkhomenko, E.I., 1967, Electrical Properties of Rocks. Plenum Press, New York, NY.

Rauch, H.W., Personal Communication, West Virginia University, Morgantown, WV.

Ritter, A.I., 1997, Geochemistry of Acid Mine Drainage Neutralization at the Greer Mansion Site. Unpublished Masters Thesis, West Virginia University, Dept. of Geology and Geography, 109pp.

Schlinger, C. M., 1990, Magnetometer and Gradiometer Surveys for Detection of Underground Storage Tanks: Bulletin of Association of Engineering Geologists, Vol. XXVII, no. 1, 37-50.

Sincock, J.M., 1998, Quantification of Preferred-Flow Pathways and Velocities in an Extremely Heterogeneous Mine-Spoil Aquifer, Unpublished Masters Thesis, West Virginia University, Dept of Geology and Geography, 122pp.

Sincock, M. J.; Donovan, J. J. 1997. Quantification of preferred-flow pathways and velocities using observations of springflow response to recharge and naturalgradient tracer injections. Abstracts with Programs - Geological Society of America, v. 29, n. 6, 331

Stollar, R. L., and Roux, P., 1975, Earth Resistivity Surveys - A Method for Defining Ground-Water Contamination: v. 13, No. 2, Ground Water, 145-150. 
Sweetman M.B. and Bergstrom, W.R., 1993, Use of a Magnetometer/Gradiometer to Locate Abandoned Wells. Proceedings of the Seventh Annual Outdoor Action Conference and Exposition, Las Vegas, 315-324.

Telford, W.M., Geldart, L.P., and Sheriff, R.E., 1990, Applied Geophysics, 2nd ed. Cambridge Univ. Press, 770p.

Ziemkiewicz, P. F., 1999, Personal Communication, National Mine Land Reclamation Center, Morgantown, WV. 